\title{
System Losses and Assessment Trade Study
}

September 2009

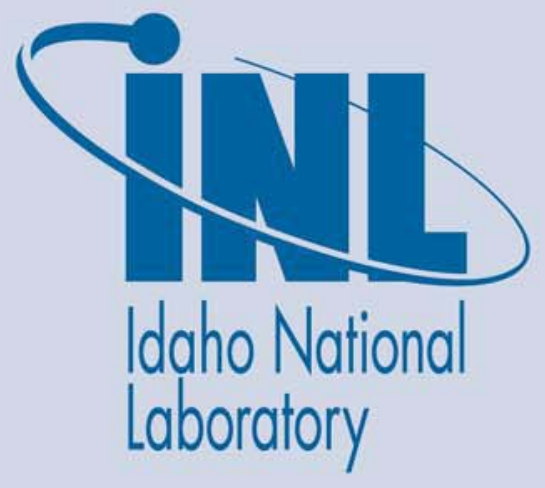

The INL is a U.S. Department of Energy National Laboratory operated by Battelle Energy Alliance 
INL/EXT-09-16891

\title{
System Losses and Assessment Trade Study
}

September 2009

\author{
Idaho National Laboratory \\ Advanced Fuel Cycle Initiative \\ Idaho Falls, Idaho 83415 \\ http://www.inl.gov \\ Prepared for the \\ U.S. Department of Energy \\ Office of Nuclear Energy \\ Under DOE Idaho Operations Office \\ Contract DE-AC07-05ID14517
}


System Losses and

Assessment Trade Study

\title{
Advanced Fuel Cycle Initiative
}

\author{
Prepared for \\ U.S. Department of Energy \\ Systems Analysis Campaign \\ David Shropshire, Steve Piet, \\ Nick Soelberg, Robert Cherry \\ Separations and \\ Waste Form Campaign \\ Roger Henry, David Meikrantz, \\ Greg Teske, Candido Pereira \\ Transmutation Fuels Campaign \\ Eric Shaber
}

September 30, 2009

AFCI-SYSA-PMO-MI-DV-2009-000203

INL/EXT-09-16891 


\section{DISCLAIMER}

This information was prepared as an account of work sponsored by an agency of the U.S. Government. Neither the U.S. Government nor any agency thereof, nor any of their employees, makes any warranty, expressed or implied, or assumes any legal liability or responsibility for the accuracy, completeness, or usefulness, of any information, apparatus, product, or process disclosed, or represents that its use would not infringe privately owned rights. References herein to any specific commercial product, process, or service by trade name, trade mark, manufacturer, or otherwise, does not necessarily constitute or imply its endorsement, recommendation, or favoring by the U.S. Government or any agency thereof. The views and opinions of authors expressed herein do not necessarily state or reflect those of the U.S. Government or any agency thereof. 


\section{SUMMARY}

This Advanced Fuel Cycle Initiative (AFCI) study has developed new analysis methods to examine old and new technology options toward the goal of improving fuel cycle systems. We have integrated participants and information from AFCI Systems Analysis, Transmutation Fuels, Separations, and Waste Form Campaigns in the Systems Losses and Assessment Trade Study. The initial objectives of this study were to 1) increase understanding of system interdependencies and thereby identify system trade-offs that may yield important insights, 2) define impacts of separations product purity on fuel manufacture and transmutation reactivity, 3) define impacts from transuranic (TRU) losses to waste, 4) identify the interrelationships involved in fuels and separations technology performance, and 5) identify system configuration adjustments with the greatest potential for influencing system losses. While bounding and analyzing this initial problem, we also identified significantly higher-level programmatic drivers with broad implications to the current fuel cycle research charter and the general issue of a DOE complex wide need for a comprehensive and integrated nuclear material management as addressed by the new DOE Order 410.2 titled "Management of Nuclear Materials." The initial modeling effort developed in this study for a much smaller subset of material (i.e., commercial fuel) and a selected transmutation scheme (i.e., fast reactor recycling) is a necessary first step towards examining a broader set of nuclear material management options, dispositioning strategies and integrated waste management options including potential areas of research leverage.

Comprehensive fuel cycle analysis is a very complicated problem. There are four major technological drivers/functions in this cycle and each of these have additional subsets of options: reactor type/fuel form, used fuel separations and waste conditioning, fuel (re)fabrication, and waste disposal. Historically speaking, the evolution of nuclear power did not occur based on a fully integrated picture for a selected fuel cycle with a complete understanding of the pros and cons related to each potential option. Never-theless, this analytical capability remains a critical path issue for optimizing the cost and risks related to the material management issues for a given fuel and the overall problem of nuclear material management for all fuel types, target/isotope production, radioactive waste and special nuclear material (SNM). Putting all of the four major technological drivers on a common design and cost estimating basis is necessary as a first step for any fuel type. However, this alone is not sufficient because the comprehensive nuclear material management strategy will have to address all of the wide range of materials that might be fed into it and the waste forms that could result. A more complete system understanding of the tradeoffs between separations, fuel fabrication, waste forms, waste disposition, and reactor performance is required. All materials fed into the system or generated within it must go somewhere; higher limits in one area can relax constraints elsewhere and limited examination of the inventory, in a segmented manner, will typically not reveal the optimum results.

In this study we have concluded that some "big-picture" issues are really the drivers for system losses and interdependencies within the nuclear fuel cycle and that there is a very pressing need to utilize these initial results to develop a life-cycle nuclear material management model that can assess the sensitivity of these big-picture drivers/issues for a selected fuel cycle (including actinides and fission products) and then proceed to develop an overall integrated picture for all fuel types, targets, and other SNM inventories. These key big picture drivers include the reactor choice, fuel isotopic composition, commercial fuel burn-up, fuel age, fuel form, fuel cladding, remote versus hands-on fabrication processes, separation technique, separated product form, final waste form, and physical conversion. These factors can also be influenced by the degree to which they are used, the complexity of the technologies, timing, and reactor operational parameters.

An initial evaluation of System Losses was performed on a straightforward example problem using data from existing studies as the basis for initial conditions. The problem set consisted of a 1-tier fast reactor recycling system with assumed input and operating conditions. Bounding system losses for oxide and metal fuel separation and fabrication were evaluated based on the back-end cost of the fuel cycle. 
Performance metrics were based on repository loading (measured as linear loading in a geologic repository) and reactor fuel performance (measured as required increase in TRU loading). This analysis helped to identify some key system relationships (e.g., increasing purity in a given aqueous separation process has little impact on system costs) and waste contamination drivers (e.g., lanthanide impact on reactor reactivity can have broad system impacts). The analysis and simple spreadsheet model allowed a means to evaluate the bounding conditions of a fuel reprocessing cycle and identify new problem areas and their potential solutions.

Consider lanthanides as a specific example of how issues are interwoven throughout the fuel cycle and where research might improve overall system performance. Separation of actinides versus lanthanides is particularly difficult in both aqueous and electrochemical separation so that producing high-purity actinide fuel and/or high-purity lanthanide waste is especially difficult. Thus, there are potential system performance gains from improved separation, relaxed fuel purity limits, or relaxed waste limits. The current Transmutation Fuels Campaign specification greatly restricts the lanthanides in both oxide and metal fresh fuels. The amount of total lanthanides generated in one pass through the reactor is an order of magnitude higher than the current lanthanide impurity limit on fresh fuel based on evidence of behavioral difference between initial impurities (segregated during fabrication) versus fission products (homogeneously spread throughout the fuel matrix). More research is needed to confirm whether homogeneity of lanthanide fission products is maintained as temperature and fluence increases. If homogeneity is confirmed, this would suggest the need for development of fabrication techniques that would enable tolerance of higher initial impurities. At the current specified limits, the lanthanides contribute a minor penalty $(\leq 1 \%)$ to fast reactor fuel value if TRU content is raised to compensate for parasitic lanthanide absorption. Lanthanide-friendly fuel fabrication or fuel cladding/coating could enable raising the lanthanide limits on actinide fuel. Meanwhile, with low TRU content, the lanthanides would pose relatively low heat and radiotoxicity disposal challenges; indeed, many of the lanthanides have economic value. So, improved lanthanide-actinide separation or raising the tolerable lanthanide level in actinide fuel (thereby reducing actinides in the lanthanide waste stream) could have waste management benefits.

Previous analyses have implicitly assumed that most of the losses occur at separation partitioning operations. However, historical experience suggests that most of the losses in aqueous separation operations occur at phase transitions (e.g., solid used fuel is sheared, homogenized to liquid via dissolution and purified, concentrated liquid product is converted to oxides via denitration processes) rather than actual separation partitioning operations. In general, losses are due more to minor upset conditions rather than during fully routine operation and therefore have more to do with design margins, buffering capacity, and how smoothly the facility can operate.

The primary outcome from this initial study has been an enhanced integration among Campaigns and associated insights and analysis methods. Opportunities for improved understanding between the groups abound. The above lanthanide-actinide example highlights the importance of evaluating options via integration across the Campaigns. Plans for Fiscal Year 2010 are being made in a coordinated fashion such that the knowledge gained from the research performed by the Campaigns can benefit on-going work of the study, and that improved understanding of the system relationships can be used to guide the specific research and development (R\&D) activities within the Campaigns. In FY-10, the System Losses and Assessment Trade Study will carry-over activities from FY-09. We will continue to refine impurity and loss estimates and impurity limits on fuels by incorporating results from ongoing R\&D. And we will begin work on an enhanced nuclear material management model to allow us to continue to improve our overall system understanding of the trade-offs between separations, fuel fabrication, waste forms, waste disposition, SNM losses, reactor performance, and proliferation resistance. In the future, we can also better understand how used fuel and other forms of remote-handled SNM can be better integrated into an overall nuclear material management program that will evolve for the DOE complex via Order 410.2 (DOE 2009). 


\section{CONTENTS}

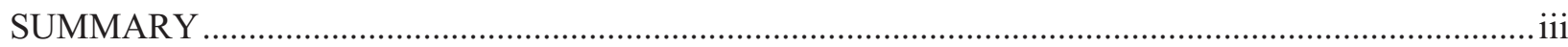

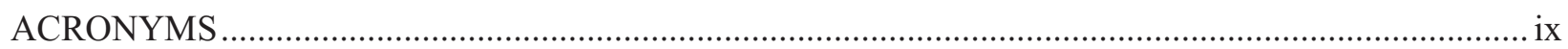

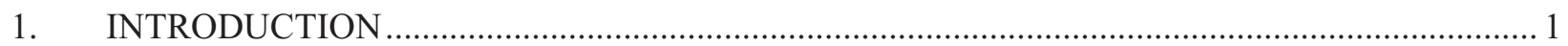

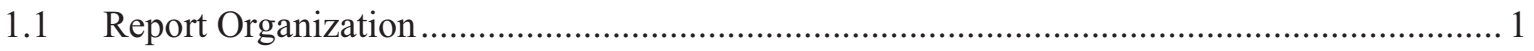

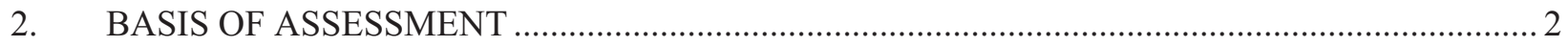

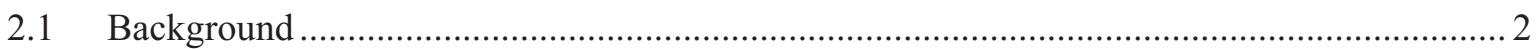

2.1.1 Aqueous and Electro-Chemical Separations Background ....................................... 2

2.1.2 Fuel Fabrication Background................................................................ 5

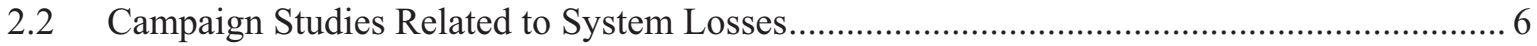

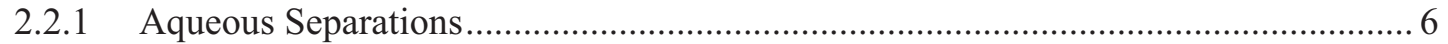

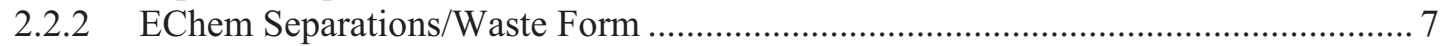

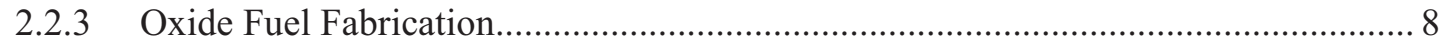

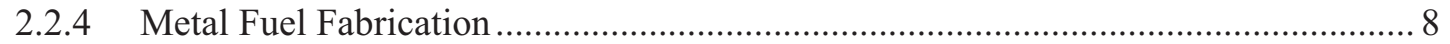

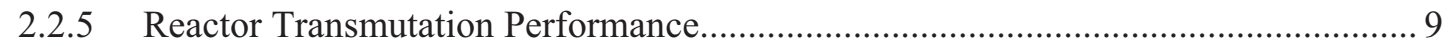

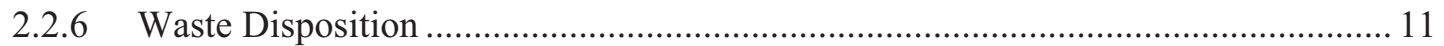

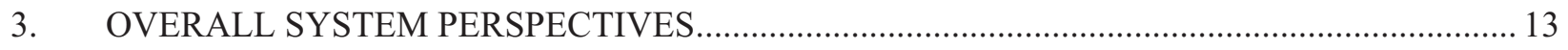

3.1 Complexity/Limitations of Fuel Cycle Analysis............................................................. 13

3.2 Limitations resulting from a Simplistic View of Losses................................................... 13

3.3 Big Picture Issues Driving Losses and Interdependencies within the Actinide Fuel

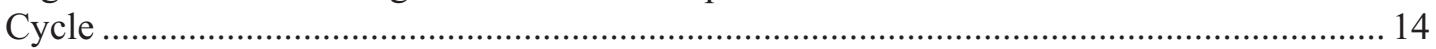

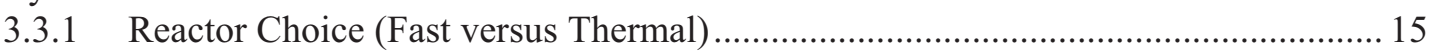

3.3.2 Fuel Composition (Generates TRU versus Minimizes TRU) …............................... 15

3.3.3 Commercial Fuel Burn-up (High TRU versus Low TRU) ....................................... 16

3.3.4 Fuel Age (Hot and Actively Transitioning versus Colder and More Stable)............ 16

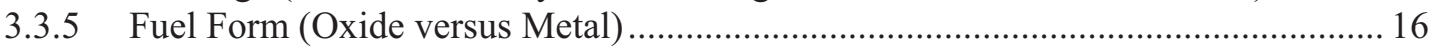

3.3.6 Fuel Cladding (Hulls versus No Hulls) ............................................................... 16

3.3.7 Remote versus Hands-on Fabrication Processes (including Head-End

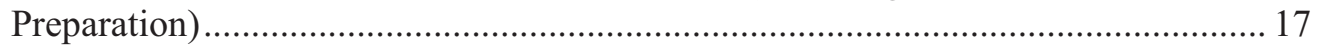

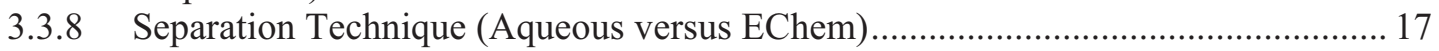

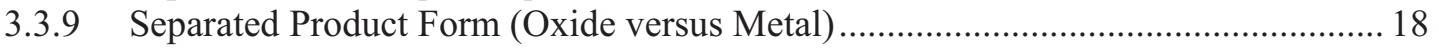

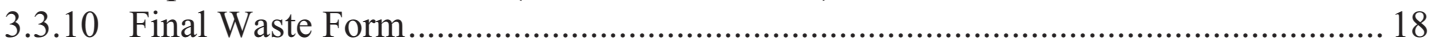

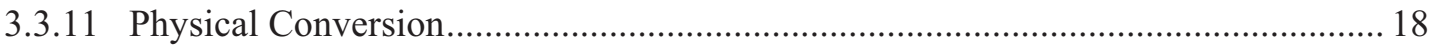

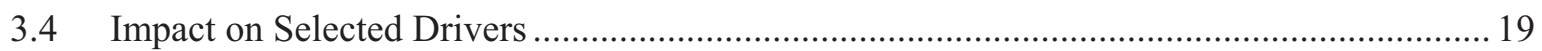

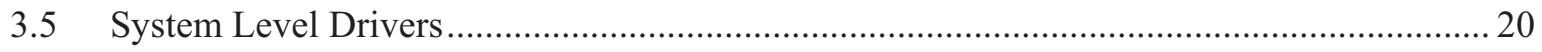

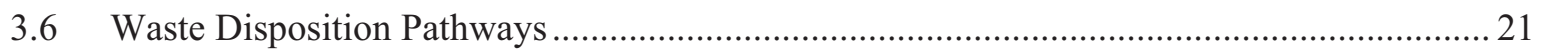

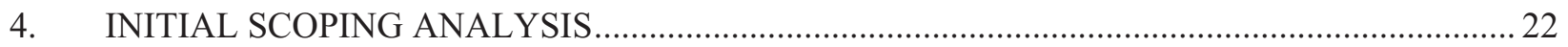

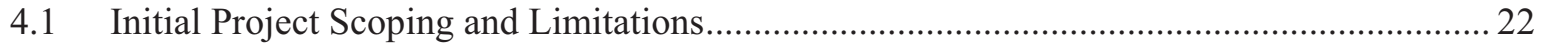

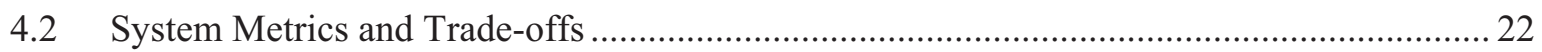

4.3 Key System Assumptions and their Impact, Influence, and Limitations ........................... 23

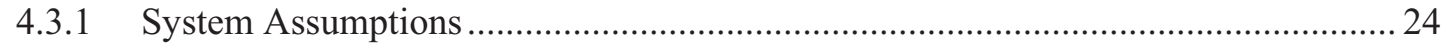

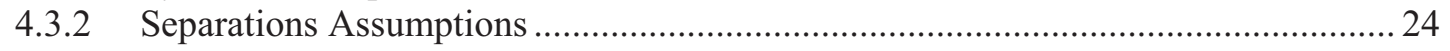




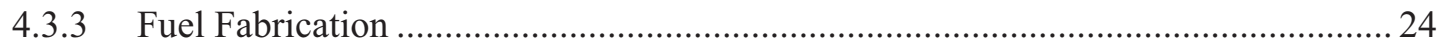

4.4 Scenarios (Cases 1-3) for Metal and Oxide ..................................................................... 24

4.5 Simplified System Losses Model ........................................................................................ 25

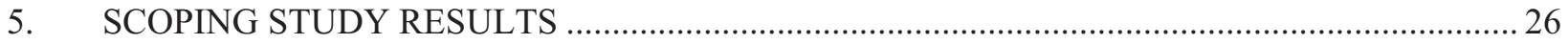

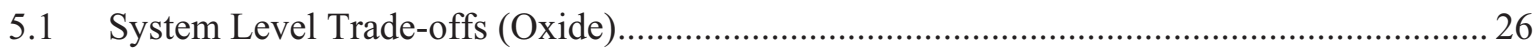

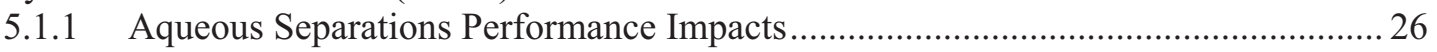

5.1.2 Oxide Fuel Fabrication Performance Impacts........................................................26

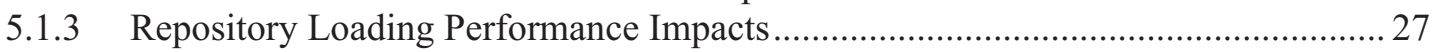

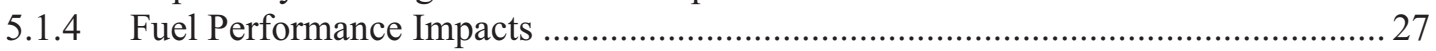

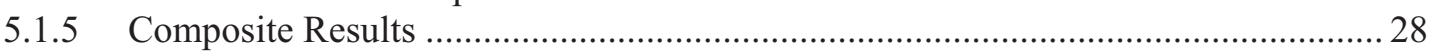

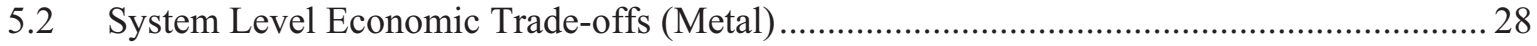

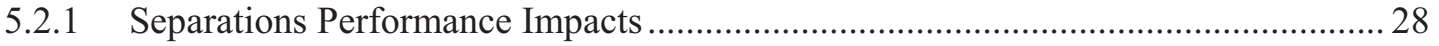

5.2.2 Metal Fuel Fabrication Performance Impacts ......................................................... 29

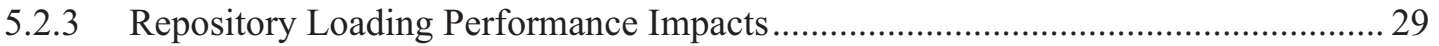

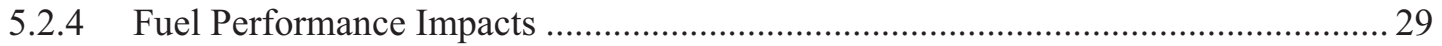

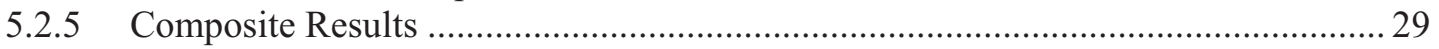

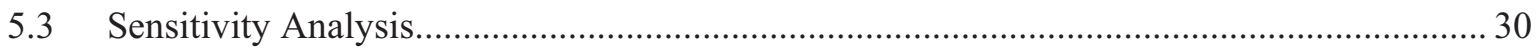

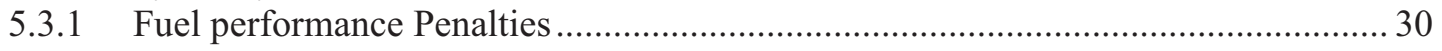

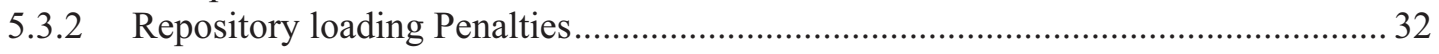

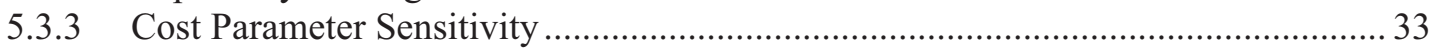

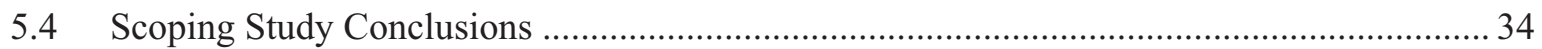

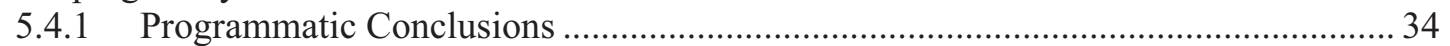

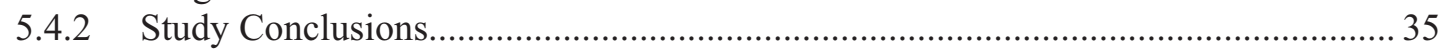

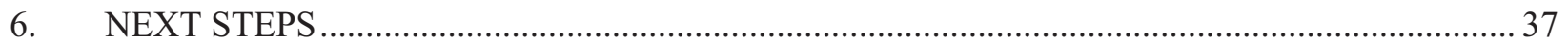

6.1 Opportunities for Improved Understanding ............................................................... 37

6.2 Expanded Analysis, Metrics, and Model Outputs................................................................ 37

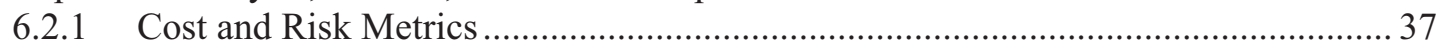

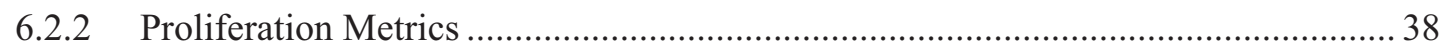

6.3 Enhanced System Losses and Assessment Model ............................................................. 38

6.3.1 System Losses and Assessment Modeling Outputs .................................................. 39

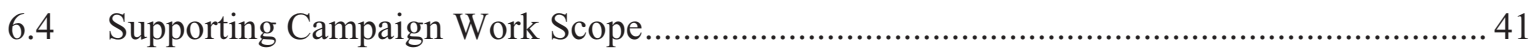

6.4.1 Aqueous Separations/Waste Forms Development and Modeling ............................ 41

6.4.2 EChem Separations/Waste Forms Development and Modeling .............................. 43

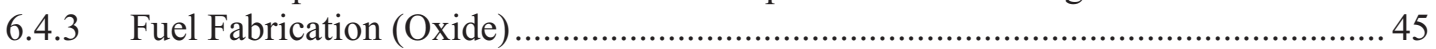

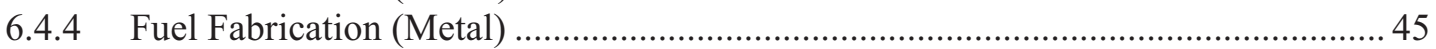

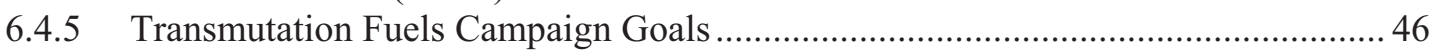

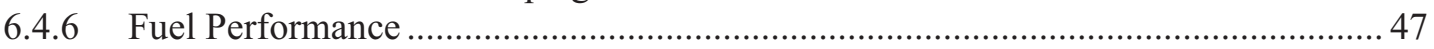

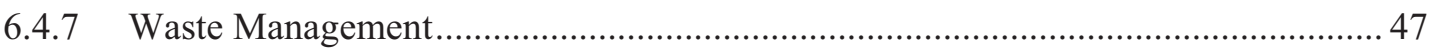

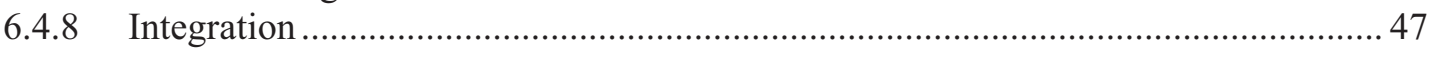

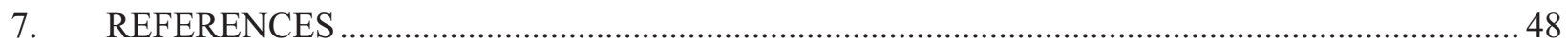

Appendix A—Data from Transmutation Reactivity Screening Analysis ............................................. 49

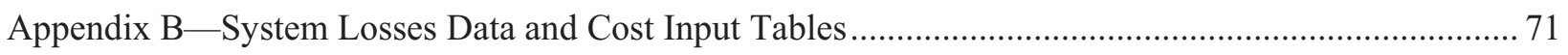




\section{FIGURES}

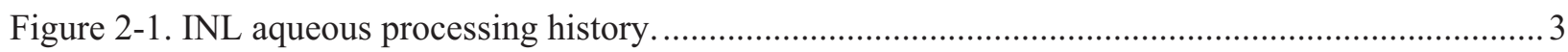

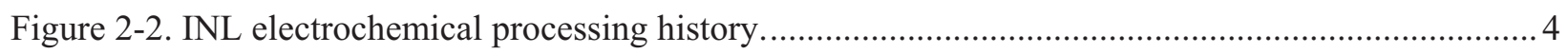

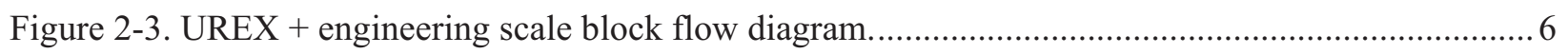

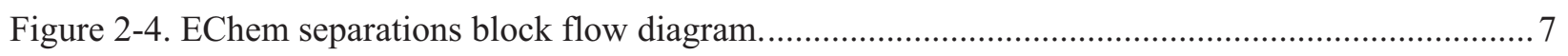

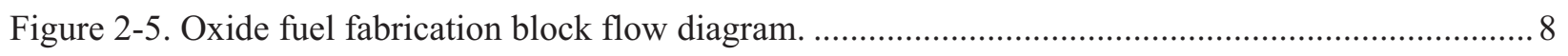

Figure 2-6. Metal fuel fabrication block flow diagram................................................................... 9

Figure 2-7. Tolerable fraction of fission products retained in next recycle to meet current fuel impurity limits. 10

Figure 2-8. Percent of metric (neutron capture cross sections or differential reactivity) for FR-

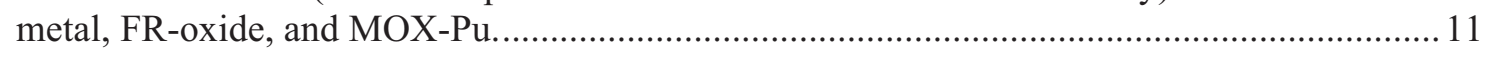

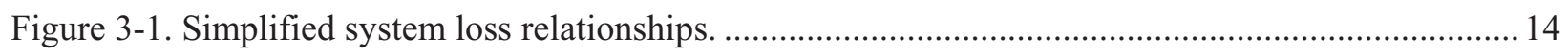

Figure 3-2. Single steady-state closed fast reactor fuel cycle (1 Tier) ................................................ 20

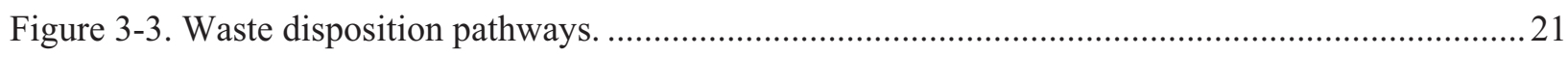

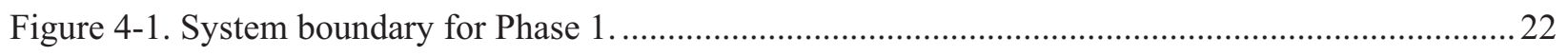

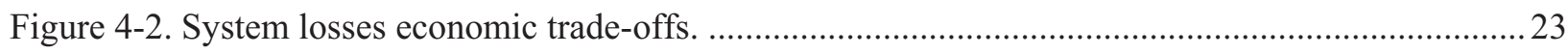

Figure 5-1. Oxide - system level tradeoffs from bounding system losses.............................................26

Figure 5-2. Metal - system level tradeoffs from bounding system losses............................................. 28

Figure 5-3. Cost uncertainty for $1 \%$ fuel performance penalty on oxide fuel. ........................................ 31

Figure 5-4. Cost uncertainty for $10 \%$ fuel performance penalty on oxide fuel. ...................................... 31

Figure 5-5. Cost uncertainty using equivalent waste loading factor for oxide fuel. ................................. 32

Figure 5-6. Cost uncertainty using 2.0 to 4.0 waste loading factor on oxide fuel. ...................................33

Figure 5-7. Cost uncertainty using low, nominal, and high values for oxide fuel variables...................... 33

Figure 5-8. Cost uncertainty using low, nominal, and high values for metal fuel variables......................34

Figure 6-1. System Losses and Assessment Model. ............................................................................... 39

Figure 6-2. Cost performance based on losses to waste and product purity ............................................ 40

Figure 6-3. Cost based on interim storage time of spent fuel before recycle........................................... 40

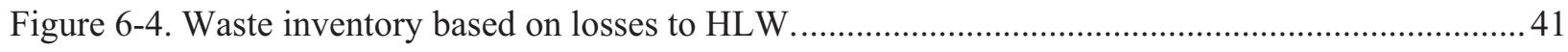

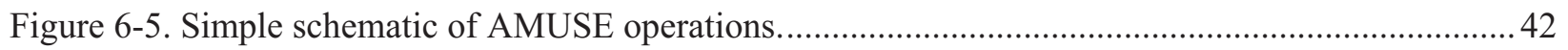

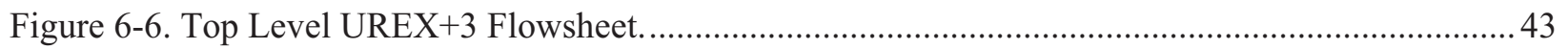

Figure A1-1. Probability of fission with fertile (left) and fissile (right) isotopes. ...................................51

Figure A1-2. Probability of neutron capture with fertile (left) and fissile (right) isotopes.......................52

Figure A1-3. Best-case neutron production divided by best-case neutron loss with fertile (left) and

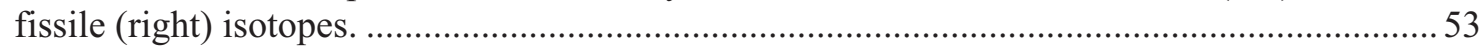

Figure A2-1. Fraction of fission products by chemical element (log plot)........................................... 64 
Figure A2-2. Fraction of fission products by chemical element (linear plot).

Figure A2-3. Fraction of fission products that can be kept in the next recycle, assuming initially pure material before the preceding irradiation, probably overestimates $\mathrm{MOX}-\mathrm{Pu}$ tolerance by an order of magnitude. 66

Figure A2-4. Percent weighted cross sections or percent of differential reactivity, assuming all elements have natural isotopic abundances.

Figure A2-5. Percent weighted cross sections or percent of differential reactivity, assuming the worse of natural or fission product isotopic abundances. 68

Figure B1-1. Performance and cost inputs used in the bounding analysis for metal and oxide fuel. .73

Figure B1-2. Cost uncertainty ranges and basis for estimate for metal and oxide fuel .74

\section{TABLES}

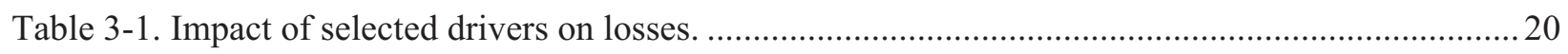

Table 4-1. Metal/oxide-bounding ranges of product purity, TRU losses, and performance.....................25

Table A2-1. Working Transmutation Fuels Campaign limits on TRU feedstock into fuel

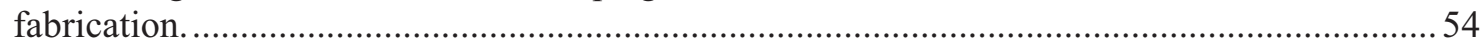

Table A2-2. Fuel TRU feed limits with group limits allocated among elements. ....................................59

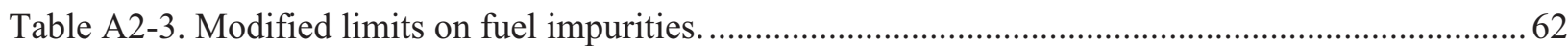




\section{ACRONYMS}

$\begin{array}{ll}\text { AFCF } & \text { Advanced Fuel Cycle Facility } \\ \text { AFCI } & \text { Advanced Fuel Cycle Initiative } \\ \text { Al } & \text { aluminum } \\ \text { Am } & \text { americium } \\ \text { ANL } & \text { Argonne National Laboratory } \\ \text { COEX } & \text { Co-extraction (of uranium and plutonium) } \\ \text { CR } & \text { transuranic conversion ratio } \\ \text { Cm } & \text { curium } \\ \text { Cs } & \text { cesium } \\ \text { DOE } & \text { Department of Energy } \\ \text { DOT } & \text { Department of Transportation } \\ \text { DPL } & \text { Decision Programming Language } \\ \text { EBR } & \text { Experimental Breeder Reactor } \\ \text { EChem } & \text { electro-chemical } \\ \text { ER } & \text { electro-refiner } \\ \text { FCF } & \text { Fuel Conditioning Facility } \\ \text { FFTF } & \text { Fast Flux Test Facility } \\ \text { FP } & \text { fission product } \\ \text { FR } & \text { fast reactor } \\ \text { FY } & \text { Fiscal Year } \\ \text { GTCC } & \text { Greater-Than-Class C } \\ \text { HEU } & \text { highly enriched uranium } \\ \text { HLW } & \text { high-level waste } \\ \text { IFR } & \text { Integral Fast Reactor } \\ \text { INL } & \text { Idaho National Laboratory } \\ \text { LEU } & \text { lowly enriched uranium } \\ \text { LLW } & \text { low-level waste } \\ \text { Ln } & \text { Lanthanide } \\ \text { LWR } & \text { light-water reactor } \\ \text { MCE } & \text { materials control and accountability } \\ \text { Materials and Fuels Complex } \\ \text { Micronization Master Blend } \\ \text { MIide }\end{array}$




$\begin{array}{ll}\text { NE } & \text { nuclear energy } \\ \text { NFBC } & \text { nonfuel-bearing components } \\ \text { NMC\&A } & \text { Nuclear Materials Control and Accountability } \\ \text { Np } & \text { neptunium } \\ \text { ORNL } & \text { Oak Ridge National Laboratory } \\ \text { Pu } & \text { plutonium } \\ \text { R\&D } & \text { research and development } \\ \text { SLAM } & \text { System Losses and Assessment Model } \\ \text { SNF } & \text { Spent Nuclear Fuel } \\ \text { SNM } & \text { special nuclear material } \\ \text { SNR } & \text { Sodium-cooled fast breeder reactor } \\ \text { Sr } & \text { strontium } \\ \text { SRS } & \text { Savannah River Site } \\ \text { Th } & \text { thorium } \\ \text { TMFP } & \text { transition metal fission products } \\ \text { TRU } & \text { transuranic } \\ \text { U } & \text { uranium } \\ \text { UREX } & \text { Uranium Extraction } \\ \text { VISION } & \text { Verifiable Fuel Cycle Simulation } \\ & \end{array}$




\section{SYSTEM LOSSES AND ASSESSMENT TRADE STUDY}

\section{INTRODUCTION}

This Advanced Fuel Cycle Initiative (AFCI) study has developed new analysis methods to examine old and new technology options toward the goal of improving potential fuel cycle systems. We have integrated participants and information from Systems Analysis, Transmutation Fuels Fabrication, Separations, and Waste Form Campaigns. The initial objectives were to (1) increase understanding of system interdependencies and thereby identify system trade-offs that may yield important insights, (2) define impacts of separations product purity on fuel manufacture and transmutation reactivity, (3) define impacts from transuranic (TRU) losses to waste, (4) identify the interrelationships involved in fuels and separations technology performance, and (5) identify system configuration adjustments with the greatest potential for influencing system losses. In analyzing the example problem, we found insights with broad implications to the current fuel cycle research charter to examine a broader set of options, including potential areas of research leverage. As work progressed on the initial study through setting bounding assumptions and scoping the initial objectives, additional system dependencies and significantly higher-level programmatic drivers were identified that warrant further investigation. These "big-picture" drivers and their related issues, trade-offs and observations are discussed in more detail in Section 3 and 6.

\subsection{Report Organization}

This report provides a big-picture overview and an initial economic application on system losses, which facilitates improved understanding of the key integration issues and future study needs.

Section 1 of this report contains the introduction and describes the objectives of the study.

Section 2 provides the basis for assessment and describes the current state of the art/background of the separation and fuel fabrication technologies. The section also provides the Systems, Separations, Waste Form, and Transmutation Fuels Fabrication Campaign's knowns versus unknowns: what is needed for improved results, and what gaps are yet to be filled.

Section 3 provides an overall system perspective on the study including the complexity of the study, limitations resulting from taking too simplistic a view of losses, big picture issues and system level drivers, and the impacts from selected drivers.

Section 4 provides a description of the initial scoping application, including the project scoping and limitations, system metrics, baseline assumptions, a description of the initial System Losses and Assessment Model, and the analyzed specific scenarios.

Section 5 provides the results from the scoping analysis, including the system level trade-offs for metal and oxide fuels, cost sensitivity analysis for reactor and repository performance, and preliminary conclusions from the initial Fiscal Year (FY)-09 study.

Section 6 describes the next steps for the study in FY-10, including opportunities for improved understanding between the Campaigns, expanded analysis and metrics, development of enhanced modeling capabilities, and supporting AFCI Campaign work scope.

Section 7 provides the references for the study.

The Appendix A provides details on transmutation reactivity screening analysis and Appendix B provides additional data and cost input tables from the economic analysis. 


\section{BASIS OF ASSESSMENT}

\subsection{Background}

Goals for loss rates were defined by the Department of Energy in 2005 based on the programmatic objectives to (1) reduce the long-term environmental burden of nuclear energy though more efficient disposal of waste materials; (2) enhance overall nuclear fuel cycle proliferation resistance via improved technologies for spent fuel management; and (3) enhance energy security by extracting energy recoverable in spent fuel and depleted uranium, ensuring that uranium resources do not become a limiting resource for nuclear power (DOE 2005). The quantification of the goals did not specifically define a limit for "losses," but they do have a direct implication on losses. For example, the first objective indicates that "fuel cycle technologies and facilities are to remove more than $99.5 \%$ of TRU from waste destined for geologic disposal," the second goal indicates the elimination of "more than $99.5 \%$ of TRU weaponsusable materials from waste streams," and goal three indicates a " 50 -fold" extension of nuclear fuel resources. The bottom-line is that all these goals result in a limit of $0.5 \%$ per recycle loss of TRU into the waste streams.

These goals did not take into account the associated costs for separations and fabrication activities, in part because those activities had not been sufficiently defined to generate meaningful cost differences as a function of process efficiency and product purity. These goals also did not consider regulatory requirements for classes of waste other than high-level waste (HLW). Much of this specific information is still lacking, but this study has developed a model that helps define how the various parameters respond to change and therefore enhances understanding of the sensitivities due to key parameters.

In this section a brief history is provided on separations (aqueous and electro-chemical [EChem]) and fuel fabrication (oxide, metal) technology and their respective technical maturities. This background is provided to lay a foundation of experience and expertise that is being drawn from in support of this study. The experience in managing a diverse fuel and waste inventories (including special nuclear material [SNM]) and fuel reprocessing is needed to address a broad range of nuclear material management challenges and integration options in the future.

\subsubsection{Aqueous and Electro-Chemical Separations Background}

The Department of Energy (DOE) complex has a unique history relative to nuclear materials management and waste dispositioning - more types of reactors, fuels, separation than anywhere else for a range of commercial and defense purposes. The DOE laboratories have directly participated in these activities and are now is a position to help plot future strategies for nuclear materials management.

The initial cold-war era was primarily focused on the production of weapons and power production reactors and did not have a cradle-to-grave material management perspective until much later in the evolution of the nuclear power industry. Along the way a large quantity and variety of nuclear material was processed and related facility infrastructure was developed to demonstrate first wet and then dry processing technologies. Much of the diversity in processing was due in a large part to the history with reactor testing programs, weapons and special isotope production, and the research/production work related to processing/dispositioning these materials and managing the associated waste streams. The three principal fuel/target processing and waste management sites included Hanford, Savannah River Site (SRS), and Idaho National Laboratory (INL). Of these three sites, INL stores fuel that is generally representative of DOE's current inventory (including SNM), and has an extensive fuel reprocessing history including the waste management of multiple fuel types. This is in contrast to the processing capabilities at the other two sites, which focused primarily on weapons and isotope production. Researchlevel processing occurred at other sites (e.g., Oak Ridge National Laboratory [ORNL] on a smaller scale similar to laboratory and/or pilot plant operations). 
Most of the initial separations programs were focused on the aqueous processes, which were capable of treating all types of fuel meat (e.g., metal, oxide,) clad in all kinds of material (e.g., Al, Zircaloy or stainless steel). Electrochemical processing has been focused on metal-type fuel, but can process oxide fuel once the oxide is reduced to a metal. For the purpose of this study, aqueous processing has been assumed for commercial light-water reactor (LWR) oxide used fuel and electrochemical for fast reactor metal used fuel. This assumption is not intended to suggest that metal fuel cannot be processed via an aqueous flowsheet or that oxide fuel cannot be processed with an electrochemical flowsheet, and no attempt has been made to compare which process would perform better for a given fuel. The following paragraphs detail the INL's experience as a representative historical benchmark for the DOE complex. With the end of the cold war, DOE's processing capabilities have been significantly restricted (i.e., electrochemical processing at INL and limited aqueous capabilities at SRS).

A historical overview of the aqueous processing capability at INL is provided in Figure 2-1. As noted in the figure, the INL aqueous production scale operations were shutdown in 1992. However, aqueous treatment of used aluminum (Al) highly enriched uranium (HEU) fuel continues at SRS. The liquid HLW was stored on an interim basis at both sites to await conversion to a solid product (e.g., granular oxide material called "calcine" at INL and a vitrified glass at SRS). The calcine was pneumatically transferred to stainless steel bins at INL that are seismic-hardened and housed in seismic-hardened concrete storage vaults (500-year design life) where it awaits final treatment and disposition. The HLW at SRS is processed into a glass form and stored to await final disposition. A waste treatment facility similar to the one at SRS is being constructed at the Hanford site to convert its tank farm waste into a stable glass form that will also be stored to await its final disposition path.

INL

- Most Diversified Processing Experience in DOE Complex

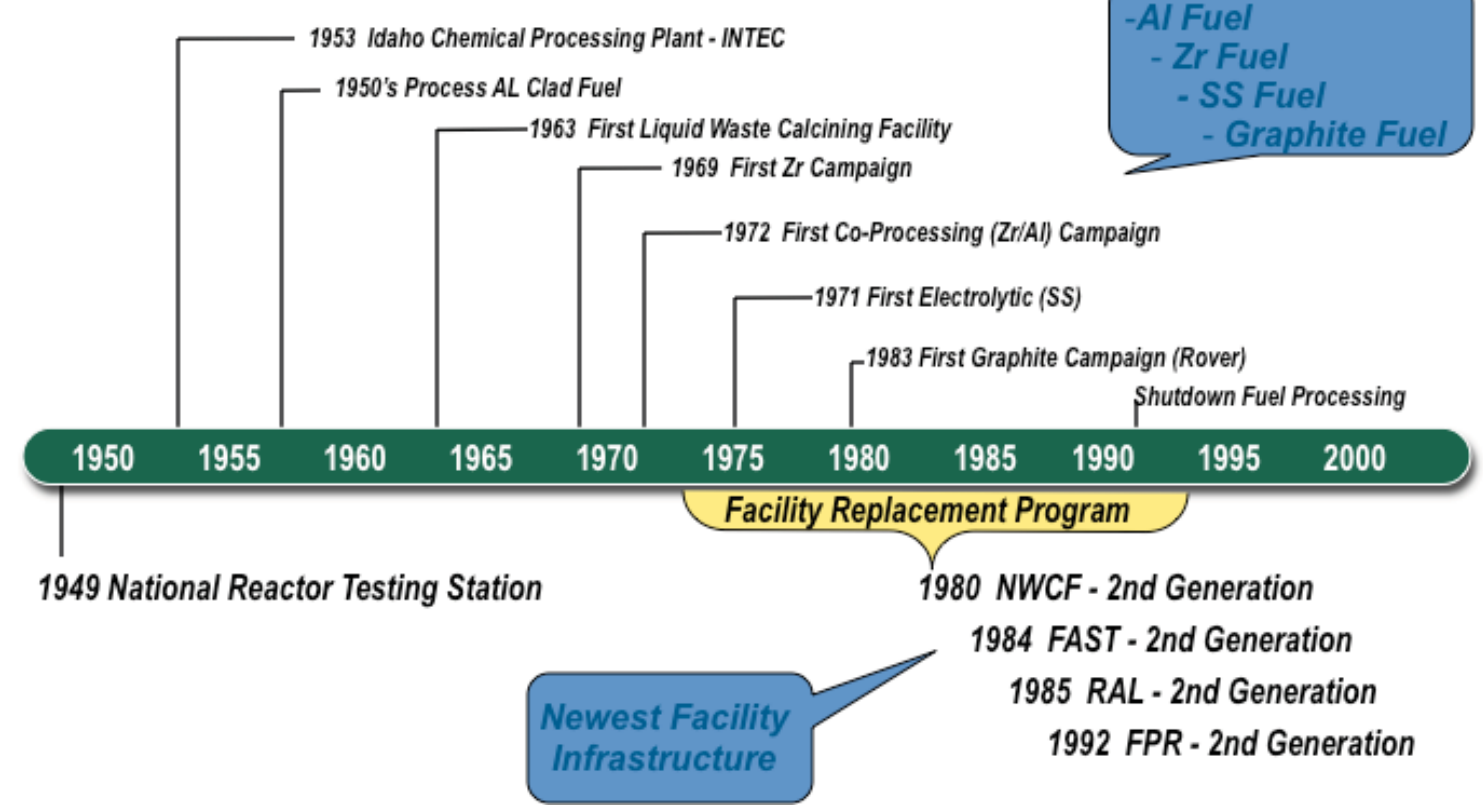

Figure 2-1. INL aqueous processing history.

A similar history for EChem processing of metal fuel is shown in Figure 2-2, which starts in the 1960s and continues today. The EChem program includes the dispositioning of EBR-II used fuel, R\&D work related to NE's AFCI program, and expansion into processing oxide nuclear fuel. Treatment of EBR-II fuel via EChem processing has produced metal and ceramic waste forms that are qualified for long-term geologic storage. 


\section{Electrochemical Processing Development}

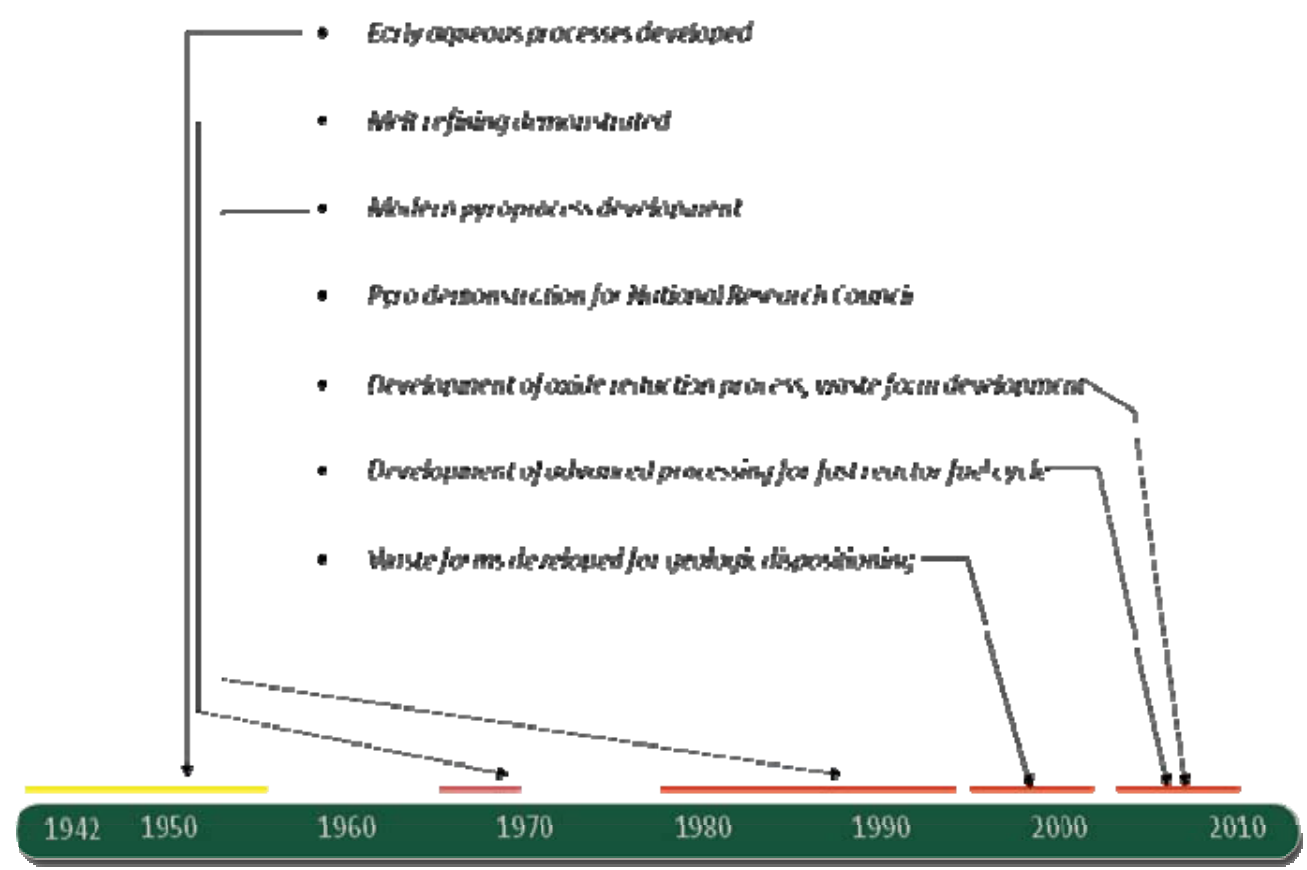

Figure 2-2. INL electrochemical processing history.

EChem separation has not been used for processing irradiated fuel to the degree that aqueous separations has, but it is currently being used to treat legacy spent fuel from the EBR-II. EBR-II was a sodium-cooled fast reactor that operated from 1965 to 1995 at the Argonne National Laboratory (ANL)-West facility, which is now called the Materials and Fuels Complex (MFC) and is part of INL. EBR-II fuel elements contain sodium to thermally bond the uranium metal alloy fuel to the stainless steel cladding. The spent fuel is being treated to put the reactive sodium metal in a stable form suitable for disposal.

The EChem technology being used, molten salt electrorefining, was developed in the 1980s to recycle fast reactor fuel. The equipment being used was designed and built in the early 1990s to support a recycle demonstration using the EBR-II and the Fuel Conditioning Facility (FCF). The original demonstration flowsheet included a process to recover a pure uranium product and another process to co-recover a uranium/transuranic elements (U/TRU) product, which would be used to re-fabricate fuel in FCF and recycle it to the EBR-II. The flowsheet also included processes to consolidate cladding and noble metal fission products into a metal waste form and immobilize fission product salts in a ceramic waste form. The recycle demonstration project was cancelled in 1995. The current treatment project, which started in 1996 with a 3-year demonstration, only recovers a uranium product, leaving the transuranics as salts for disposal in the ceramic waste form. Approximately $3900 \mathrm{~kg}$ of spent fuel heavy metal have been processed to date (2009).

The treatment project was included in the AFCI program starting in 2002. Since then limited research has resumed on recovery of transuranics for recycle, including the reduction of losses of transuranics to waste streams. This research is mainly being conducted at laboratory-scale (e.g., small prototype equipment processing to recover gram quantities of product and prove chemistry). Additional research is needed to develop a thorough understanding of the U/TRU recovery processes before the technology can be scaledup to engineering-scale (e.g., saleable pilot plant equipment processing to recover kilogram quantities of product and prove equipment performance scalable to full-size). 
Generally speaking the aqueous operations developed by the federal government have matured to commercial capability and have been utilized around the world to process LWR-used fuel. Electrochemical processes tend to be more focused on processing fast reactor metal fuel and may be judged to be less mature in terms of commercial application and regulatory support and review. This lack of maturity results in greater uncertainties on losses, hence research is being focused in these areas.

\subsubsection{Fuel Fabrication Background}

Metal fuels were first used in the 1940s to produce plutonium $(\mathrm{Pu})$ for military purposes. Metal fuels were first selected as they could be produced and irradiated in large quantities and were simplest to reprocess. Oxide fuels were developed somewhat later to allow higher temperature reactor operation for the efficient production of steam for generation of electricity. However, both metal and oxide fuel have been used in steam generating power reactors and both metal and oxide fuel have been used in sodium cooled fast reactors.

The basic reactor metal fuel was developed in the 1950s, leading to a product that could be irradiated to high heavy metal burnup. From 1964 to 1969, EBRI-II demonstrated recycling of all the TRU elements. The fuel was reprocessed in a hot cell and reused in the reactor; ${ }^{a}$ the reprocessed fuel performed to the same reactor specifications as the original cold-fabricated fuel.

The basic principles used in the fabrication of EBR-II fuels, and the innovations that had been planned for use at the INL FCF for reprocessing EBR-II fuel for the Integral Fast Reactor (IFR) program, form the design bases of the current metal fabrication process.

Currently, mixed oxide (MOX) fuel is made by mixing plutonium oxide and uranium oxide, pressing the powder into pellets, then sintering to final density. MOX fuel demonstration programs began in the U.S. and Europe in the 1960s with the Fast Flux Test Facility (FFTF) reactor in the U.S. irradiating more than 63,000 MOX pins. By the mid-1970s, the U.S. nuclear industry was ready to implement a large-scale MOX utilization program. Events at the time altered the direction of the nuclear industry in the U.S.; however, Europe and Asia continued to develop MOX fuel programs that dominate the fast reactor market today with fuel produced for the SNR-300 reactor in Germany, the Phénix and Super-Phénix reactors in France, and others in Russia and Japan.

The U.S. MOX fuel fabrication process is derived from the processes used to fabricate LWR (thermal) MOX fuel rods in Europe. Hundreds of metric tons of MOX fuel have been fabricated and irradiated in Europe. The fabrication process used in Europe by the French and Belgians is known as the Micronization Master Blend (MIMAS) process. The process enables a sintered material recycle stream $(\sim 11 \%)$ within the process that helps stabilize process parameters and results in a very high material yield $(>99 \%)$ to final fuel pellets. The process for fabrication of transuranic-bearing MOX (TRUMOX) fuel for fast reactors is expected to be similar to existing MOX processes, but will require remote fabrication that has not yet been demonstrated for MOX fuels.

A variety of issues must be overcome to achieve TRU oxide fuel fabrication in a remote environment. Remote TRU metal fuel fabrication has been demonstrated. Both fabrication processes need to be further refined to minimize complexity and maximize process yields prior to production implementation of TRU fuel manufacturing. Major opportunities exist for the improvement of existing fuel forms. Simplification and improvement of fuel processes is needed to maximize fabrication efficiency while providing a product that allows increased fuel burn-up even when additional impurities are incorporated in the fuel. Opportunities for improved interface include: number and types of fuel assemblies in the reactor, number of composition and enrichment variants, and use of separate oxide poison or target assemblies. The separation of the spent fuel and especially the finishing of the separations product to be used as feed

a. They did not separate out the noble metals, Ru, Mo, Pd, or Zr. 
material for fuel fabrication have a direct impact on fuel fabrication options and the possible quality of fuel produced for transmutation irradiation.

\subsection{Campaign Studies Related to System Losses}

This section summarizes the current technologies and the areas where gaps need to be filled.

\subsubsection{Aqueous Separations}

Figure 2-3 depicts a functional block flow diagram for a URanium-EXtraction (UREX)+ type aqueous separations flowsheet that could be used to process LWR commercial fuel. Standard PUREX or CoExtraction (COEX) like processes are designed to separate only $\mathrm{U}$ and $\mathrm{Pu}$ and are significantly less complicated. This flowsheet is benchmarked for this study because it presents a number of separation steps where losses could occur.

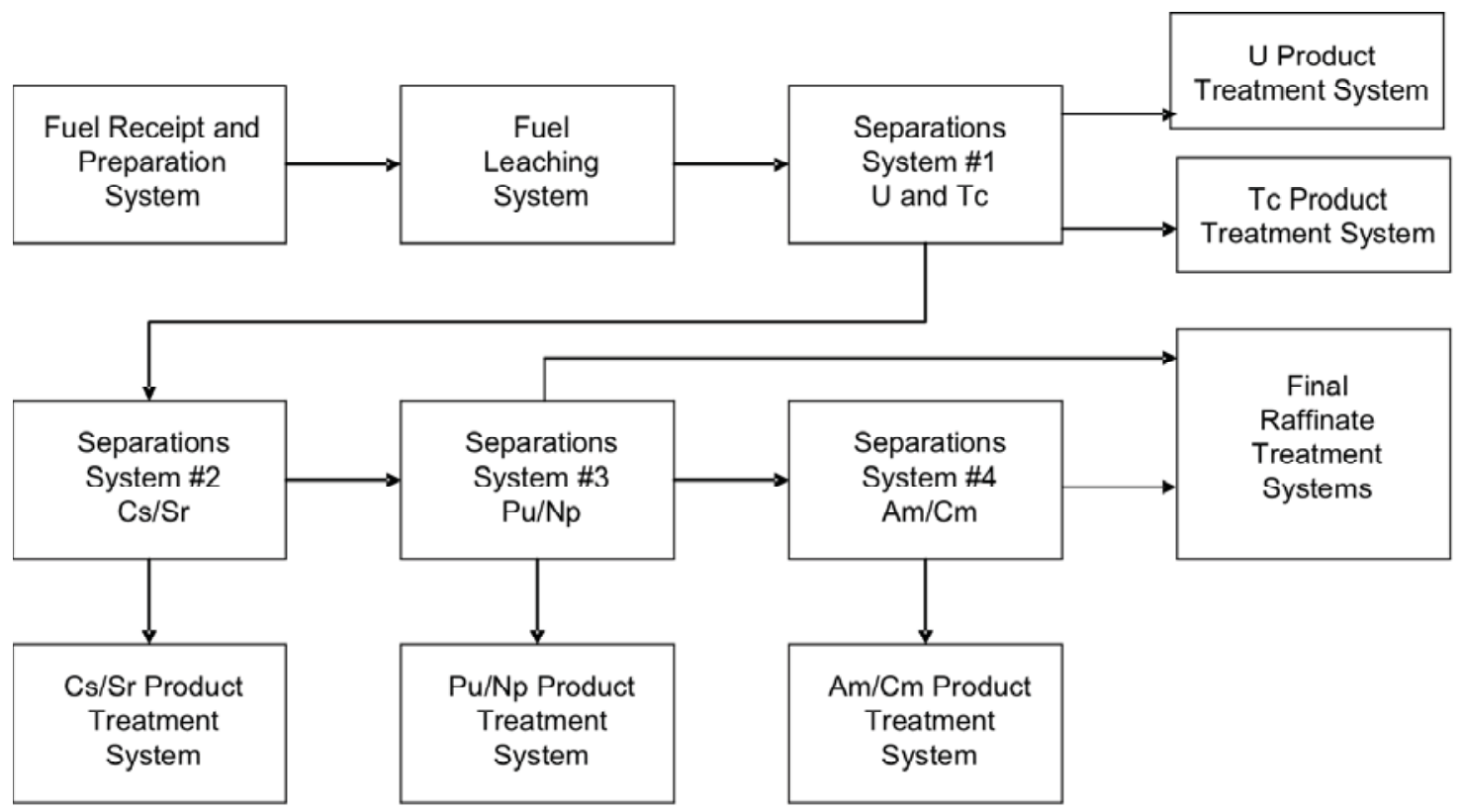

Figure 2-3. UREX + engineering scale block flow diagram.

Most of the losses in aqueous separation operations occur in the phase transition steps (e.g., solid used fuel is sheared, homogenized to liquid via dissolution and purified, concentrated liquid product is converted to oxides via denitration processes) and not in the actual partitioning operations. Aqueous separation/extraction systems are typically designed with significant recovery margins, and therefore they tend to easily endure minor process upsets. When these abnormal operating conditions are too severe, the consequences are managed by recycling off-spec material until the desired recovery limits are met. Applying a similar recycle strategy to the headend dissolution process (e.g., extended leaching operations for hulls and improved efforts to recycle the very fine oxides that are trapped in the filtration systems) is typically not cost effective relative to the value of the material that is lost.

The Separations Campaign is developing better estimates of losses via predictive computer codes (AMUSE, ASPEN, etc). New ways to simplify separations and fuel fabrication flowsheets are being sought. Engineering-scale data are needed to validate the predictions from these models, and the current strategies need to be re-evaluated to determine if the greater number of separations in UREX+ separations capabilities is really the best path forward. Aqueous separations modeling using the AMUSE generates the expected fuel separations process outputs and predicts the gross impurity levels in feed-to-fuel fabrication. Modeling with AMUSE code can be used to evaluate the effectiveness of modifications to processes in minimizing impurities, but only to the extent that real processing data is generated to validate 
and/or "tune" the code. Modeling predicts the impact of these changes on waste and product streams, such as the behavior of particular metals. Estimates of metals content in process solutions due to process conditions and corrosion can be made. Modeling studies that have been developed from real processing data can be used to help evaluate the impact on flowsheet designs if specific system losses or product purity requirements are loosened or tightened (for fuel fabrication feed or other products product and waste streams).

Step improvements in sampling and analytical capabilities can have dramatic impacts on the area requirements for the facility processing core (i.e., less turnaround time equates to less storage volume, less tankage, and less operating space). Future work is needed to validate modeling codes with real data at an engineering scale. Once validated, these codes can be used to help optimize operations, minimize losses, and minimize facility cost and risk.

\subsubsection{EChem Separations/Waste Form}

The EChem Separations/Waste Form flow sheet for application to a fast reactor metal fuel cycle is defined by the block flow diagram shown in Figure 2-4.

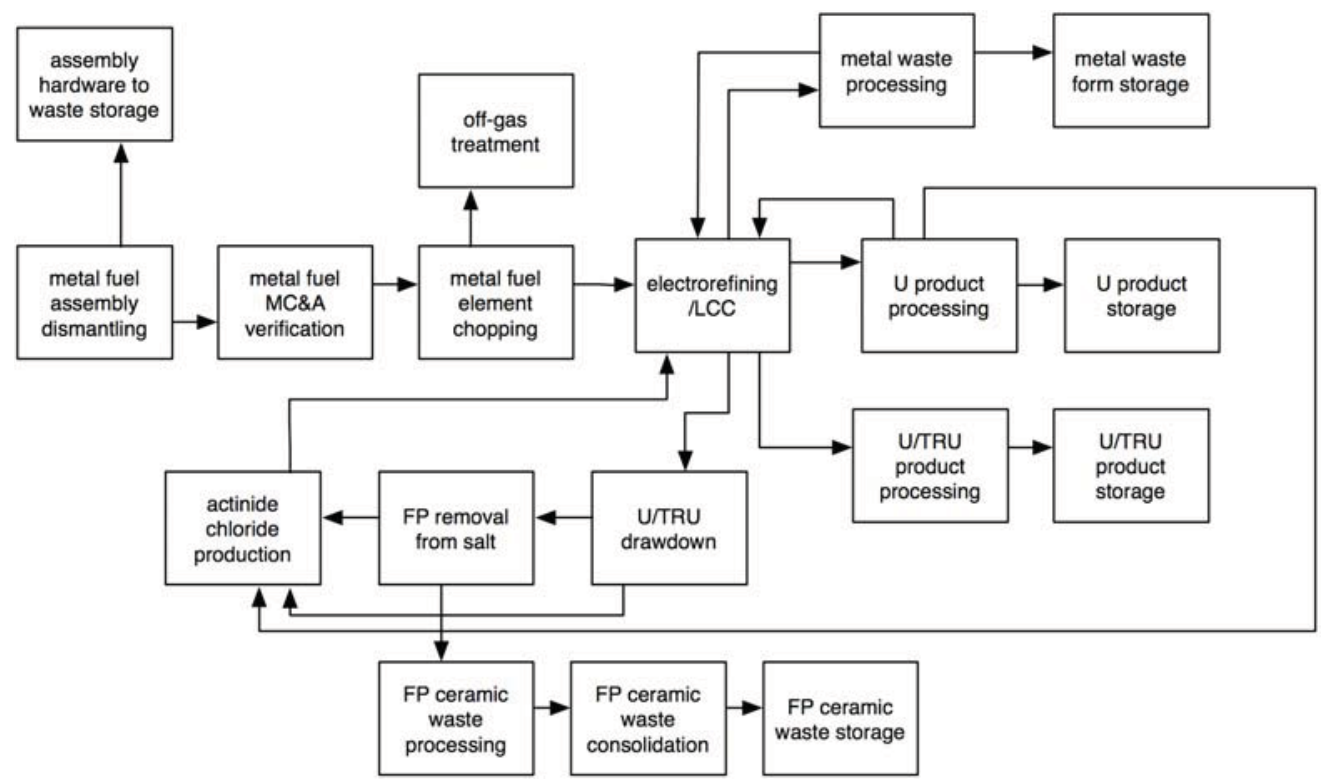

Figure 2-4. EChem separations block flow diagram.

Some of the unit operations in this diagram (e.g., assembly dismantling, assembly hardware to waste, fuel chopping, electrorefining, U product processing, U product storage) are routinely performed as part of the EBR-II spent fuel treatment flowsheet. Other operations (e.g., metal waste processing, metal waste storage, ceramic waste processing, ceramic waste consolidation, and ceramic waste storage), which are also part of the EBR-II flowsheet, are still being implemented.

One focus of EChem Separations R\&D under the AFCI Separation Campaign has been to improve or modify these operations for application to a fast reactor transmutation fuel cycle. Current research activities include advanced $U$ product processing, electrorefining process monitoring, and advanced salt waste form development.

Another focus of the EChem Separations Campaign has been to develop those unit operations in the diagram that are not currently being performed. Current research activities include off-gas treatment, U/TRU product recovery, U/TRU product processing, U/TRU drawdown of salt, and fission product removal from salt. 
The Separations Campaign has supported development of dynamic process models based on fundamental chemical and thermodynamic principles to provide the tools to develop advanced process flowsheets and predict process throughputs. Since most of the electrochemical processes are not steady state, the unit operation models using commercial software application (e.g., ASPEN ${ }^{\circledR}$ ) use rule-based separation logic rather than kinetic or thermodynamic based calculations. The rules are based on experience to predict mass flow. However, this method does not provide an effective method to optimize the process or evaluate alternative processing strategies. To provide this capability, dynamic modeling methods need to be developed to supplement, and eventually replace, the rule based logic. Further discussion on the requirements for EChem modeling is provided in Section 5.2.1.

The primary goals of the EChem Separations R\&D have been to (1) determine the range of impurities in the U/TRU product for alternative recovery methods (estimated to vary by several orders of magnitude according to some theoretical models) and (2) understand the cause and extent of TRU losses to waste in the U/TRU product processing (current $U$ product processing losses can be as much as $2 \mathrm{wt} \%$ of the input heavy metal due to interaction with crucible coatings) and TRU drawdown operations (losses estimated to be as much as $1 \mathrm{wt} \%$ of input heavy metal if operated to minimize lanthanide element drawdown).

\subsubsection{Oxide Fuel Fabrication}

Fuel Fabrication is currently defined by the block flow diagram as shown in the Figure 2-5. Development and analyses are being performed as part of the Transmutation Fuels Campaign to revolutionize the existing fuel form and process to provide a higher burn-up fuel while reducing the number of fabrication process steps, eliminating most of the process wastes, and minimizing scrap recycle requirements. The major thrusts for the Transmutation Fuels Campaign are shown in Section 6.4.5.

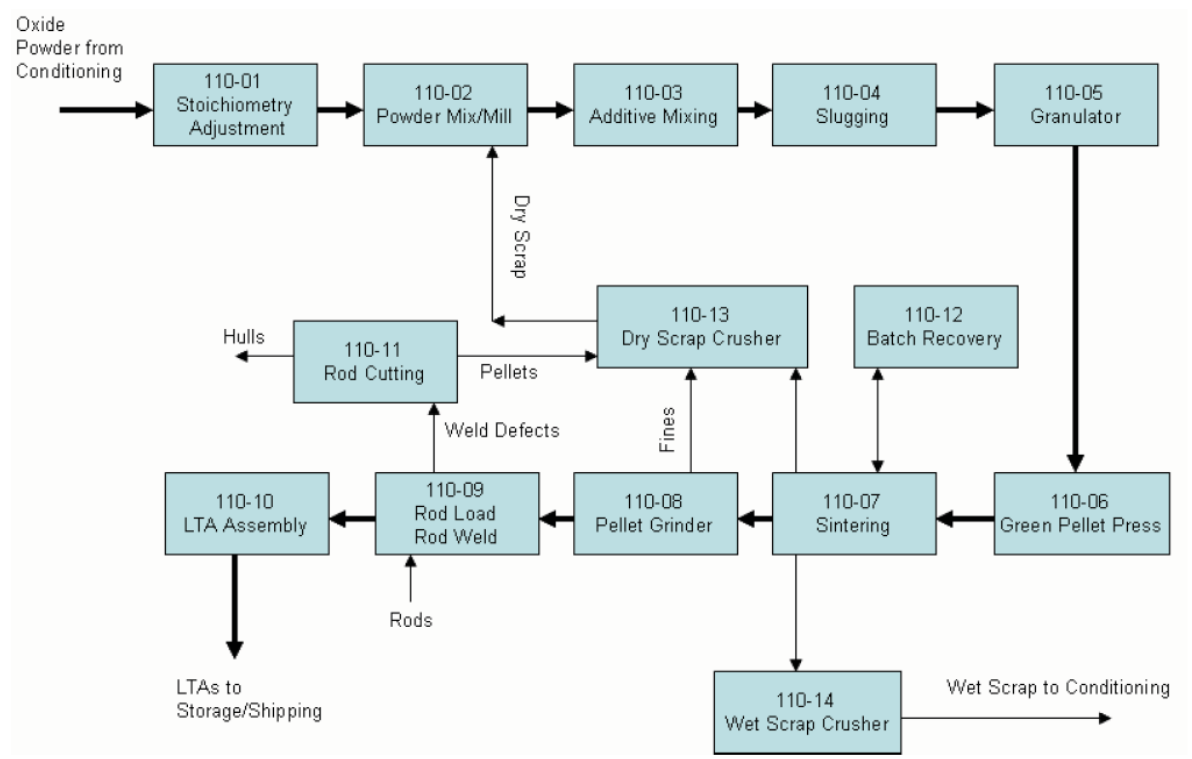

Figure 2-5. Oxide fuel fabrication block flow diagram.

\subsubsection{Metal Fuel Fabrication}

Metal Fuel Fabrication is currently defined by the block flow diagram as shown in the Figure 2-6. Development and analyses are being performed as part of the Transmutation Fuels Campaign to revolutionize the existing fuel fabrication approach to provide a higher burn-up fuel that is less susceptible to lanthanide content while reducing the number of process steps, eliminating most of the process waste, and significantly reducing required scrap recycle streams. The major thrusts for the Transmutation Fuels Campaign are shown in Section 6.4.5. 


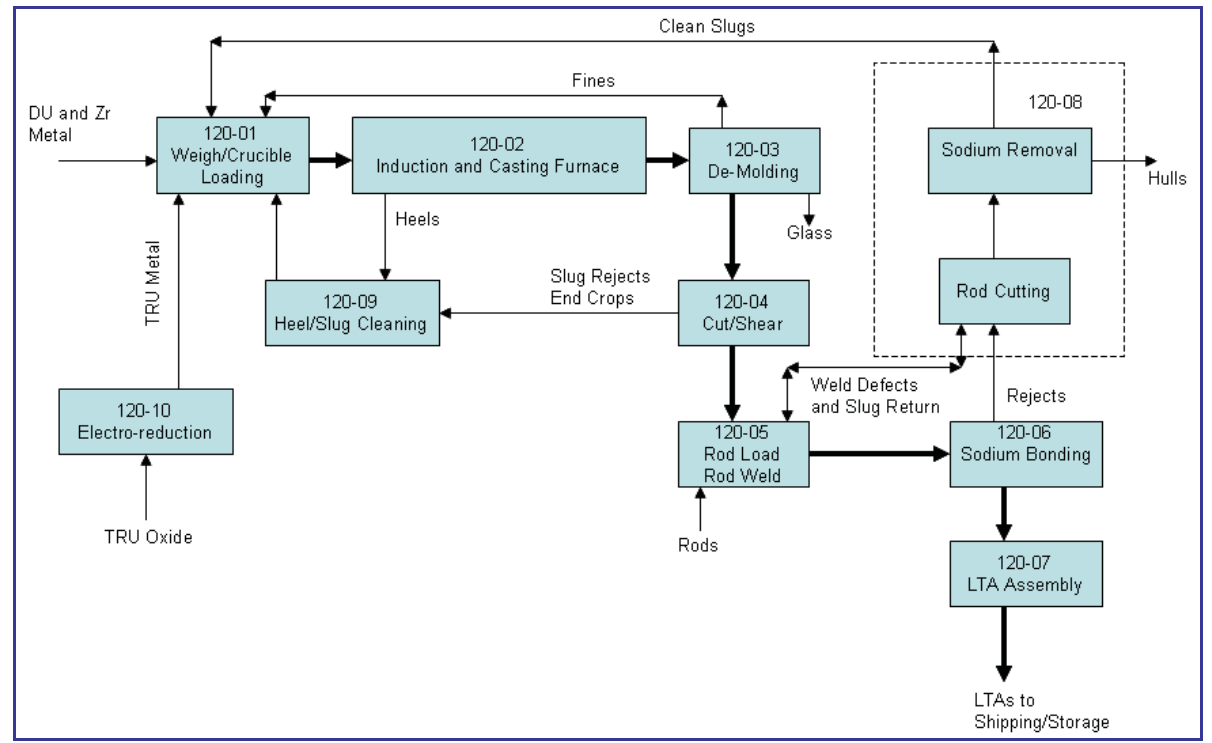

Figure 2-6. Metal fuel fabrication block flow diagram.

\subsubsection{Reactor Transmutation Performance}

This component of the System Losses and Assessment Trade Study involves the analysis of the impact of fuel impurities on fuel value (reactivity) and impact on fuel radioactive characteristics (gamma, neutron, heat). The fission product production, neutron capture, and differential reactivity was examined for fast reactor metal fuel $(C R=0.50)$, fast reactor oxide fuel $(C R=0.50)$, and LWR MOX-Pu.

The current Transmutation Fuels Campaign working limits on impurities in fast reactor fuels require modification and interpretation before they can be used in system and transmutation analysis because (a) they are defined for the TRU feedstream rather than the fuel itself, (b) they do not cover all elements (i.e., some elements are not explicitly limited), and (c) because most limits are specified for groups of chemically similar elements rather than individual elements. For exploratory analysis, it is inappropriate to include zero amounts of elements without specified limits. Note that elements that are chemically similar are not necessarily neutronically similar. So, the current Transmutation Fuels Campaign working limits were extended by chemical element analogy to all elements from $\mathrm{H}$ to $\mathrm{Th}$ and those limits for groups of elements were evenly divided among elements in that group for exploratory assessments. This assumed allocation of "group" limits is a starting point but future work must consider the relative contribution of the sources of such impurities (fission products, corrosion of materials in the fuel clad, fuel separation, and fuel fabrication systems, and any deliberate addition of materials).

This analysis lead to calculation of two sets of results. The first was to compare the calculated rate of production of elements via fission to the modified Transmutation Fuels Campaign limits to determine what fraction of fission product production has to be removed before subsequent recycle. Figure 2-7 shows that the fission yield of elements Selenium (Se) through Dysprosium (Dy) are sufficiently high that they must be removed before subsequent recycle of recovered transuranic material. The tolerable fraction of these fission products remaining in recycled fuel is lower than $0.1 \%$ for some individual elements. ${ }^{\mathrm{b}}$ Rebalancing the group-element-allocation assumption will even out the values in Figure 2-7 in future work, but the fundamental message is that the impurity/losses assessment must consider accumulation from multiple recycles and the multiple sources of impurities.

b. No value in Figure 2-7 is shown for $\mathrm{Kr}$ and $\mathrm{Xe}$ as they are assumed totally removed during separations. 


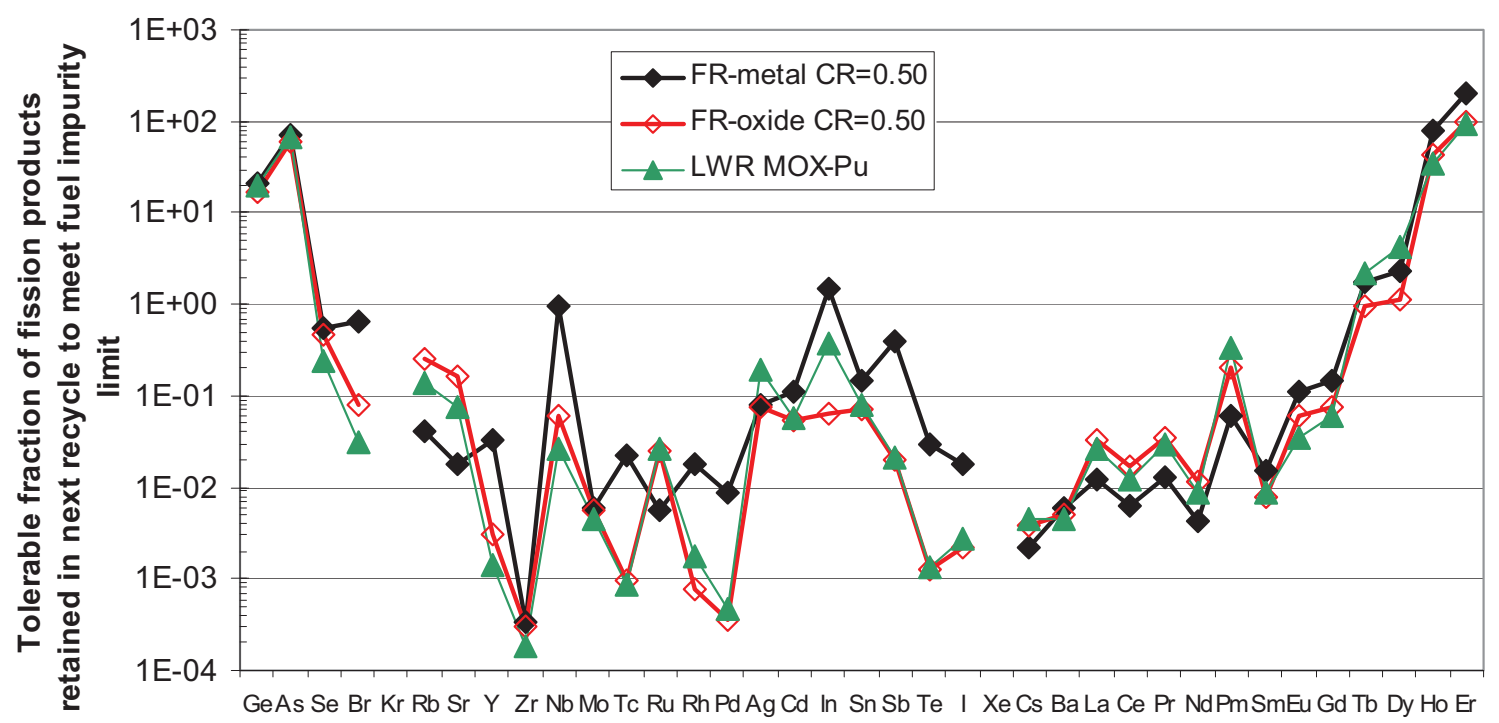

Figure 2-7. Tolerable fraction of fission products retained in next recycle to meet current fuel impurity limits.

The second set of results pertain to the impact of impurity levels (at the modified Transmutation Fuels Campaign working limits) on fuel value. We considered the impact of impurity levels using two methods. The first method used differential reactivity coefficients calculated (Hoffman 2009) that measure the change in reactivity from displacing a fuel atom with an impurity atom, this accounts for both neutron capture and physical displacement of fuel atoms by non-fuel atoms thereby reducing fuel density. If kept at the Transmutation Fuels Campaign working limits, the upper bound reactivity impact of impurities is below $1 \%$ in fast reactors and below $4 \%$ for LWR MOX-Pu, assuming that the reactivity penalty was met by increasing the TRU content of fuel by such amounts. The impact of the reactivity penalty is larger if met by decreasing the fuel residence time.

The second method used 1-group neutron captured cross sections to determine the neutron capture penalty without consideration of physical displacement of fuel atoms, which is effectively the case if the volume of fuel in a reactor were increased to compensate for impurities in fuel. Figure 2-8 shows the relative contribution to differential reactivity and neutron capture. In either approach, the dominant set of elements is the lanthanides. The light elements are important contributors to differential reactivity because they displace fuel atoms but they have little impact to neutron capture. Details on the reactor transmutation fuel value assessment are included in Appendix A. 


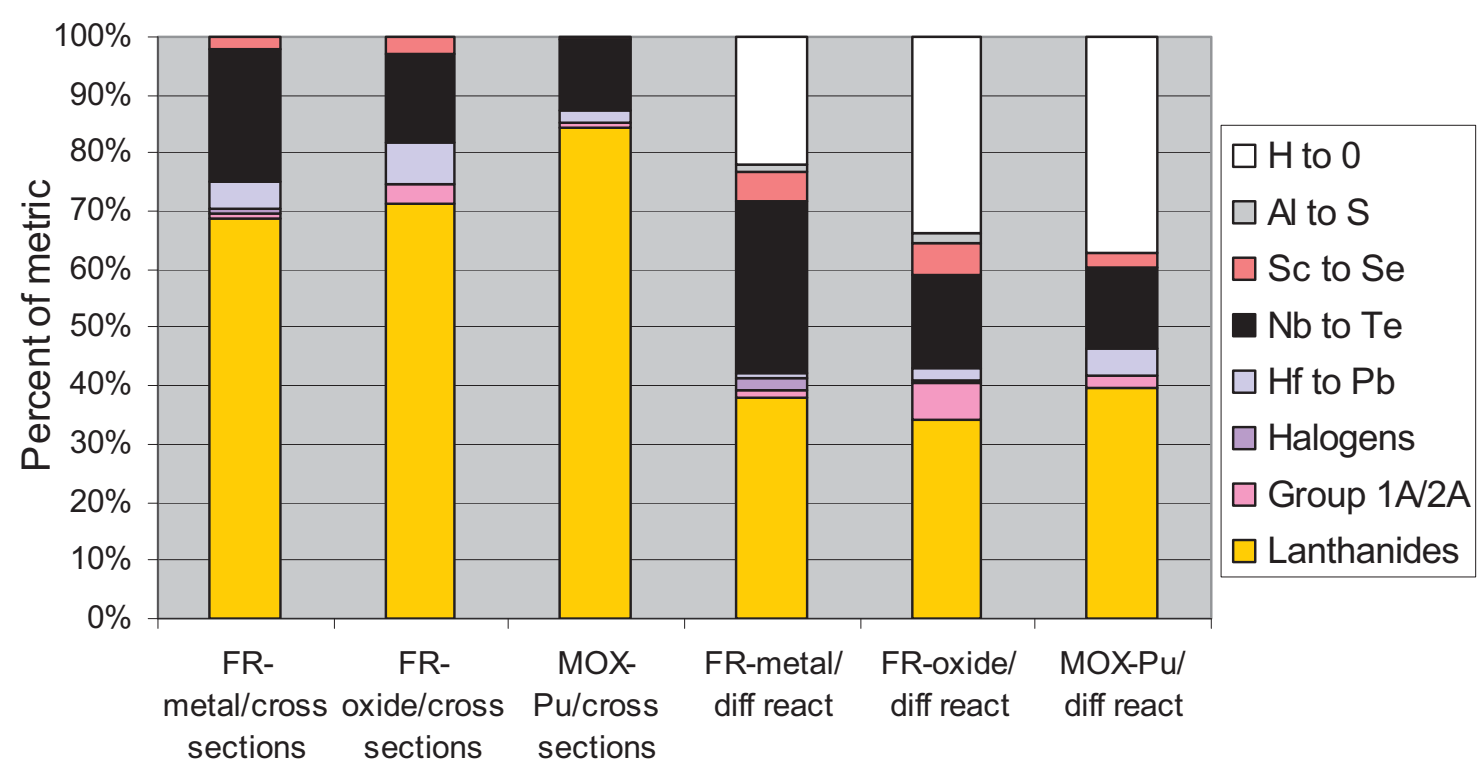

Figure 2-8. Percent of metric (neutron capture cross sections or differential reactivity) for FR-metal, FRoxide, and MOX-Pu.

\subsubsection{Waste Disposition}

Many evaluations in recent years have resulted in estimates of possible waste streams resulting from spent fuel separations (Gombert 2007, Jones 2007a, Jones 2007b, GNEP 2007, Gombert 2008). The amounts and types of possible waste streams vary based on different assumptions made by the authors regarding the spent fuel properties, separations processes, separation efficiencies, waste forms, and assumed waste stream dispositions.

As shown in Sections 2.2.1 and 2.2.2, any SNF components that are not recovered for recycle must be safely dispositioned in waste streams. Prior studies have developed potential waste disposition pathways for all components of the spent fuel that are not recycled, although most studies have assumed that, at a minimum, some of the $\mathrm{U}$ and all of the recovered $\mathrm{Pu}$ are recycled into new fuel. In this case, disposition pathways have been developed for the (a) remaining $\mathrm{U}$ (that is not recycled with the $\mathrm{Pu}$ ), (b) the cladding and other nonfuel-bearing components (NFBC), (c) minor actinides, (d) lanthanides, (e) group IA and IIA elements (the CsSr waste stream), (f) transition metal fission products (TMFP), and radioactive gaseous fission products (I-129, C-14, $\mathrm{Kr}-85$, and $\mathrm{H}_{3}$ ).

Separations processes now under consideration in the U.S. provide both (a) the opportunity to dispose of SNF reprocessing wastes in the most safe and environmentally protective manner according to their waste form, radiotoxicity, heat generation, and chemical characteristics, and (b) the challenge of complying with existing U.S. radioactive waste policies and regulations that were not developed considering such varied waste forms. Waste disposition is complicated by the current status of radioactive waste disposal sites in the U.S. While several commercial disposal sites now exist for Class A, B, and C low-level waste (LLW), Class B and C disposal sites only accept waste from certain compacts. No commercial Greater-Than-Class C (GTCC) LLW or HLW disposal sites are currently available in the U.S.

This situation affects the ability of the losses study to evaluate the impact of contamination of various candidate waste forms with $U$ and TRU elements (that would otherwise be recycled except for imperfect recovery efficiencies) and from cross-contamination of some waste forms with waste elements from other waste forms. The evaluation in the losses study to determine if some waste streams comply with Class A, $\mathrm{B}$, or $\mathrm{C}$ disposal requirements according to federal regulations (10 CFR 61.55) is straightforward; but 
evaluations must assume the requirements of the waste form compliance to GTCC and HLW disposal sites.

Current waste form research and development activities focus on a range of potentially highly durable waste forms tailored for the potential separated waste streams. This is intended to achieve the most durable waste forms that are practical because of the current uncertainty of GTCC LLW and HLW waste form requirements and much of the separated waste from SNF reprocessing could be either GTCC LLW or HLW. ${ }^{\mathrm{c}}$ Borosilicate and other types of glass waste forms and denitrated calcine waste forms have been developed, studied, and produced worldwide at full-scale for solidifying radioactive waste for decades. Therefore, current efforts focus on alternative waste forms including waste forms for captured gaseous fission products (mainly zeolites), glass-ceramic, ceramic-metal (cermet), monozite, Vycor, and metal alloys for different combinations of waste streams from SNF separations.

c. Durability is of course required for long-term storage and disposal. Durable forms, however, tend to be hard to undo later if requirements change. So processing waste into durable waste forms prior to identifying the ultimate disposal site with its waste form requirements creates the risk that the waste form made earlier might not qualify. 


\section{OVERALL SYSTEM PERSPECTIVES}

\subsection{Complexity/Limitations of Fuel Cycle Analysis}

Comprehensive fuel cycle analysis is a complicated problem. The four major technological functions in this cycle-reactor selection and fuel (e.g., metal, oxide) used in reactors, used fuel separations and waste conditioning, fuel (re)fabrication, and waste disposal - did not evolve in an integrated fashion. Putting all of these processes on a common design and cost estimating basis is necessary as a first step in understanding the overall interdependencies and sensitivities. However, this alone is not sufficient because a unified reprocessing scheme will still have to deal with the wide range of materials that might be fed into it. A large part of this potential feed stock is the inventory of used LWR fuel, now stored at commercial power plants, which came from a variety of reactor types and has zero to 50 years of aging since being removed from the reactor. Aging between a few years up to several decades allows some or most of several key shorter-lived fission product isotopes to decay. Two of the highest heat isotopes, Cs-137 and Sr-90 are important since the longer the used fuel ages, the better with respect to these isotopes and some others. But aging also allows Pu-241 to decay to Am-241, which lowers the fuel value of the recycled $\mathrm{Pu}$, and increases the importance of removing not only $\mathrm{U}$ and $\mathrm{Pu}$ isotopes but also minor actinides from the remaining waste. Variable age fuel requires more processing flexibility to be handled economically. The problem of different remote handled SNM feed stock is aggravated by the wide variety of materials controlled by DOE such as irradiated fuel, targets, test material, sealed sources, etc., which have radioactive isotope issues similar to used commercial LWR fuels but typically require different chemical treatments. These materials may have to be treated by separate processes or in an especially versatile process that handles both commercial and DOE materials. Further complicating the fuel cycle analysis problem, as it stands today, will be future innovations in reactor and fuel design and also various geologic waste repository and disposal options that remain in transition.

These transitioning issues further underscore the need to develop a more comprehensive model to help resolve the pro and cons the various options related to these decisions and thereby provide a timely and integrated fuel cycle management strategy,. At this stage, setting up even a simple example problem is as valuable for illuminating new issues and potential options as it is for solving them. Continued iteration of the possibilities for an integrated and optimized fuel reprocessing cycle will be necessary to identify the key problems and their potential solutions. Expansion of this model to address all forms of remote handled SNM will have to follow to assume optimum management programs are identified.

\subsection{Limitations resulting from a Simplistic View of Losses}

We have learned some specific limitations in regards to the relationships between losses and the cost of SNM recovery, burn-up/transmutation, fuel fabrication costs, etc. Figure 3-1 provides a simplistic view of system losses by providing a limited set of trade-off relationships between fuel performance, fabrication losses, and fuel cost. However, we have learned that this knowledge is not transferable, that is, "one size does not fit all." The relationships derived for one system do not necessarily apply to other systems. This concept was initially developed from a fuel fabrication perspective for system recycling losses. Now that we have studied the losses issue in more detail, we have come to understand the limitations of this simplistic concept.

A more complete system understanding of the tradeoffs between separations, fuel fabrication, waste forms, waste disposition, and reactor performance is required. Future analysis will need to interface at some level with the more detailed models (e.g., VISION, VISION.ECON, reactor performance, waste form/disposition models) and analysis. A capability is needed to evaluate a wide range of system configurations, including 1 and 2-tier systems, different spent fuels, spent fuel recycle options, and waste disposition options. The capability needs to result in useful insights on system performance that can be used to support decisions regarding different fuel cycle options, provide information about how waste can be safely and cost effectively managed, and provide information for guiding the focus of future fuel cycle 
$\mathrm{R} \& \mathrm{D}$ as well as the overall aspects of optimizing nuclear material management be it remote or contact handled nuclear material (SNM or radioactive waste).

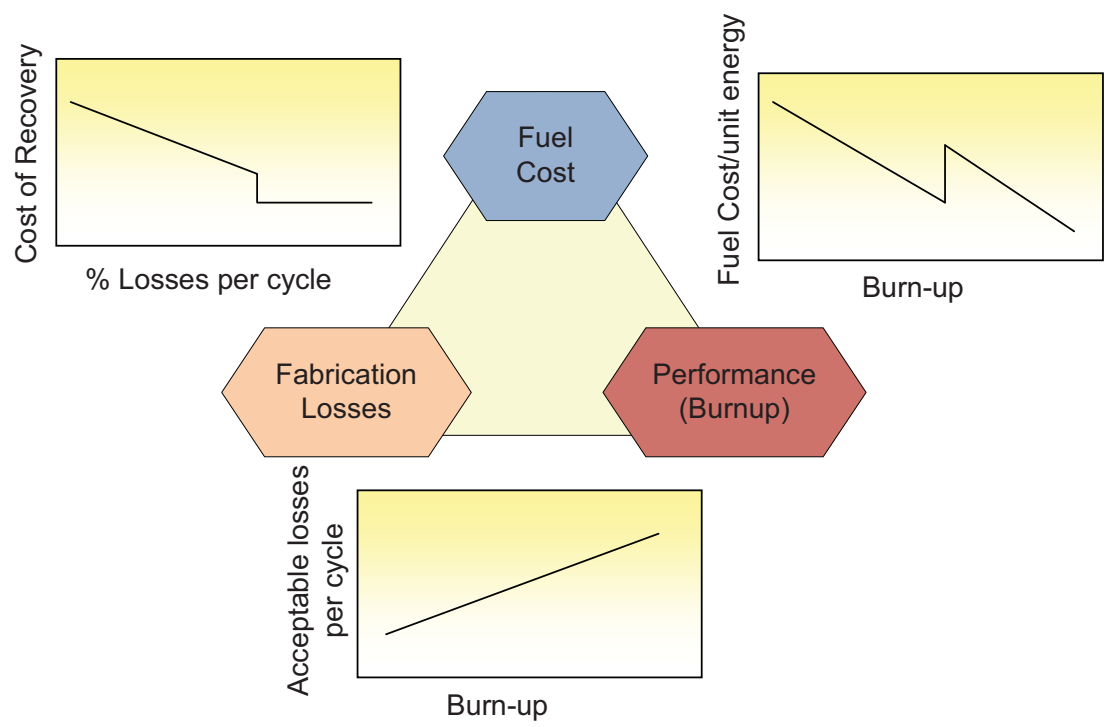

Figure 3-1. Simplified system loss relationships.

\subsection{Big Picture Issues Driving Losses and Interdependencies within the Actinide Fuel Cycle}

This section describes eleven factors from a "Big-Picture" stand-point that can influence losses and their interdependencies within the actinide fuel cycle and the general management of used nuclear fuel. They are listed as follows:

- Reactor Choice (e.g., fast, thermal, breeder)

- Fuel Choices

- Contents (e.g., Pu, HEU, U-233/Th)

- Fuel Physical Form (e.g., oxide, metal)

- Fuel Matrix/Cladding Material

- Chemical and Isotopic Composition

- Commercial Fuel Burn-up

- Used Fuel Age and Transitioning Inventory

- Remote versus Hands-on Fabrication Processes

- Separation Technology (e.g., aqueous, EChem, other)

- Flowsheet Selection

- Complexity - Number of by-products and purity

- $\quad$ By-product forms (e.g., liquid, oxide, metal)

- $\quad$ Final Waste Form

- Physical Packaging Requirements for Storage and/or Transportation. 
These factors are discussed independently in the following subsections; however, they have a combined effect based on the fuel cycle scenario.

\subsubsection{Reactor Choice (Fast versus Thermal)}

All fuel cycles ultimately start with the only fissile isotope in nature, U-235, which is $0.7 \%$ of natural uranium. Fuel cycles are then characterized in two ways: reactor neutron spectrum and fertile isotope.

The choice of reactors, using a fast or thermal spectrum, is an important consideration. Although it is possible from the physics standpoint to repeatedly recycle $\mathrm{Pu}, \mathrm{NpPu}, \mathrm{NpPuAm}$, or even all TRU elements in either thermal or fast reactors (Bays 2009), there are important fundamental differences. Nuclear fuel ultimately requires that the production of neutrons by fission is balanced by neutron absorption, which includes neutrons causing fission, neutrons being captured, and neutrons leaking from the reactor. So, to understand the differences between reactors we look at the probability of a neutron causing fission, probability of neutron being captured, and the overall neutron balance. This analysis shows that fast reactors are more neutron efficient (i.e., neutrons are more likely to produce a fission versus being wasted) and are more robust to fuel impurities (i.e., performance not degraded as much as thermal reactors). As noted in Section 2.2.5, for the initial exploratory cases, the current working TRU feedstream impurity limits for oxide fuels would pose approximately 4 times more fuel value penalty if making and using MOX-Pu than if that TRU feedstream were used to make fast reactor oxide fuel at $\mathrm{CR}=0.50$. In other words, if one wanted to keep fuel value penalty constant, impurities would have to be more strictly limited for MOX than for fast reactor use. We caution that the quantitative comparison is only an illustration and it would change on the basis of any one of a host of input parameters and assumptions. Additional details on the differences between reactors across a range of isotopes are provided in Appendix A.

Because there is only one fissile isotope in nature and it is a small fraction of its element $(0.7 \%)$, all fuel cycles involve one or both of the two fertile isotopes that occur in nature, U-238 (99.3\% of natural uranium) or Th-232 (100\% of natural thorium). These fertile isotopes then transmute to fissile isotopes, Pu-239 from U-238 or U-233 from Th-238. This transmutation of fertile to fissile is true whether material is recycled or not (e.g., the current conventional once-through uranium fuel cycle starts with fuel that is $\sim 4.3 \%$ enriched in U-235 [hence $95.7 \% \mathrm{U}-238$ ]), but by the time the fuel is removed from the reactor a significant fraction of fissions is coming from $\mathrm{Pu}-239$ that was created from the initial U-238. U-Pu fuel cycles (built on U-238 to $\mathrm{Pu}-239$ ) have received the most attention in large part because the alternative Th-U fuel cycle (built on Th-232 to U-233) requires chemical engineering for two natural resource elements (Th for Th-232 and U for U-235) instead of one (U for both U-238 and U-235). Nonetheless, Th- $\mathrm{U}$ remains an option and all the issues posed in this study for the U-Pu fuel cycles have analogs in the Th-U option space. We have not done any quantitative estimates for fuel impurity ramifications in the Th-U option space, but there is little reason to believe that they would be radically different than for U-Pu option space.

\subsubsection{Fuel Composition (Generates TRU versus Minimizes TRU)}

The reactor fuel isotopic composition may be metal or oxide or other ceramic forms. The relative capability of the fuel to burn TRU is tied directly to the fuel composition and the length of time it can remain in the reactor. Maximum TRU transmutation will occur with a fuel that is high in TRU content and low in U-238 content or high TRU with no U-238 (e.g., TRU/Th fuel). As the U-238 content increases, the TRU is displaced and the U-238 breeds more Pu and other actinides than are transmuted. This issue would be minimized with a TRU/Th fuel because there would be no U-238 present. A usable fuel form must provide an appropriate balance between burnup, TRU production, TRU transmutation, and power production. An optimized fuel would deliver high burnup, have minimal TRU production, high TRU transmutation, long-lived performance, and high power production. Future commercial reactor designs should utilize a fuel meat that minimizes the generation of TRU if it continues to be viewed as a problematic fuel cycle issue. 


\subsubsection{Commercial Fuel Burn-up (High TRU versus Low TRU)}

Fuel burnup is determined both by the quantity of fissionable material in the fuel and the capability of the fuel and cladding materials to withstand irradiation without failure. High TRU fuels operate primarily through fission with $\mathrm{Pu}-239$ and will tend to have a shorter lifetime due to the percentage of neutrons involved in transmutation reactions. Low TRU fuels (i.e., diluted with U-238) will breed Pu-239 from the U-238 matrix of the fuel so the total quantity of fissionable material is reduced at a slower rate allowing higher overall burnup. With any scenario, the fuel cladding must retain its integrity until the fissionable material is essentially expended.

\subsubsection{Fuel Age (Hot and Actively Transitioning versus Colder and More Stable)}

Actinides are highly radioactive and change isotopically as a function of decay time. Both recycled uranium and recycled TRU will change isotopically depending on the number of recycles and the feed compositions used in fuel fabrication. If fuel is processed with minimal cooling (e.g., $<2$ years) then the recovered TRU needs to be fabricated into new fuel and placed in a reactor before the isotopic content of the fuel changes enough to impact fuel fabrication and reactor performance. Used fuel can be aged for several hundred years to stabilize this isotopic transition, which provides a more consistent feed for fuel fabrication and removes the schedule constraints related to fuel fabrication and reactor loading. Operating in the "middle" of this aging envelope is possible, but is much more complicated by the transitioning TRU inventory. Because of this, processing of fuel soon after discharge requires a fuel cycle where the separations, fuel fabrication, and reactor use are closely coupled. Old spent fuel, in which the isotopes are more stable, allows using a fuel cycle where the coupling is more relaxed. Choosing the fuel content (meat) that minimizes the production of TRU (i.e., Th fuel cycle is another way to help resolve these issues for future power producing reactors).

\subsubsection{Fuel Form (Oxide versus Metal)}

Both metal and oxide fuel forms are usable for TRU fuels in fast and/or thermal reactor systems. However, there are significant differences between the fuel types from the viewpoint of the complexity of remote fabrication. Metal fuel is relatively simple to fabricate and has been demonstrated in a remote environment. System losses in metal fuel are mostly related to metal holdup in the furnace and mold materials during fabrication. Oxide fuel fabrication is well developed and typically highly automated, but TRU remote oxide fuel fabrication has not been demonstrated. The complexities involved with fabricating oxide fuel in a remote environment are significant. Rather than a maximum of two actinides for MOX fuel, five actinides ( $\mathrm{U}, \mathrm{Pu}, \mathrm{Np}, \mathrm{Am}, \mathrm{Cm}$ ) are involved in TRU fuel so feed material preparation technology will require development. Binders and lubricants normally used in new oxide fuel fabrication suffer radiolytic degradation if they are used in the fabrication of used fuel that contains TRU elements and possibly other contaminants. These binders and lubricants will also need to be replaced with more radiation-proof equivalents of those used in current processes. Oxide fuel lines typically require some recycle of sintered fuel to make the process work correctly. ${ }^{\mathrm{d}}$ Losses are primarily from aerosolized dust that accumulates in the filters of the ventilation systems.

\subsubsection{Fuel Cladding (Hulls versus No Hulls)}

Nuclear fuel designs have taken several different approaches relative to providing an isolation barrier for the fuel isotopic composition (i.e., cladding). Some designs are heterogeneous with the fuel encased with

d. The Sintering process requires a balance between powder reactivity (O:M ratio) and shrinkage for a given set of process parameters (time, temperature, gas composition). If straight green powder is used without pre-sintered recycle powder, excess reactivity will cause excessive shrinkage. If too much pre-sintered recycle powder is used, the powder is not sufficiently reactive and the pellets may fall apart. In theory, the powder O:M ratio could be adjusted correctly for a sintering process designed for $100 \%$ green powder. However, industry has designed their fabrication processes to use slightly higher O:M ratios in the feed to compensate for the scrap recycle they expect in the process. This approach minimizes overall loss to scrap while maximizing product output. 
a separate cladding metal with a helium or sodium-filled gap between the fuel and cladding. Other designs are more homogeneous in that the fuel is dispersed in a matrix that is metallurgically bonded to the cladding and cannot be readily separated. Metal fuel encased in metal cladding is usually designed to be dissolved with the fuel meat rather than require some type of specialized mechanical and/or chemical de-cladding step. There are pros and cons to each type of cladding strategy. In the heterogeneous cladding case (i.e., commercial fuel) the fuel is encased a metal rod (stainless steel or Zircaloy), which serves as the barrier to prevent the escape of fission products. The headend equipment for reprocessing this type of fuel typically includes treatment systems (voloxidation, chop/shear, etc.) that are designed to enhance the dissolution of the fuel by increasing the surface area that is exposed to the acid. During dissolution the cladding material is not expected to be dissolved and despite the pretreatment steps, complete removal of the fuel is never attained. The hulls are washed several times to remove as much SNM as possible before they are sent to waste disposal.

This headend treatment system for reprocessing fuel with heterogenous cladding is not a trivial materials control and accountability (MC\&A) or capital cost issue. A significant amount of hot cell processing area is required to house the SNF pre-treatment and hull dispositioning equipment. Furthermore, these processes require remote operation and maintenance. MC\&A measurements and losses are hard to assess and control. Fuel that is designed for complete dissolution of the cladding and the fuel tend to generate more first-cycle raffinate. However, the headend system and MC\&A issues are significantly simplified. Thus, it follows that the principal issue is to select a fuel design that is optimized for the entire fuel cycle (i.e., "user friendly" to recycling/processing) and not focused on optimizing just the reactor performance.

\subsubsection{Remote versus Hands-on Fabrication Processes (including Head-End Preparation)}

The fabrication of recycled TRU fuels that contain minor actinides requires remote hot cell fabrication and remote line maintenance. For metal fuel, remote fabrication has been demonstrated and has no major technical barriers. Since oxide fuel remote fabrication has not been demonstrated and represents a significant leap forward in remote fabrication technology, there is a driver for providing additional separation of actinides to allow hands-on fabrication and maintenance of a U-Pu (MOX) fuel plus remote fabrication of minor actinide targets. The economics and technical basis for such an approach is unclear since the fuel plus the target system would require two manufacturing lines, including a remote fabrication line. Some studies also assume that hands-on fabrication may be used with a U-Pu-Np oxide fuel form, but current U.S. regulatory requirements on allowable radiation dose to workers makes contact handling of this fuel form unlikely.

\subsubsection{Separation Technique (Aqueous versus EChem)}

Spent fuel can be processed using either aqueous processes, such as solvent extraction and product solidification technology; or electrochemical processes, such as molten salt electrorefining and metal/salt separation technology. Aqueous processes have been demonstrated at commercial-scale for separating uranium and plutonium products, and electrochemical processes have been demonstrated at engineeringscale for separating uranium and uranium-TRU products, but both methods are challenged by the fuel performance requirement related to transmutation fuel (i.e., to provide a uranium-TRU product that is very low in lanthanide impurities while minimizing TRU losses to waste streams).

No separations processes are perfect. Thermodynamic, kinetic, or mass transfer limitations prevent $100 \%$ efficient separations of one element or group of elements from others. All separated product streams will contain various levels of undesired contaminants. Radioactive contaminants in recycled product streams will make recycled fuel fabrication more challenging, and can impair the performance of the fuel in recycle reactors. Contamination of TRU elements and of radioactive waste elements in different waste streams can affect how those waste streams are processed into their final waste forms (or recycled for beneficial use), their waste loadings, waste classification, radiolytic heat generation, radiolysis characteristics, radiotoxicity, storage, shipping, and their final disposition. 


\subsubsection{Separated Product Form (Oxide versus Metal)}

Separated product in the form of liquid, oxide or metal can be used to manufacture either fuel type. A liquid product may be preferred if isotopic blending is required at the molecular level. This would be followed by the conversion of the blended liquid to an oxide product. An additional conversion step would be required if an oxide product is used for fabrication of metal fuel an additional oxide reduction step is required at the start of the process. Either metal or oxide separations product used for an oxide fuel will require dissolution and co-precipitation as an oxide at the start of the fuel process. If separations are not collocated with the fuel fabrication capability, use of a metal separations product form may be beneficial as it provides a storable and shippable material form that can be dissolved with lower losses (i.e., less loss of undissolved solids than a high-fired oxide). High firing of oxide feed stock may not be necessary if no Department of Transportation (DOT) shipping is required and it can be demonstrated that the recovered oxide will be fabricated into fuel in a timely manner. If this is not the case, then the oxide would likely need to be high-fired for storage or public transportation (because of current regulations and the uncertain timeline for storage and fuel fabrication operations). High-fired oxide is more difficult to dissolve.

\subsubsection{Final Waste Form}

Many different waste forms (e.g., glass, zeolite, ceramic, oxide, and/or metal waste forms) have been conceived for waste streams separated from spent nuclear fuel, depending on the separations process and waste management strategy. Spent fuel separations processes use chemical properties (and electrochemical properties in the case of electrochemical separations) unique to different elements in the spent fuel to separate some of these elements from others. Waste forms generated from aqueous and electrochemical separations typically include (a) a compacted or melted metal waste form consisting of stainless steel and zircaloy cladding and other nonfuel-bearing components (which could in fact be a recycle stream, or it could also be melted together with other waste elements such as Tc and TMFP), (b) waste forms containing fission product elements including shorter-lived $\mathrm{H}_{3}$ and $\mathrm{Kr}-85$, and longerlived I-129 and C-14, prone to evolve in gaseous species during reprocessing, and (c) one or more glass, ceramic, other oxide waste forms that contain the remainder of the waste isotopes (including the Tc and TMFP if they are not included in a metal waste form).

The acceptability of different waste form options will depend on the acceptability of the combined waste form plus storage/disposal site capability to isolate the waste from the environment for the period needed to limit dose to the public to within acceptable limits, considering the longevity, radiotoxicity, heat generation, and chemical durability of the waste form, and the characteristics of the storage/disposal sites. The longevity, radiotoxicity, heat generation, and chemical durability of the waste forms depend on the separation processes and efficiencies (losses) that result in the major and minor constituents in the waste forms.

\subsubsection{Physical Conversion}

As stated previously, a large amount of the separation losses can result from chemical conversions. Physical conversion processes occur when the spent fuel elements are chopped and treated by voloxidation when spent oxide or metal fuel is dissolved into aqueous or molten salt solutions needed to separate waste from recycled materials, when the dissolved isotopes are converted to solid oxide or metal forms needed for temporary storage or transportation, and when recycled solid oxide or metal forms are processed into fuel.

- Spent fuel element chopping. Chopping spent fuel elements can release some fuel meat fragments and dust that are difficult to quantitatively capture. Any fragments and dust that are not quantitatively collected and processed with the chopped fuel in the downstream steps represent losses. 
- Voloxidation. Like chopping, voloxidation can also cause fragmentation and dust generation from the fuel meat. Any fragments and dust that are not quantitatively collected and processed with the chopped fuel in the downstream steps represent losses.

- Oxide (spent fuel) to Aqueous phase. Dissolution of used oxide fuels is necessary to separate the fuel meat from cladding, and separate recycled isotopes from the remaining waste. The fuel meat is dissolved into an acidic aqueous phase during aqueous separations (after fuel rod chopping and voloxidation).

- Metal (spent fuel) to dissolved Metal-Salt phase. Dissolution of used metal fuel is necessary to separate the fuel meat from cladding, and separate recycled isotopes from the remaining waste. The fuel meat is electrochemically dissolved into a molten salt phase during electrochemical separations (after fuel rod chopping and voloxidation).

- Aqueous to Oxide. The physical conversion of an aqueous nitrate to a solid oxide product can be accomplished via denitration for uranium bearing solutions and precipitation and calcining for $\mathrm{Pu}$. The most common and best accepted $\mathrm{Pu}$ precipitating agent is oxalic acid although hydrogen peroxide, ammonium hydroxide, and ammonium nitrate have also been used.

- $\quad$ Oxide to Metal (O:M). Once calcined, a reduction step in an argon-hydrogen atmosphere is required to adjust the oxygen to metal ratio in the feed material for fuel pellet fabrication.

- Metal to Oxide. Although Pu metal to oxide conversion can theoretically be done through direct oxidation, most processes dissolve the metal in nitric acid and then precipitate it as discussed above. Direct $\mathrm{Pu}$ oxidation is typically not used as oxide surfaces may passivate leaving reactive metal in the product.

- Metal-Salt to Metal. Metal salts are typically converted using electrodeposition of the metal from the salt. Residual salt entrapped in the product can be dissolved, distilled away from the metal, or the metal product melted to allow gravity separation of the salt from the metal.

\subsection{Impact on Selected Drivers}

The factors described in Section 3.3 are relevant can be influenced by the degree to which they are used, the complexity of the technologies, timing, and reactor operation parameters. Some examples (partial list) of these influencing factors are provided in Table 3-1 along with the conditions in which they could result in greater or reduced system losses. 
Table 3-1. Impact of selected drivers on losses.

\begin{tabular}{|c|c|c|}
\hline Choices/Drivers: & Greater Loss Impact & Less Loss Impact \\
\hline FR Fuel Choice & $\begin{array}{l}\text { Oxide Fuel } \\
\text {-More unit processes with tight } \\
\text { dimensional and composition specs } \\
\text {-Large \# of pellets } \\
\text {-No remote experience }\end{array}$ & $\begin{array}{l}\text { Metal Fuel } \\
\text {-Fewer unit processes } \\
\text {-Minimal slugs to manage } \\
\text {-Demonstrated remote feasibility }\end{array}$ \\
\hline $\begin{array}{l}\text { Amount of } \\
\text { Separation and } \\
\text { Aqueous } \\
\text { Separation } \\
\text { Complexity }\end{array}$ & $\begin{array}{l}\text { Greater \# of separation } \\
\text { processes/Complex (e.g., UREX) } \\
\text {-Aqueous phase change losses in } \\
\text { product solidification steps } \\
\text {-Larger process equipment } \\
\text {-Multiple steps with >potential losses }\end{array}$ & $\begin{array}{l}\text { Fewer \# of separation processes } \\
\text { Simple (e.g., Coex) } \\
\text {-Less steps with <potential losses }\end{array}$ \\
\hline $\begin{array}{l}\text { EChem } \\
\text { Separations }\end{array}$ & $\begin{array}{l}\text { Simpler } \\
\text {-Less steps, but with potential losses }\end{array}$ & $\begin{array}{l}\text { More Complex } \\
\text {-Additional steps to recover lost TRU and/or } \\
\text { multiple by-products }\end{array}$ \\
\hline Fuel Aging & $\begin{array}{l}\text { Quick processing }<2 \text { yrs } \\
\text {-Higher TRU but less Pu decay to Am }\end{array}$ & $\begin{array}{l}\text { Delayed processing }>150 \text { yrs } \\
\text {-Reduces TRU limit on waste } \\
\text {-Eliminates short term decay heat (Cs/Sr) } \\
\text {-Better isotopic stability for fuel fab and } \\
\text { separations, requires less shielding }\end{array}$ \\
\hline $\begin{array}{l}\text { TRU Conversion } \\
\text { Ratio }\end{array}$ & $\begin{array}{l}\text { Lower CRs (lower U/TRU) } \\
\text { - Tighter TRU impurity limits }\end{array}$ & $\begin{array}{l}\text { Higher CRs (higher U/TRU) } \\
\text {-Higher allowed impurities }\end{array}$ \\
\hline
\end{tabular}

\subsection{System Level Drivers}

The initial FY-09 study focuses on system-level drivers that influence performance on a closed fast reactor fuel cycle. Figure 3-2 shows a single steady-state closed fast reactor fuel cycle system. The four boxes indicate the primary functions and flows along with feedback processes, such as fuel specifications, fuel feed specs, and waste acceptance criteria, which serve to modify the composition of the flows. The key system drivers are indicated in each of the function boxes.

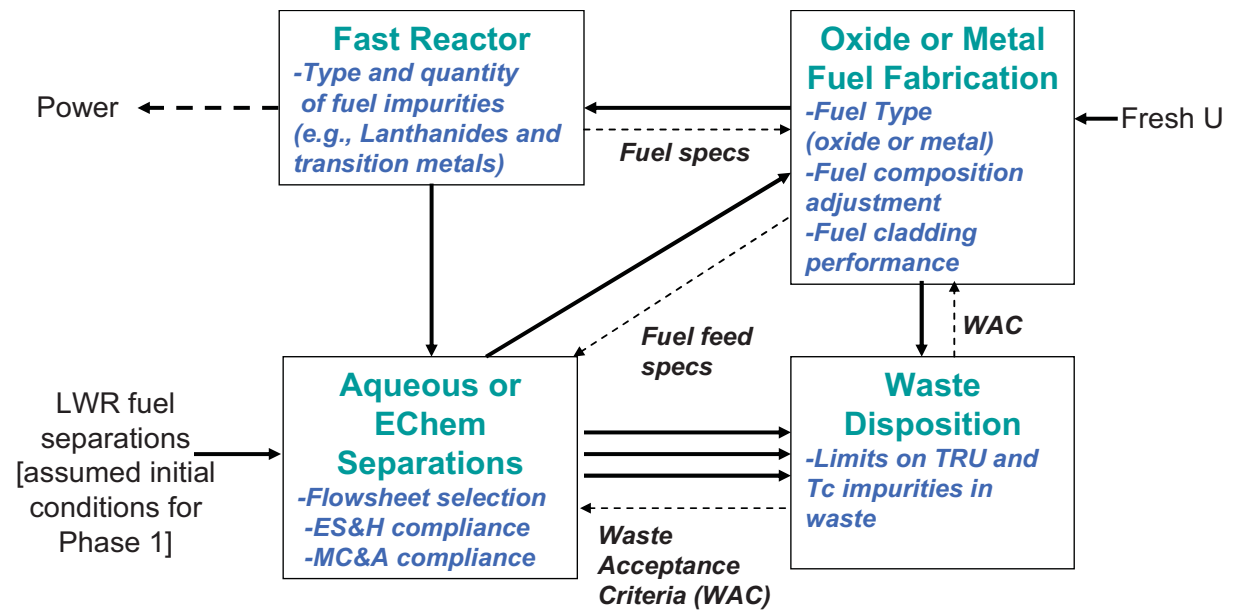

Figure 3-2. Single steady-state closed fast reactor fuel cycle (1 Tier). 


\subsection{Waste Disposition Pathways}

There are multiple possible dispositions for components of used fuel. The impurities may end up in the fuel product or they may end up in waste streams that have multiple potential disposition pathways. A waste stream could have multiple disposition options as shown in Figure 3-3. The approach shown in this figure is based on determining waste stream disposal pathways based on the waste stream radiotoxicity and heat generation characteristics; it is intended to be fully compliant to radioactive waste disposal regulations and policies. While this figure focuses on the final disposition (e.g., deep geological burial, recycle in used fuel, or near surface burial), the process(es) used to stabilize and package the waste streams for those final dispositions are also implicit, and depend on the characteristics and final disposition of the waste stream.

\begin{tabular}{|c|c|c|} 
& $\begin{array}{c}\text { Heat is constraint on } \\
\text { handling, storage, } \\
\text { emplacement }\end{array}$ & $\begin{array}{c}\text { Short-term heat not } \\
\text { a constraint }\end{array}$ \\
$\begin{array}{c}\text { Peak dose } \\
\text { up to } \\
1,000,000 \\
\text { years }\end{array}$ & $\begin{array}{c}\text { Deep geological } \\
\text { burial }\end{array}$ & How dispose? \\
\hline $\begin{array}{c}\text { Peak dose } \\
\text { up to } 500 \text { yrs }\end{array}$ & Group 1A/2A & $\begin{array}{c}\text { Tcel Halogens? } \\
\text { Transition metals? }\end{array}$ \\
\hline
\end{tabular}

Figure 3-3. Waste disposition pathways.

For example, a waste stream could require deep geologic disposal if it has high heat and radiotoxicity. A waste stream could be disposed in near-surface burial (compliant to LLW Class C) if short-term heat is not a constraint and the peak dose is limited to 500 years. Other possibilities for alternative disposal could result with wastes that either have a peak does less than 500 years (e.g., group 1A/2A elements) or where short-term heat is not a constraint (e.g., Tc, halogens, transition metals). Some range of disposition options may exist for these high heat, but lower/shorter duration dose, or lower heat, but higher/longer duration toxicity waste streams if they can be classified as GTCC LLW, and deep geological burial is not a requirement. The acceptability of different disposition pathway options depends on the separation efficiencies (separation losses) that result in cross-contamination of higher-heat, longer-lived, or higher radiotoxicity isotopes in waste streams tailored for lower-heat, shorter-lived, and less-radiotoxic isotopes. 


\section{INITIAL SCOPING ANALYSIS}

\subsection{Initial Project Scoping and Limitations}

Due to the complexity and number of options, the study uses simplistic assumptions and placeholder technologies to help develop an initial model that can perform limited sensitivity analysis. The model will be enhanced based on the initial application to be able to address more complex issues in the future. Further, the study was initially divided into two phases. Phase 1, is a single steady-state closed fuel cycle using a fast reactor (1 Tier). In Phase 2, a thermal MOX recycle is added prior to the fast reactor recycle (2-Tier). Figure 4-1 shows the system boundary for the Phase 1 system evaluated in FY-09.

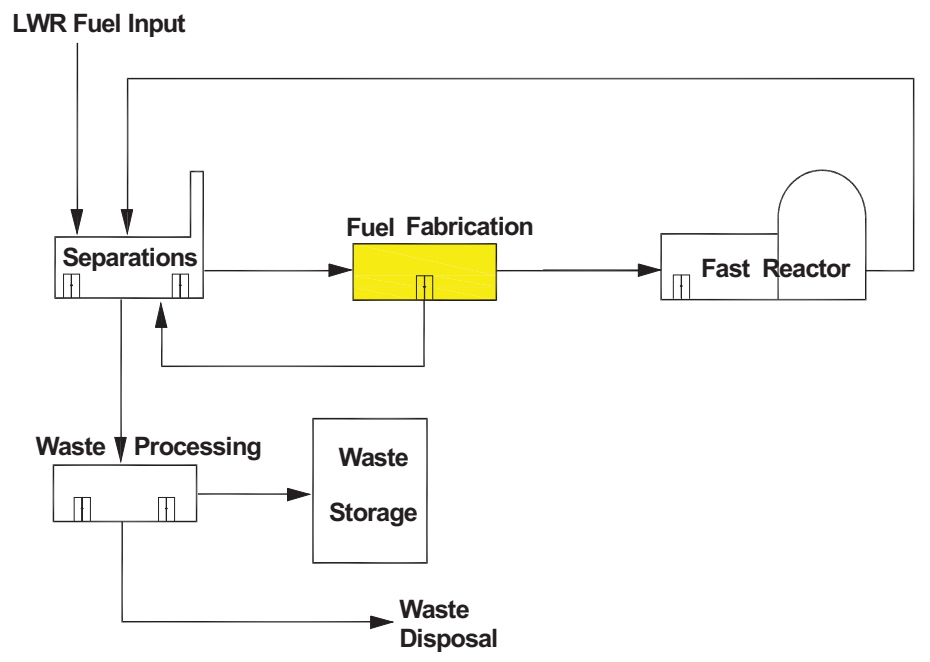

Figure 4-1. System boundary for Phase 1.

The Phase 1 study is focused on system-level drivers that influence performance on a closed fast reactor fuel cycle. We will evaluate the primary drivers for the fast reactor including the type and quantity of fuel impurities (e.g., lanthanides and transition metals), aqueous/EChem separations, and oxide/metal fuel fabrication.

In the future, this study could examine new fuel cycles like thorium, where the fast reactor would be replaced by a thermal reactor, fueled by a Th-based fuel that would burn transuranics and produce U-233 to produce energy, at the same time reducing the future production of the higher actinides.

\subsection{System Metrics and Trade-offs}

There are many potential ways in which fuel cycle can be configured or operated, and many potential metrics that might be used to measure the performance of any particular configuration. This problem is best approached by first clarifying the metrics - the indicators of what is trying to be achieved.

The primary metric initially used is the fuel cycle back-end cost as it relates to losses in fuel separation and fuel fabrication, with impacts to waste loading and waste disposition, and reactivity of fuels. However, cost is not the only performance criterion that will be considered in optimizing fuel reprocessing schemes. Others that might be or become important include minimizing the production of HLW or proliferation-sensitive materials (to facilitate public acceptance), the ease of operating the chosen separations steps (to reduce the amount of off-specification material that must be reworked), the ability of the complete process to handle a wide range of used fuel compositions currently in storage, or the ability to produce recycled fuel compositions that might be needed for future reactor designs. 
In the FY-09 study, system trade-offs were considered, where the costs for fuels and/or separations are balanced against waste costs and reactor performance. Offsetting measures are evaluated with respect to identifying efficient system trade-offs, as illustrated in Figure 4-2.

\begin{tabular}{|c|c|c|c|c|}
\hline Separations & Fuel Fab & Waste Processing & Waste Disposition & Reactor \\
\hline $\begin{array}{l}\text { 1) Losses of } \\
\text { product to waste }\end{array}$ & $\begin{array}{l}\text { Losses of product } \\
\text { to waste } \longrightarrow\end{array}$ & $\begin{array}{l}\text { Waste form } \\
\text { and waste }\end{array}$ & $\rightarrow \begin{array}{c}\text { Performance } \\
\text { (repository loading) }\end{array}$ & \multirow[b]{2}{*}{$\begin{array}{c}\text { Performance } \\
\text { (burn-up) }\end{array}$} \\
\hline $\begin{array}{l}\text { 2) Product } \\
\text { Impurities }\end{array}$ & $\rightarrow \begin{array}{c}(\text { mostly } \\
\text { passed thru) }\end{array}$ & & & \\
\hline $\begin{array}{l}\text { Reduce losses } \\
\text { and impurities }\end{array}$ & Reduce losses & $\begin{array}{l}\text { Maximize waste } \\
\text { loading }\end{array}$ & Reduce HLW & $\begin{array}{l}\text { Increase fuel } \\
\text { burn-up }\end{array}$ \\
\hline Increases costs & Increases costs & Increases costs & Reduces cost & Reduces cost \\
\hline
\end{tabular}

Figure 4-2. System losses economic trade-offs.

An example of an economic trade-off is the cost of the fabricated fuel delivered to a reactor balanced against the energy value of the product. The cost of this fuel, which contains reprocessed material and possibly some makeup uranium, includes separation of undesired materials, their disposal, and fabrication of new fuel pellets and elements. The value to the user is tied to the burnup possible with that fuel's combination of fissile materials, poisons, and materials performance. Tradeoffs occur between having a higher purity fuel that might perform better in a reactor but either spending more to achieve that greater separation of undesirable elements or losing more of the desirable elements to the waste stream by using a less expensive but less selective separation process. Excessive losses of fissionable material reduce the amount of refabricated fuel that can be sold while increasing the amount of waste material that must be disposed. The range of performance values applied to metal and oxide fuels are provided in Appendix B.

\subsection{Key System Assumptions and their Impact, Influence, and Limitations}

A set of initial boundary assumptions were made to enable use of a simple high-level spreadsheet model. The following assumptions from the Systems, Separations, Waste Forms, and Fuel Fabrication experts were made in order to baseline the Losses analysis on recent studies that contain well understood assumptions and results. From these analyses we could evaluate the impacts from varying the losses rates and understanding the impacts to reactor performance and repository waste loading.

The nominal case (initial condition for comparison) for the System Losses and Assessment Trade Study is based on the separation efficiencies and fuel parameters defined in Appendix C of the Dynamic Systems Analysis Report for Nuclear Fuel Recycle (DSARR 2009). The DSARR defined separation efficiencies at $99.9 \%$ with corresponding $0.1 \%$ TRU losses to waste. However, these losses for an integrated separation/fabrication facilities may be more stringent than necessary to meet overall system requirements. Independent separation and fabrication facilities would require high firing of the separation product, which equates to about $4 \%$ losses from the undissolved solids when attempting to re-dissolve the material to make fuel.

Critical evaluation of these parameters should provide insight to the economic versus performance tradeoffs of the recycling systems. The parameters set for losses must first be guided by safety (no uncontrolled criticalities, minimal exposure for plant personnel, etc.) and security-minimize proliferation risk. Then it is economics relative to value added results from the waste forms and the fuel fabrication and performance. Additionally, stake holder perspectives (e.g., concerns about Kr emissions) could guide decisions. Results will vary with each fuel type, flowsheet, process, facility integration strategy, etc. 
Assumptions were also provided by the Transmutation Fuels and Separations Campaigns based on recent studies (fuels - Advanced Fuel Cycle Facility [AFCF], Aqueous Separations - UREX 1A, EChem Separations - AFCF). The AFCF study provided a draft TRU separations feedstock specification with tables of allowable chemical impurity levels by element for the aqueous and comparable impurity levels for the electrochemical processes. These specifications are provided in Appendix A.

\subsubsection{System Assumptions}

The assumptions provided by the System Campaign were primarily based on the DSARR, and are summarized as follows:

1. Considered losses for metal fuel (EChem) and oxide fuel (aqueous)

2. Assumed a conversion ratio $(\mathrm{CR})$ of 0.50 for fast reactor

3. For simplicity, was initially limited to only the fast reactor (FR) closed fuel cycle (no thermal cycle).

\subsubsection{Separations Assumptions}

The assumptions provided by the Separations Campaign were primarily based on the UREX 1A flowsheet for aqueous and the AFCF for EChem, and are summarized as follows:

1. Considered losses related to EChem and Aqueous

2. Focused on losses from the head-end treatment through product solidification, packaging and storage

3. Assumed aqueous processing for commercial fuel-losses would likely be lower for processing metal fuel

4. Assumed electrochemical processing for fast reactor-losses would likely be similar for processing an oxide fuel

5. Assumed a metal fuel form for the fast reactor

6. Assumed normal operating condition for assessing losses

7. Assumed no losses to analytical systems (i.e., samples are returned and SNM recovered)

8. Nominal total separation losses of $0.1 \%$ TRU into waste (however, $1 \%$ is more consistent with current spreadsheet assumptions).

\subsubsection{Fuel Fabrication}

The assumptions provided by the Separations Campaign were primarily based on the AFCF for metal and oxide, and are summarized as follows:

1. Homogeneous recycle (all actinides) from LWR fuels

2. Remote fuel fabrication for TRU/U-238 fuel

3. Loss range of $0.1-3.5 \%$ for metal and oxide fuels for recycle in-process

4. Maximum impurity limits on TRU feedstock. A dilution factor of 2.5 times is needed to use these impurity requirements for a finished fuel (assumed 40\% TRU/HM ratio).

\subsection{Scenarios (Cases 1-3) for Metal and Oxide}

Three cases were defined as follows:

- Case 1. Low product purity and high loss to waste

- Case 2. Nominal product purity and nominal loss to waste

- Case 3. High product purity and low loss to waste. 
These cases bound the parameter space of separations and fuel fabrication fuel impurities and TRU losses to waste. Performance data for these cases are based on past/current research and operational experience. The Campaigns provided a range of performance values related to product purity, TRU losses to waste, and performance improvement (waste loading factor, fuel burn-up). Separations defined ranges for headend loss, separation loss, and process losses. Fuels defined losses in fabrication (including recycle sequences). Systems provided the range of performance on the repository loading (linear loading factor relative to spent fuel) and fuel performance in the reactor (burnup in units of mega-watt-days per metric tonne heavy metal [MWD/MTHM]). The range of performance factors were matched to their relative economic cost factors. The bounding range of product purity, TRU losses to waste for Separations (Headend, Separation, Process losses) and Fuel Fabrication, and waste and fuel performance for metal and oxide fuels is provided in Table 4-1. A complete breakdown of the system losses performance factors and associated costs are provided in Appendix B.

Table 4-1. Metal/oxide-bounding ranges of product purity, TRU losses, and performance.

\begin{tabular}{|c|c|c|c|c|c|c|}
\hline \multicolumn{7}{|c|}{ Metal } \\
\hline $\begin{array}{l}\text { Product Purity } \\
\text { (\% Ln) }\end{array}$ & \multicolumn{4}{|c|}{$\begin{array}{c}\text { TRU Losses to Waste } \\
\text { (\% TRU) }\end{array}$} & \multicolumn{2}{|c|}{$\begin{array}{c}\text { Performance Improvement } \\
\text { (waste loading factor, fuel burn-up) }\end{array}$} \\
\hline Separation & Head-end & Separation & Process & Fuel Fab & HLW Loading & Fuel Performance \\
\hline Low $=1.00 \%$ & $1.0 \%$ & $1.0 \%$ & $2.0 \%$ & $1.0-3.5 \%$ & 2.0 (unitless) & 125,267 MWD/MTHM \\
\hline Nominal $=0.50 \%$ & $0.6 \%$ & $0.6 \%$ & $0.6 \%$ & $0.5-1.0 \%$ & 2.5 (unitless) & 131,860 MWD/MTHM \\
\hline High $=0.25 \%$ & $0.3 \%$ & $0.3 \%$ & $0.3 \%$ & $0.1-0.5 \%$ & 4.0 (unitless) & 138,453 MWD/MTHM \\
\hline \multicolumn{7}{|c|}{ Oxide } \\
\hline Low $=0.600 \%$ & $3.00 \%$ & $6.3 \%$ & $2.0 \%$ & $1.0-3.5 \%$ & 2.0 (unitless) & 125,267 MWD/MTHM \\
\hline Nominal $=0.110 \%$ & $1.50 \%$ & $1.1 \%$ & $<1 \%$ & $0.5-1.0 \%$ & 2.5 (unitless) & 131,860 MWD/MTHM \\
\hline High $=0.002 \%$ & $0.15 \%$ & $0.1 \%$ & $0.3 \%$ & $0.1-0.5 \%$ & 4.0 (unitless) & 138,453 MWD/MTHM \\
\hline
\end{tabular}

\subsection{Simplified System Losses Model}

A simple, high-level (spreadsheet) model was developed to demonstrate feasibility on a system loss scenario. The model used in FY-09 was an Excel spreadsheet that was coupled to decision analysis/uncertainty software called DPL (Decision Programming Language), which has the capability to perform variable uncertainty analysis and run optimizations (e.g., minimize cost). The model was used to assess boundary conditions of cost and performance trade-offs on fast reactor fuel product purity and losses of TRU to wastes. The basic spreadsheet model contains the unique performance and cost data for oxide and metal fuels. The cost data for the back-end of the fuel cycle were derived from cost distributions generated for the AFC Cost Basis report (Shropshire 2008) and the AFCI Economic Analysis (Shropshire 2009). The total separation cost was further broken down into head-end, separations, and product processing as a function of facility space. Fast reactor performance data (i.e., burn-up, annual power generation, and heavy metal requirements) were based on the DSARR analysis. Further details on the inputs used in the model are provided in Appendix B. 


\section{SCOPING STUDY RESULTS}

Refer to Sections 4.4 and 4.5 for a description of the cases and simplified system losses model.

\subsection{System Level Trade-offs (Oxide)}

In the initial scoping study, the bounding system performance losses were evaluated based on the variation on the back-end cost of the fuel cycle. In Figure 5-1, the three cases were evaluated over the full range of performance values for oxide fuel as defined in Table 4-1. The resulting cost variation was normalized to 1.0. Simplifying assumptions were made on the modeling (e.g., data was based on best engineering judgment) to be able to demonstrate how the model would work. The actual results or relations shown by the models are not indicative of all systems. A description of the impacts on each of the variables on the $\mathrm{x}$-axis is provided in the following sections. As can be seen in the figure, very little cost variation resulted from head-end losses, separation losses, or product purity. Process losses have some variation ( $+3 \%$ to $-1 \%$ ), and fuel fabrication had by far the greatest cost variation of plus or minus $10 \%$. The performance impacts on repository and fuel were similar in the plus or minus $5-6 \%$ range.

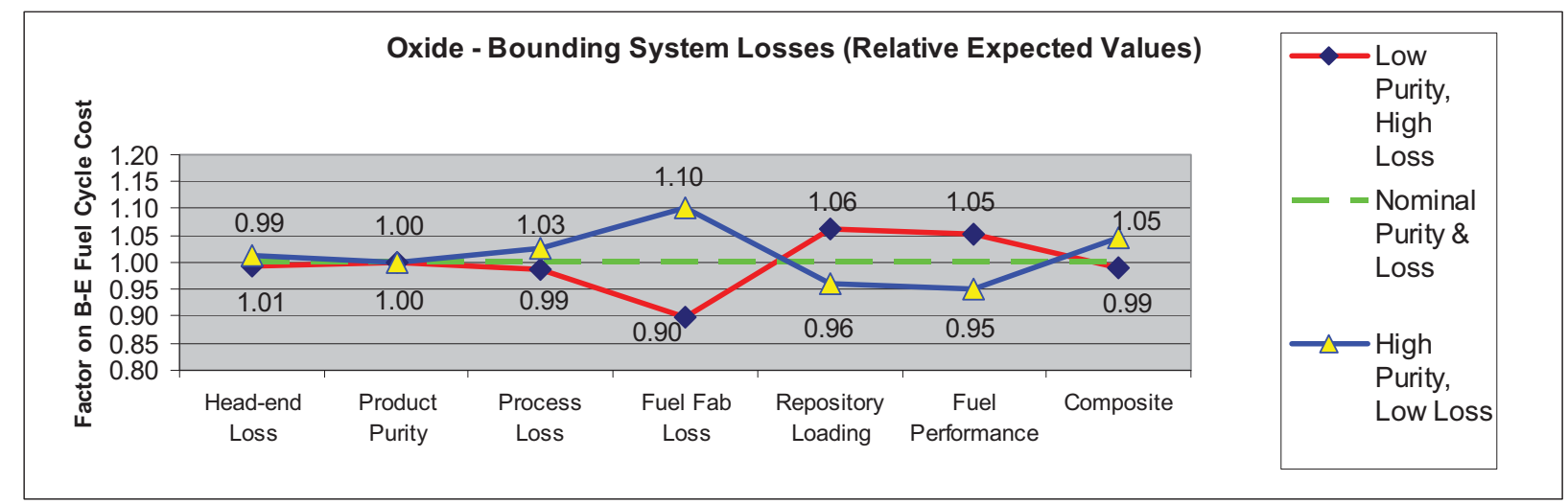

Figure 5-1. Oxide - system level tradeoffs from bounding system losses.

\subsubsection{Aqueous Separations Performance Impacts}

As shown in Figure 5-1 the impact on product purity is minimal for aqueous separations (consisting of head-end, separation losses, and product purity). This is due to the fact that the facility footprint to house the facility separations equipment is small and increases very little to acquire greater product purity. Thus, it follows that most separations systems are designed with excess capability to avoid recycling off-spec solutions that may result from minor process upsets (minor changes chemistry, flow rates, operating temperature, etc.). Aqueous separations operations experience most of their losses in the phase transition steps (e.g., solid used fuel homogenized to liquid via dissolution and concentrated liquid product converted to oxides via denitration processes). As previously mentioned, separation/extraction systems are typically designed with significant recovery margins, and therefore they tend to easily endure minor process upsets. When the abnormal operating conditions are too severe, the consequences are managed by recycling off-spec material until the desired recovery limits are met.

\subsubsection{Oxide Fuel Fabrication Performance Impacts}

Case 1 (low product purity, high TRU loss to waste) is considered to be the classic oxide fuel fabrication manufacturing approach used in industry. It is considered high loss at this time as application to TRU fuel has not been attempted and significant loss issues are expected with radiation damage to the binders and lubricants currently used in the process. The presence of impurities in the fuel material also increases the technical issues with fuel pellet sintering to achieve the desired O:M ratio in the finished product. Fuel impurities also reduce the overall burnup potential of the finished fuel. 
Case 3 (high product purity, low TRU loss to waste) fabrication with high purity feedstock could be accomplished using an improved oxide fabrication process. Losses would be reduced through the replacement of some powder preparation unit processes with more efficient methods that will reduce much of the dust loss from the process. Sintering losses should also decrease as impurity content in the feed is not present to cause issues with the O:M ratio. Lower fuel impurities will allow higher burnup of these fuels in the reactor. Higher costs would be expected for the more efficient process to defray development and implementation costs. Once in production use, unit costs would be expected to decrease below the baseline.

\subsubsection{Repository Loading Performance Impacts}

In Case 1, less efficient waste loading/packaging and lower linear waste loading in the repository would result from higher TRU losses in the waste. The higher TRU losses would increase the waste heat and radiotoxicity. The fuel cycle costs would increase by around $6 \%$ as a result of the lower repository loading factors.

In Case 3, more efficient recovery of TRU for recycle would enable more efficient waste loading/packaging and higher linear waste loading in the repository. The lower TRU losses in the waste would decrease waste heat and radiotoxicity. The fuel cycle costs would decrease by around $4 \%$ as a result of the higher repository loading factors.

\subsubsection{Fuel Performance Impacts}

Section 2.2.5 described reactor transmutation performance calculations, which are based on a modified version of current Transmutation Fuels Campaign impurity limits. There are two impacts.

First, one must consider the accumulation of impurities from subsequent recycle of material. An equilibrium is established between production and removal. As production increases or removal efficiency (measured as \% of inventory) decreases, the equilibrium inventory of impurities in fresh fuel material increases. Production can arise via fission products, corrosion/erosion of process equipment (fuel cladding, fuel separation equipment, fuel fabrication equipment), or deliberate use of chemical additives. Currently, we can estimate only the first. Removal can occur from transmutation of one element to another or deliberate removal during separation of used fuel.

For example, earlier Figure 2-7 shows that the tolerable fraction of individual lanthanide elements (using modified Transmutation Fuels Campaign limits and assuming the only source is fission) retained in recycled product ranges from less than 1\% (implying the need to remove more than $99 \%$ of the element) to $100 \%$ (implying the need to remove none of the element). Taking the lanthanides as a whole, the required removal fraction would be $\sim 10 \%$. The lanthanides are a relatively easy case to analyze because neutron capture by one lanthanide isotope always leads to another lanthanide isotope so that neutron capture does not change the net mass of lanthanides as a group. More detailed element-specific analyses are required that account for multiple sources of each element, transmutation, and allocation of "group" Transmutation Fuels Campaign limits to individual elements.

The second impact is fuel performance from neutron capture and/or fuel atom displacement. For the fast reactor cases that are the current focus of the study, the impact is bounded by $1 \%$ as a nominal result.

The worst case would arise if distribution of impurity lanthanides in the fuel matrix is not benign as currently considered. Lanthanide accumulation and subsequent impact on fuel cladding during irradiation is one of the factors considered in fuel lifetime. The initial impurity lanthanides do not seem to be counted against this limit. Since the initial impurity lanthanides are $\sim 10 \%$ of the life-limit fission produced lanthanides, if the initial impurity lanthanides have to be counted against the lifetime limiting amount, the impurities would have a $\sim 10 \%$ impact on fuel performance. 


\subsubsection{Composite Results}

The overall result indicates that the Case 1 (low purity, high loss) strategy would result in the lowest overall costs. This composite cost is driven by the high variable costs of fuel fabrication, which currently tends to overshadow the burnup penalty involved with the finished fuel. Due to the simplicity of the model used in this analysis, the systemic implications from the burnup penalty are understated. In reality, the burnup penalty could result in a much greater impact due to the perturbation on the entire fuel cycle because more material would have to be produced (and faster) to maintain energy production at the lower burn-up.

A truly integrated model of the integrated system would include the feedback effects from the (high or low burnup) irradiated fuels to separations. In future Losses studies, we plan to develop an enhanced system losses and assessment model as described in Section 6.3 to address these system effects.

\subsection{System Level Economic Trade-offs (Metal)}

In the initial scoping study, the bounding system performance losses were evaluated based on the variation on the back-end cost of the fuel cycle. In Figure 5-2, the three cases were evaluated over the full range of performance values for metal fuel as defined in Table 4-1. The resulting cost variation was normalized to 1.0. Simplifying assumptions were made on the modeling (e.g., data was based on best engineering judgment) to be able to demonstrate how the model would work. The actual results or relations shown by the models are not indicative of all systems. A description of the impacts on each of the variables on the $\mathrm{x}$-axis is provided in the following sections. As can be seen in the figure, very little cost variation resulted from head-end losses, separation losses, or product purity. Process losses have some variation $(+1 \%$ to $-1 \%)$, while fuel fabrication had a cost variation of plus or minus $5 \%$. The performance impacts on repository and fuel were similar in the plus or minus $5-6 \%$ range, similar to oxide fuel.

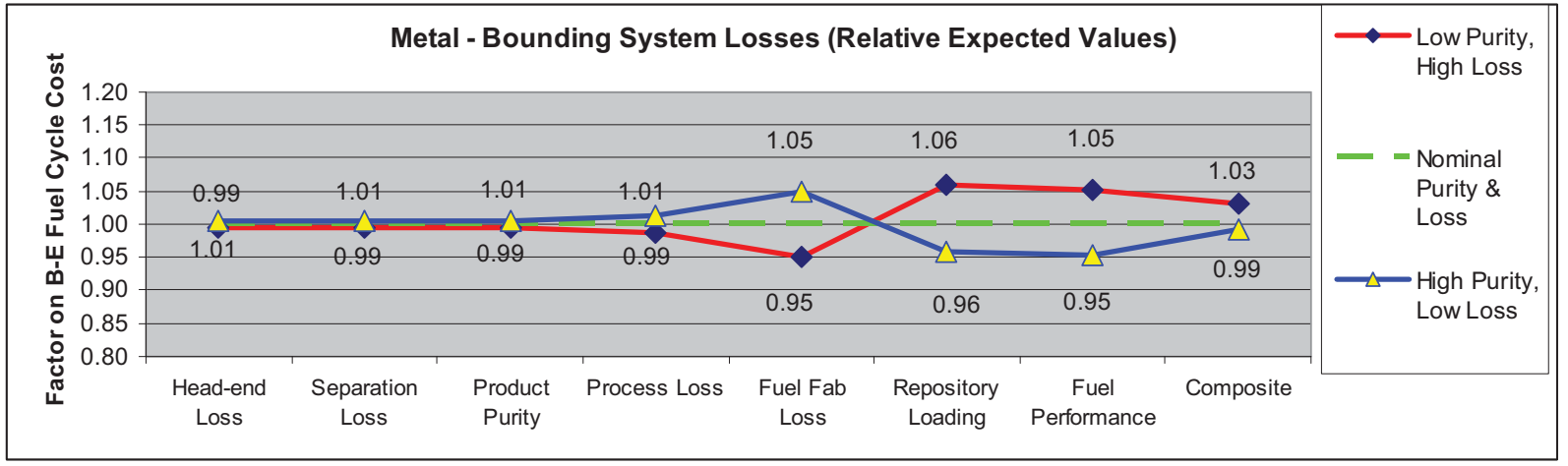

Figure 5-2. Metal - system level tradeoffs from bounding system losses.

\subsubsection{Separations Performance Impacts}

The electrochemical separations process described in Section 2.2.2 has been used for over 10 years to treat sodium-bonded EBR-II driver and blanket fuel. This treatment process has produced a significant amount of separated uranium product and stainless steel cladding hulls under varying conditions. Some of these conditions are representative of an advanced recycling process at the current state of the technology. Samples from these operations and tests have been characterized and the results are the basis for Case 1 (low-purity, high-loss system). The heavy metal products produced contain some impurities (e.g., recovered U contains some Pu impurities). Some of the waste streams from the process contain a small amount of heavy metals (e.g., cladding hulls contain some residual heavy metal). 
It has been recognized for a long time that the process used for EBR-II fuel treatment does not meet all the objectives of an advanced recycling process due to the level of impurities and losses and the absence of key unit processes (e.g., U-TRU recovery). Therefore, as EBR-II fuel has been treated, numerous experiments have been conducted under the AFCI program to improve processing performance and investigate advanced process technologies. Modeling activities have also been supported to improve the processes with the same goals. The heavy metal products produced in these tests or predicted by modeling simulations contain some impurities (e.g., recovered U-TRU metal product contains some level of lanthanide impurities). Also, the advanced waste processes result in some heavy metal being lost to the waste form (e.g., salt waste contains some residual heavy metal). The results of these small-scale tests and the predictions from modeling are the basis for Case 3 (high-purity, low-loss system).

\subsubsection{Metal Fuel Fabrication Performance Impacts}

Metal fuel fabrication using the historical process represents the bounding Case 1, low-purity, high-loss system. With the exception of $\mathrm{C}, \mathrm{N}, \mathrm{O}$, and $\mathrm{Si}$, the impure metal coming from separations passes through the fabrication process without any significant effects. The elements that do affect the fabrication cause additional losses in metal melts (as slags) and disrupt the required composition limits for $\mathrm{Zr}$ in the melt. Most high losses result from high-scrap recycle rates in the crucible heels and slug end crops. This material must go back through the process, and each recycle increases the potential losses from metal diffusion into crucibles and retention on mold surfaces. This existing 1960's technology is usable but not optimized. The low purity of the fuel material from separations carries an inherent penalty in lower burnup achievable due to fuel cladding interaction from the impurities.

For metal fuel the Case 3, high-purity, low-loss case is a win-win situation. Fabrication losses can be significantly reduced by process improvements, minimizing scrap recycle, and overall process losses. Addition of a forming step can further minimize scrap and break up any remaining impurities in the fuel material. The cleaner fuel, especially with dispersion of the impurities that remain, is expected to allow a significant increase in fuel burnup. Case 3 then benefits from lower repository disposal costs and higher fuel performance, and has lower relative composite costs for higher purity/lower loss metal fuel.

\subsubsection{Repository Loading Performance Impacts}

In Case 1, less-efficient waste loading/packaging and lower linear waste loading in the repository would result from higher TRU losses to the waste. The higher TRU losses would increase the waste heat and radiotoxicity. The fuel cycle costs would increase by around $6 \%$ as a result of the lower repository loading factors.

In Case 3, more efficient recovery of TRU for recycle would enable more efficient waste loading/packaging and higher linear waste loading in the repository. The lower TRU losses to the waste would decrease waste heat and radiotoxicity. The fuel cycle costs would decrease by around $4 \%$ as a result of the higher repository loading factors.

\subsubsection{Fuel Performance Impacts}

The fuel performance impacts would be the same indicated for oxide fuel in Section 5.1.4. However, the data for oxide and metal fuel are specific as identified in Appendix A.

\subsubsection{Composite Results}

The overall result indicates that the Case 3 (high purity, low loss) strategy would result in the lowest overall costs. The added benefits to repository loading and fuel performance overcome the additional costs from separations and fuel fabrication. 


\subsection{Sensitivity Analysis}

\subsubsection{Fuel performance Penalties}

Many fuel impurities have a direct affect on the longevity of fuel in reactor service. Impurity elements that are reactor poisons capture neutrons needed for fission reactions reducing fuel power and shortening the overall fuel lifetime (an exception to this is a fuel designed with excess reactivity with burnable poisons designed to maintain correct activity early in the fuel lifetime).

Impurity element lanthanides tend to cause localized corrosion of fuel cladding resulting in premature fuel failure so high lanthanide content fuels will carry a significant burnup penalty. Impurity elements such as chlorine and fluorine are also highly corrosive to fuel cladding and can shorten allowable fuel burnup. Although both metal and oxide fuels may have reduced lifetimes due to impurities, there are differences in the expected impacts from specific impurity species. Mobile impurities that can cause fuel-cladding interaction in oxide fuel may be the most detrimental to fuel lifetime, but high-temperature sintering tends to help remove mobile impurities before the oxide fuel is inserted in fuel cladding. Metal fuel does not involve any high-temperature treatments, but has an advantage in that the fuel material is separated from the cladding with a sodium bond layer that helps restrict the interaction of fuel impurities with the cladding material.

An excess of impurities in the fuel material that are not removed during fabrication will significantly limit fuel burnup, eventually to the point that the fuel is not economical to use. These limits for poisons and lanthanides in fast reactor fuels have not yet been established.

A cost sensitivity analysis was run on oxide and metal fuels to evaluate the impacts resulting from an increased fuel performance penalty due to fuel impurities. Figure 5-3 shows the cumulative cost probability for oxide fuels for the three cases using a 1\% fuel performance penalty. Figure 5-4 shows the cumulative cost probability for oxide fuels for the three cases using a 10\% fuel performance penalty. The resulting data indicate that the greater the fuel performance penalty (i.e., 10\%) due to fuel impurities (e.g., lanthanides) then the less viable a low-purity strategy (Case 1). With the higher penalty (10\%) case the costs for the purity option increase to about the same cost as the nominal purity and loss case (Case 2). A similar analysis was performed for metal fuel that resulted in the same cost behavior. 


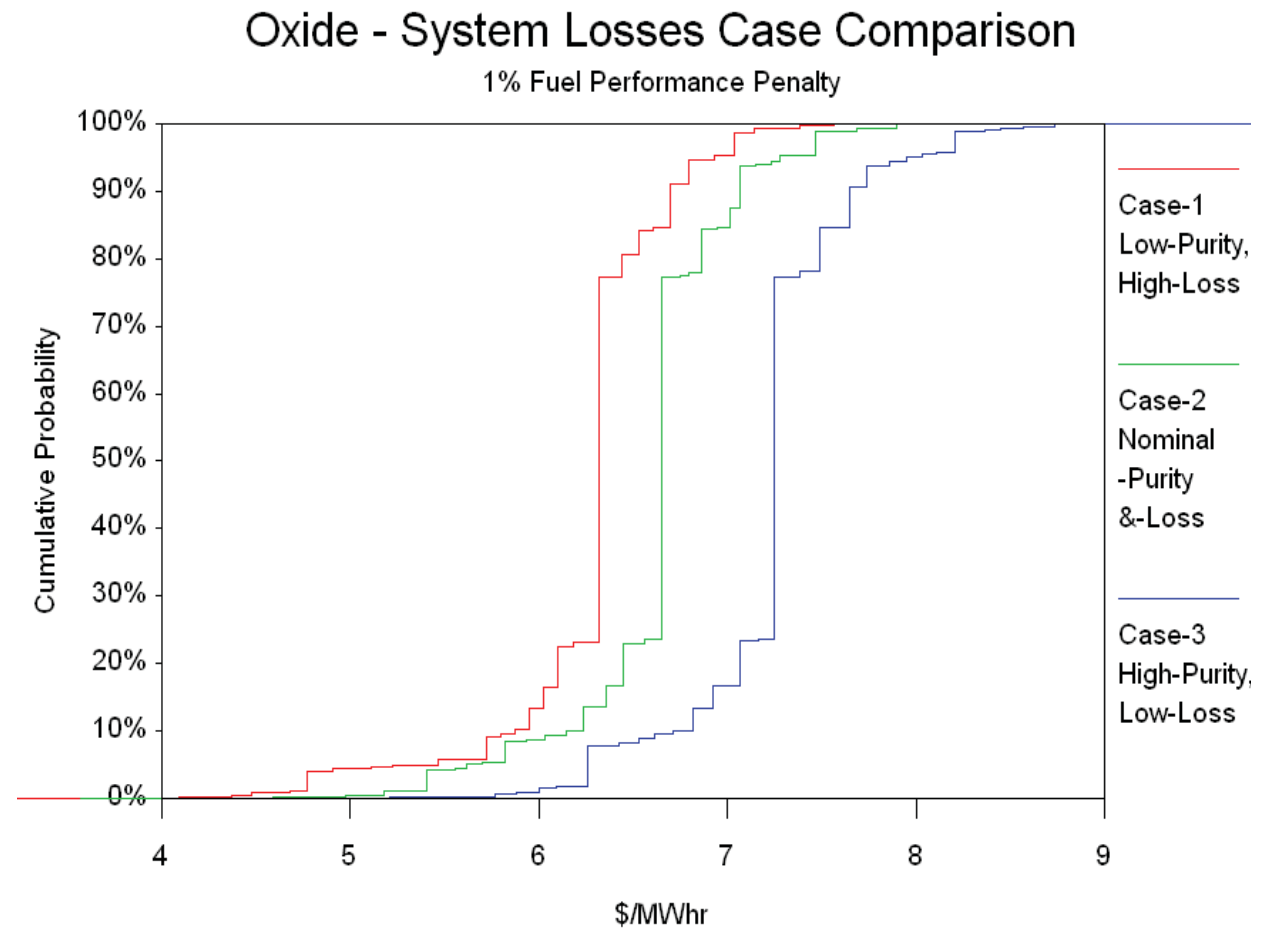

Figure 5-3. Cost uncertainty for 1\% fuel performance penalty on oxide fuel.

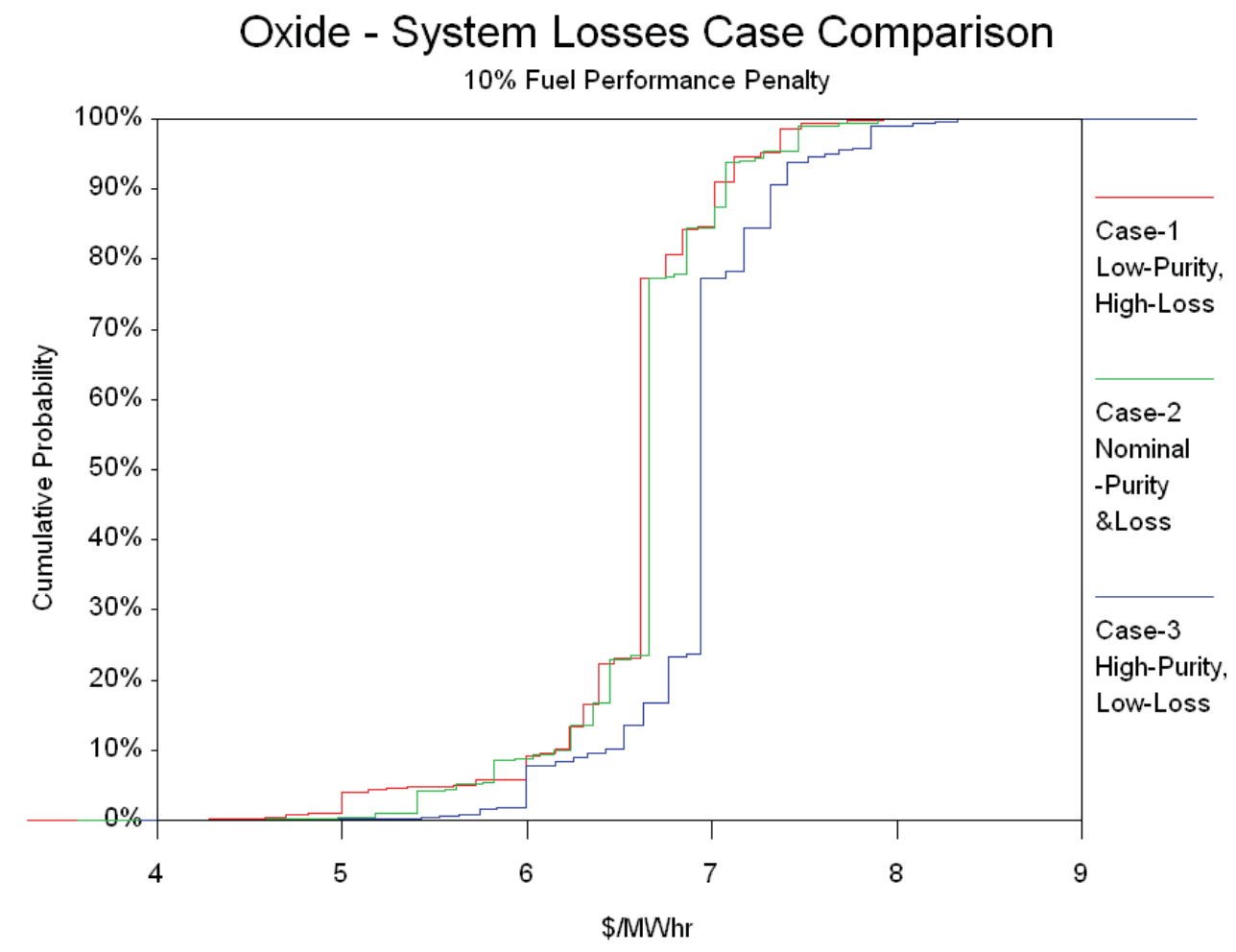

Figure 5-4. Cost uncertainty for 10\% fuel performance penalty on oxide fuel. 


\subsubsection{Repository loading Penalties}

If all of the TRU isotopes were removed from the SNF waste for recycle, then the remaining waste streams could be loaded at higher concentrations in a repository than could original SNF if it were directly disposed and still stay under expected repository temperature and dose limits. When separations of TRU isotopes from the SNF for recycling is not perfect, then TRU isotopes that remain in the separated waste streams will decrease the repository loading factor that could have been achieved with $100 \%$ TRU recycle. It has been assumed in the losses study that the assumed low, medium, and high-percentage losses of TRU to the separated waste streams will result in assumed repository loading factor increases (over the amount of direct-disposed SNF) of 4 times, 2.5 times, and 2 times, respectively.

The high-level sensitivity analysis results of the losses study are corroborated by results of other more detailed studies including the recently completed Heat Management Study (Soelberg 2009). The Heat Management Study showed that limiting the loss of $\mathrm{Pu}$ in the waste form to $2 \%$ or less enables up to a 5-times increase in the repository loading factor. The results of the Losses Study are similar are to these results, but (appropriately, considering the reduced level of detail) more conservative at a 4-times factor.

A cost sensitivity analysis was run on oxide and metal fuels to evaluate the impacts from an increased repository loading penalty (resulting from TRU losses to waste). Figure 5-5 shows the cumulative cost probability for oxide fuels for the three cases using a 2.5-times loading factor (as compared to SNF $=1.0$ ). Figure 5-6 shows the cumulative cost probability for oxide fuels for the three cases using a range from 2.0 to 4.0 times loading factor. The resulting data indicate that the greater the repository loading penalty (i.e., 2.0 times) due to TRU losses to waste, than the less viable a high-loss strategy (Case 1). With the higher penalty (2.0 times) the costs for the high-loss case (Case 1) increase to about the same cost as the nominal purity and loss case (Case 2). A similar analysis was performed for metal fuel that resulted in the same cost behavior.

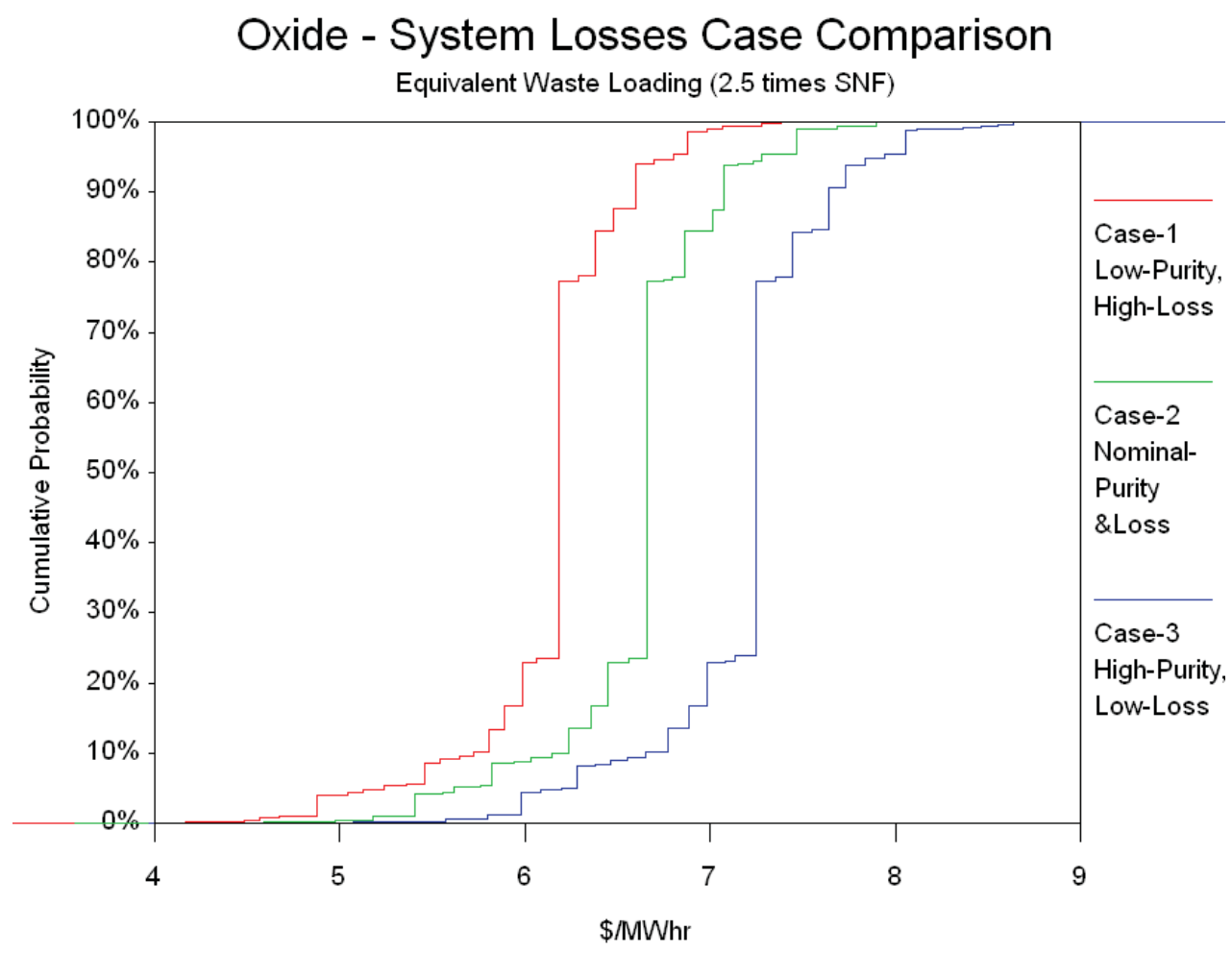

Figure 5-5. Cost uncertainty using equivalent waste loading factor for oxide fuel. 


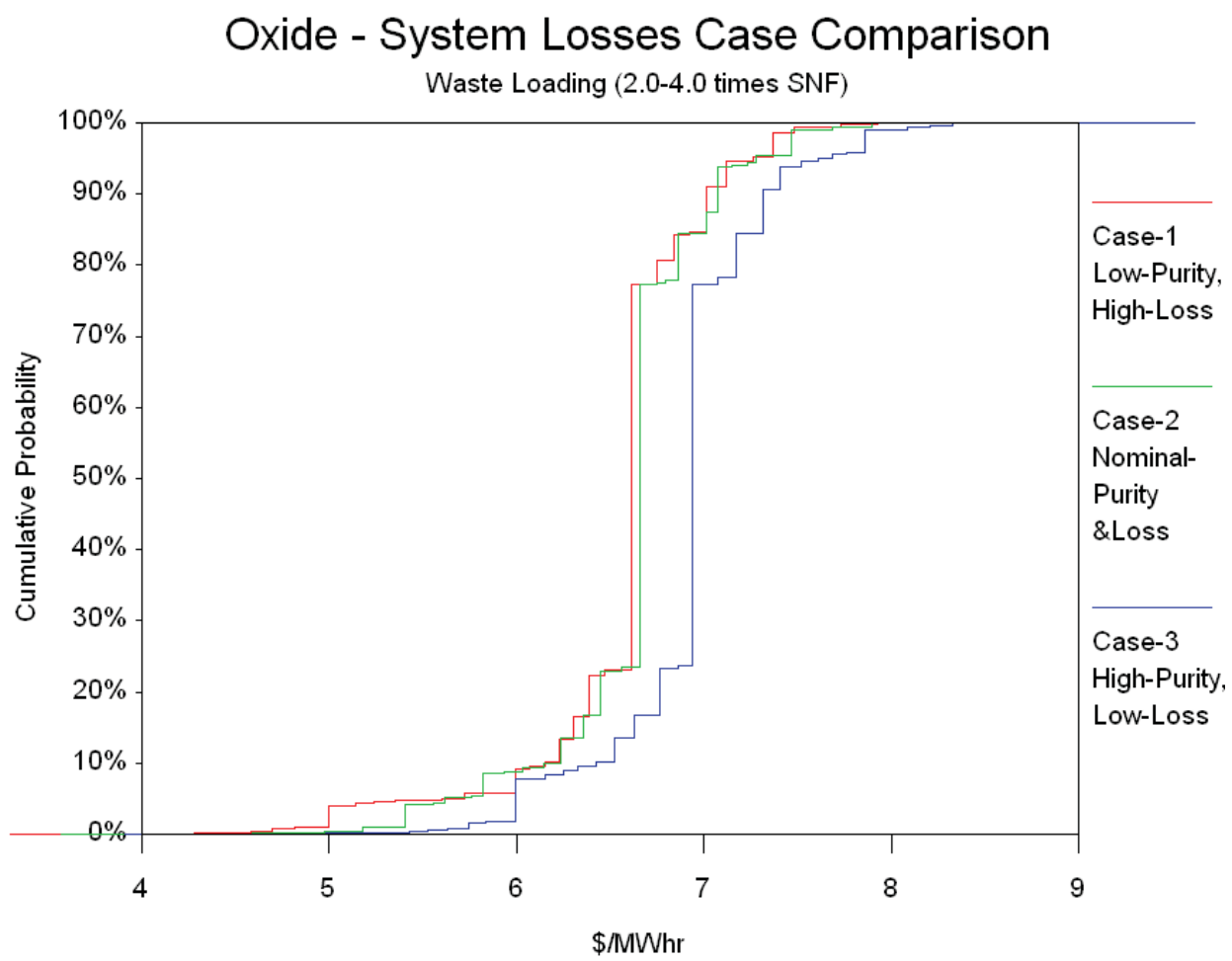

Figure 5-6. Cost uncertainty using 2.0 to 4.0 waste loading factor on oxide fuel.

\subsubsection{Cost Parameter Sensitivity}

A cost range was used for each of the loss and performance variables to better understand the impacts due to cost uncertainty. Upper and lower cost limits were defined that are compared to the nominal costs. Figure 5-7 shows the expected cost range for oxide fuel for each of the variables. Based on the range of the cost values taken from the reference cost information (Shropshire 2008), the variables with the greatest cost sensitivity on oxide fuels are the repository and fuel fabrication. Less sensitivity is shown for the Aqueous Separation subprocesses (head-end, separations, processing).

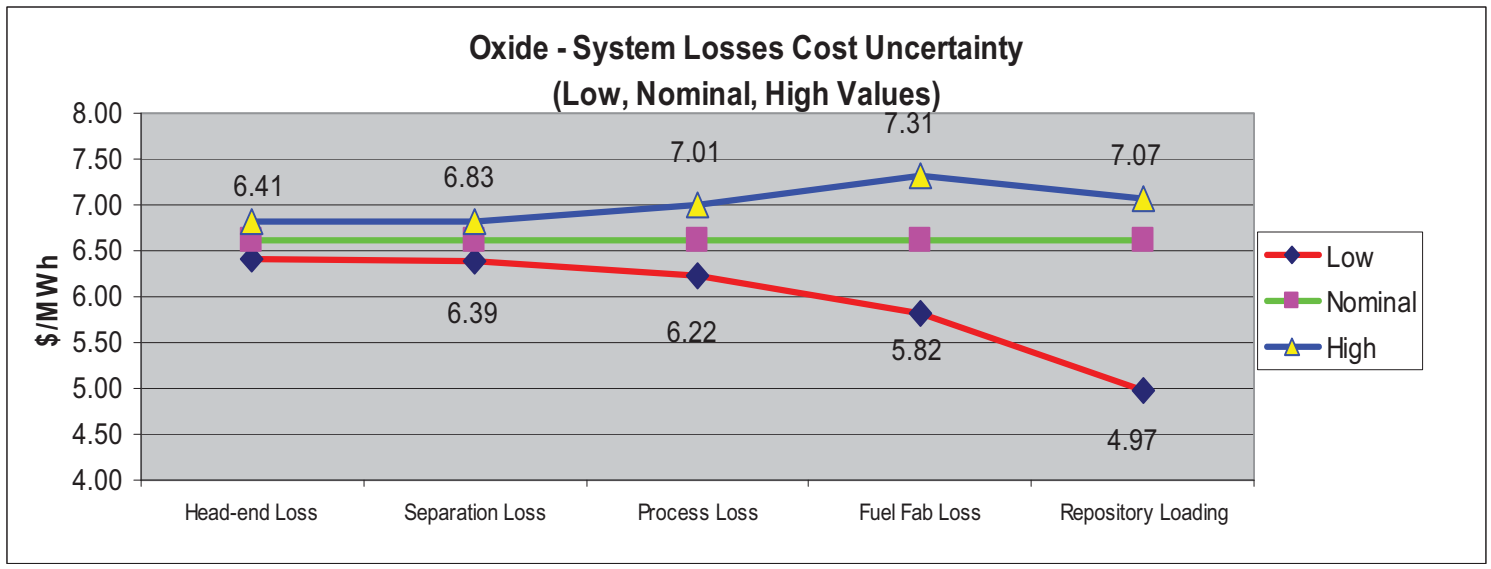

Figure 5-7. Cost uncertainty using low, nominal, and high values for oxide fuel variables. 
Figure 5-8 shows the cost range for metal fuel. For metal fuel the waste processing, fuel fabrication, and repository variables have similar cost sensitivities.

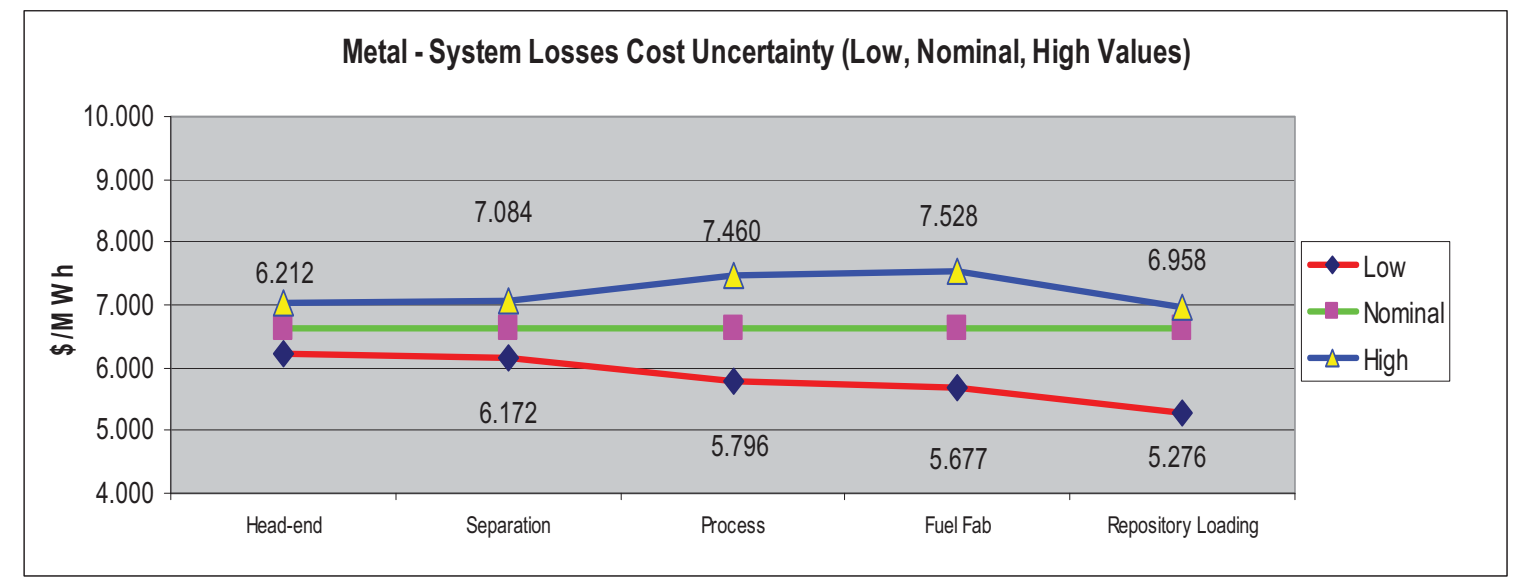

Figure 5-8. Cost uncertainty using low, nominal, and high values for metal fuel variables.

\subsection{Scoping Study Conclusions}

Although it is traditional to list individual conclusions, it is appropriate to consider how issues are interwoven. Consider lanthanides as a specific example of how issues are intertwined throughout the fuel cycle and where research might improve overall system performance. Separation of actinides versus lanthanides is particularly difficult in both aqueous and electrochemical separation so that producing high-purity actinide fuel and/or high-purity lanthanide waste is especially difficult. Thus, there are potential system performance gains from improved separation, relaxed fuel limits, or relaxed waste limits. Current Transmutation Fuels Campaign limits greatly restrict the lanthanides in both oxide and metal fresh fuels. The amount of total lanthanides generated in one pass through the reactor is an order of magnitude higher than the current lanthanide impurity limit on fresh fuel based on evidence of behavioral difference between initial impurities (segregated during fabrication) versus fission products (homogeneously spread throughout the fuel matrix); more research is needed to confirm whether homogeneity of lanthanide fission products is maintained as temperature and fluence increases, which may suggest fabrication techniques that would enable tolerance of higher initial impurities. At the current specified limits, the lanthanides contribute a minor penalty $(\leq 1 \%)$ to the fast reactor fuel value if TRU content is raised to compensate for parasitic lanthanide absorption so that lanthanide-friendly fuel fabrication or fuel cladding/coating could enable raising the lanthanide limits on actinide fuel. This could allow an increase to $\sim 10 \%$ of initial impurity lanthanides and behave more like lanthanides accumulating during irradiation. Meanwhile, with low TRU content, the lanthanides would pose relatively low heat and radiotoxicity disposal challenges; indeed, many of the lanthanides have economic value. So, improved lanthanide-actinide separation or raising the tolerable lanthanide level in actinide fuel (thereby reducing actinides in the lanthanide stream) could have waste management benefits.

The following conclusions in Section 5.4.1 are focused first on the "big picture" issues and then on the specific conditions (Section 5.4.2) that were imposed on this study. The latter study conclusions are based on limited scoping study analysis with placeholder data.

\subsubsection{Programmatic Conclusions}

1. Integrated life-cycle material management modeling is needed to resolve the "cradle to grave" issues related to the entire inventory of used nuclear fuel and all other forms of remote handled and contact handled SNM. This initial effort is a small step in that direction, but one that needs to proceed to help resolve specific programmatic questions as well as the corporate nuclear management issues that are 
now being addressed in the newly passed DOE Order on Management of Nuclear Materials 410.2 (DOE 2009).

2. Segmented analysis has limited benefits and analyzing only part of a bigger issue may or may not provide insight for solutions that are needed to address the overall nuclear material management needs (i.e., Will the conclusions on recycling commercial fuel with fast reactor transmutation change when the entire inventory of used fuel and all other RH SNM are integrated into the program?).

3. More analysis needs to be done on the "big picture" drivers to better understand how to move towards a more integrated and optimized nuclear material management program (i.e., Are there co-processing strategies that can recycle commercial fuel with other used fuel and/or RH SNM for less cost? What are the impacts of implementing simpler and more cost effective flowsheets? If we intend to transition to a new reactor type why would we select one that makes TRU when we are trying to destroy/transmute TRU?).

4. What are all the pros and cons of fuel aging? How do we maintain things like infrastructure and technical core competency in the separations fields if we decide to age fuel for hundreds of years?

\subsubsection{Study Conclusions}

1. Lanthanides appear to be the main drivers with the broadest impact on separations, fuel fabrication costs, and in fuel performance.

Actual data, different assumptions, fuel types, etc., could change these observations. Lanthanide contamination in separations feedstock causes multiple downstream purity issues. With metal fuel fabrication, the process results in solidification of islands of lanthanide impurities. If they are along the fuel surface, the localized lanthanide concentration is sufficient to cause fuel-cladding corrosion reducing the irradiation lifetime of the fuel. With oxide fuel fabrication, the impurities are typically better dispersed throughout the matrix of the fuel, but the lanthanides affect the O:M ratio and make it difficult to control sintering to achieve the desired fuel product. Lanthanides in oxide fuel are still capable of causing fuel-cladding interaction and the cladding is potentially more susceptible as there is no sodium metal buffer present. Lanthanides appear to be the main drivers with the broadest impact on separations, fuel fabrication costs, and in fuel performance.

2. Reducing separation and fuel fabrication costs by lowering the purity of U/TRU products (leading to lower TRU losses to waste) may decrease overall system costs.

Various tradeoffs will be evaluated further, such as the potential benefits of reducing the purity of U/TRU products (e.g., increase lanthanide content) to the reactor to determine if this results in lower overall system costs.

The current guidance from the Transmutation Fuels Campaign on some of their individual impurity limits suggests fuel atom displacement or neutron capture as the rationale. Armed with more comprehensive data, these limits should be reexamined.

3. Increasing purities in aqueous separations $(99.9,99.99,99.999)$ has little impact on system costs; however, operational issues (e.g., need for surge tanks and off-spec conditions) can significantly drive costs.

4. Similarly, fuel refabrication is a major cost driver and could be significantly reduced through process refinement and integration with separations.

5. The impurity/losses assessment must consider accumulation from multiple recycles and the multiple sources of impurities. Fission products at AFCF derived limits do not cause major fuel performance penalties (1\% range) if dispersion of initial impurity lanthanides are benign relative to lanthanides produced during irradiation as fission products, otherwise could be a $10-15 \%$ impact. 
6. In the future, all analyses should consider the range of elements from $\mathrm{H}$ to actinides and both fission and non-fission sources of those elements.

7. From the standpoint of transformational science, we can qualitatively point to some potential areas to investigate:

- Lower cost separation, especially lanthanides-actinides

- Tolerating higher levels of some impurities in recycled fuel material

- Fuel cladding or fuel cladding coatings that tolerate higher fuel impurities

- Approaches to recycling fuel cladding, keeping the significant mass out of residual waste

- Approaches to recycling fuel matrix material (e.g., Zr in TRU-Zr fuel), keeping the significant mass out of residual waste.

Through this preliminary investigation we have begun to improve our understanding of:

- The value of increasing the product purities in through additional aqueous separations $(99.9,99.99$, 99.999).

- How operational issues (e.g., need for surge tanks and off-spec conditions) can affect costs?

- How fuel scrap recycle affects cost and can be reduced through process refinement and integration with separations?

- How fission products affect fuel performance penalties? Preliminary analysis suggests minor impacts if FPs are in 1\% range and the lanthanide FPs are uniformly distributed in fuel. If lanthanide FPs are nonuniform in the fuel then the impact could be a $10-15 \%$ decrease in reactivity.

In the future, these studies will help guide spent fuel recycle research and development studies by (a) determining practical limits for allowable levels of contamination in product and waste streams from elements that belong in other streams, and (b) developing and demonstrating technologies that can practically achieve the necessary separation efficiencies, (c) developing and demonstrating fuel fabrication and waste treatment technologies that can tolerate practical levels of radioactive contamination in product and waste streams, and (d) developing waste disposition pathways that adequately isolate the waste from the environment considering the waste composition and other characteristics.

Final note: these conclusions were not intended and cannot be made in regards to comparing Aqueous to EChem. 


\section{NEXT STEPS}

\subsection{Opportunities for Improved Understanding}

The interfaces between separations and fuel fabrication and the transmutation currently represent a wide open field in need of integration. The number and types of fuel assemblies in the reactor, the number of composition and enrichment variants, and the involvement of poison or target assemblies have direct effects on fuel fabrication. Many of these effects on fuel fabrication continue back to the separation of the spent fuel and especially to the finishing of the separations product to be used as feed material for fuel fabrication. Full integration of the closed fuel cycle requires an evaluation of the need within separations or fuel fabrication to adjust fuel feed material compositions on an isotopic as well as a chemical basis to obtain a usable fuel product. Optimum interface points between fuels and separations would allow adequate fuels flexibility to deal with the expected range of reactor fuel and target variants, while minimizing the interruption of material flows between separations and fuels. As an example, the following analysis could be performed:

- Identify the expected number of reactor fuel/target variants involved.

- Formally define the required specification hierarchy: Reactor, to fuels, to separations, and need for operational controls within fuels and separations.

- Review the pertinent technical aspects of separations product purification, precipitation, and blending. Provide similar analysis for product reduction to metal.

- Review the pertinent Nuclear Materials Control and Accountability (NMC\&A) aspects of separations product management.

- Review the involvement of separations product storage requirements and limitations and their effect on appropriate interface direction.

- Determine if there is any need for separations polishing and where it would best be performed (if required).

- Evaluate the recovery of fuel fabrication by-products within separations and determine the advisability of that approach.

\subsection{Expanded Analysis, Metrics, and Model Outputs}

A more complete systems view would address a number of related issues that are significant cost, risk, and proliferation drivers. The impact of these drivers can vary a great deal by fuel type and the selected separations process.

\subsubsection{Cost and Risk Metrics}

The following list is not all inclusive, but it does identify related issues and the complexity of the overall management issues relative to the nuclear fuel cycle and all types of remote handled SNM (used fuel [commercial, DOE, Navy, etc.], irradiated targets, test material etc.) This kind of insight is critical to developing the corporate management perspective that is sought by DOE Order 410.2 and would also benefit specific programmatic decisions.

- Recovery cost versus fuel design versus fuel performance (i.e., results vary with fuel type). What may be true for LWR commercial fuel will change for a fuel that is designed to provide a balance between being "user friendly" for recovery and long-lived for reactor performance.

- Comprehensive assessment of all sources of elements in recycled product - initial impurities; accumulated fission products from repeated recycles; corrosion/erosion of fuel cladding, fuel separation, and fuel fabrication; fuel matrix materials; or other deliberate chemical additives. Unless elements from different sources behave differently (e.g., initial impurity lanthanides versus 
lanthanides generated during irradiation), it makes little sense to limit minor sources of individual elements.

- Waste generation versus fuel design (i.e., fuel is designed for long lived performance) and oncethrough direct disposal to minimize mass discharged to the disposal site or fuel designed to be recycled while on line with minimal waste generated from recycling fuel are likely to generate less waste than that produced by the disposition of today's LWR commercial fuel.

- Separation processes versus. fuel design (i.e., each separation process [aqueous versus electrochemical]) has its set of pros and cons for any given candidate fuel. Furthermore, each type of separations process must matched to a specific process flowsheet for a specific fuel to provide optimum results. "One size" does not fit all, and one process and a selected flowsheet should not be applied to multiple fuel types for which it is not suited.

- Separations timing versus cost (i.e., process, recycle and refuel in less than 2 or 3 years) versus process used fuel after extensive cooling (e.g., 200 to 300 years) to stabilize SNM inventory and minimize isotopic transition and feed blending issues for fuel fabrication.

- The recovery/separations flowsheet versus waste generation (i.e., What degree or amount of separations provides the least waste management cost?). Is there real value added from implementing additional separations systems to further isolate waste or byproduct components?

- Fuel burnup versus waste management costs (i.e., What is the optimum burnup and recycle scheme for minimizing waste and SNM management costs?).

- Fuel heavy metal versus waste/SNM management costs (i.e., Th/U-233 versus Pu/LEU). Why make TRU when you are trying to destroy TRU? Select a fuel meat that has the cleanest and leastcomplicated radioactive waste inventory (i.e., burn TRU to make U-233).

- Fast versus thermal reactor concepts versus waste/SNM management costs (i.e., What are the thermal reactor concepts that can be used to transmute TRU and minimize the production of TRU?).

\subsubsection{Proliferation Metrics}

Recent papers (Bathke 2009, Bjornard 2009, Goodman 2009) presented at GLOBAL 2009 have provided some very useful insights to the attractiveness of materials in advanced fuel cycles. In the Bathke study, they indicated that for a 10-year, 45,000 MWD/MTHM COEX material (i.e., plutonium), a U-238 content of $\sim 80 \%$ is required to be unattractive for use in a nuclear weapon or nuclear explosive device. The TRU from that same discharge would require $\geq 75 \%$ U-238 or $>20 \%$ lanthanide to be unattractive for use in a nuclear weapon or nuclear explosive device. However, the addition of the lanthanides to TRU is of limited value, because they must be removed before fabrication of a recycled fuel. They make the assumption - reasonable for current technology - that such lanthanide content would be unacceptable. The figure of merit (equation 1) has three components - bare critical mass, heat content, and dose rate - the third term is relatively less important. The first term gives the benefit from $U$ dilution, (i.e., the lower the TRU content the better). The second term gives the benefit of Am, Cm, FP. They calculated their metric only for first recycle but we know how the isotopics will evolve over multiple recycles, which will reduce "attractiveness" for TRU CR $<1$ and increase attractiveness for TRU CR $>1$. The metric was only calculated for the first recycle, but knowing that the isotopics evolve over multiple recycles, this will reduce the "attractiveness" for TRU $(\mathrm{CR}<1)$ and increase attractiveness for TRU $(\mathrm{CR}>1)$. This is fertile ground for future assessment and integration into the Losses Study.

\subsection{Enhanced System Losses and Assessment Model}

In FY-10, the System Losses and Assessment Model (SLAM) is planned to be developed. The primary objective of the tool is to provide an overall system understanding of the tradeoffs between Separations, Fuel Fabrication, Waste Forms, Waste Disposition, and Reactor Performance. This Systems Analysis 
Campaign tool will be used to interface with the more detailed models used by Separations,

Transmutation Fuels, and Waste Forms Campaigns. The tool will be designed to interface with other Systems' models (e.g., VISION, VISION.ECON, reactor performance, waste form/disposition models). SLAM will provide the capability to evaluate a wide range of system configurations, including 1 and 2-tier systems, different spent fuels, spent fuel recycle options, and waste disposition options. The use of the tool will result in useful insights on system performance that DOE can use to make decisions regarding different fuel cycle options, provide information about how waste can be safely and cost effectively managed, and provide information for guiding the focus of future fuel cycle research and development. The overall SLAM domain, types of fuel cycle analysis supported, and key modeling variables are illustrated in Figure 6-1. The color coding on the diagram illustrates the various focus areas of the Campaigns, where SLAM integrates these analysis into a composite structure. Key modeling variables that will be included in SLAM are listed around the periphery of the domain.

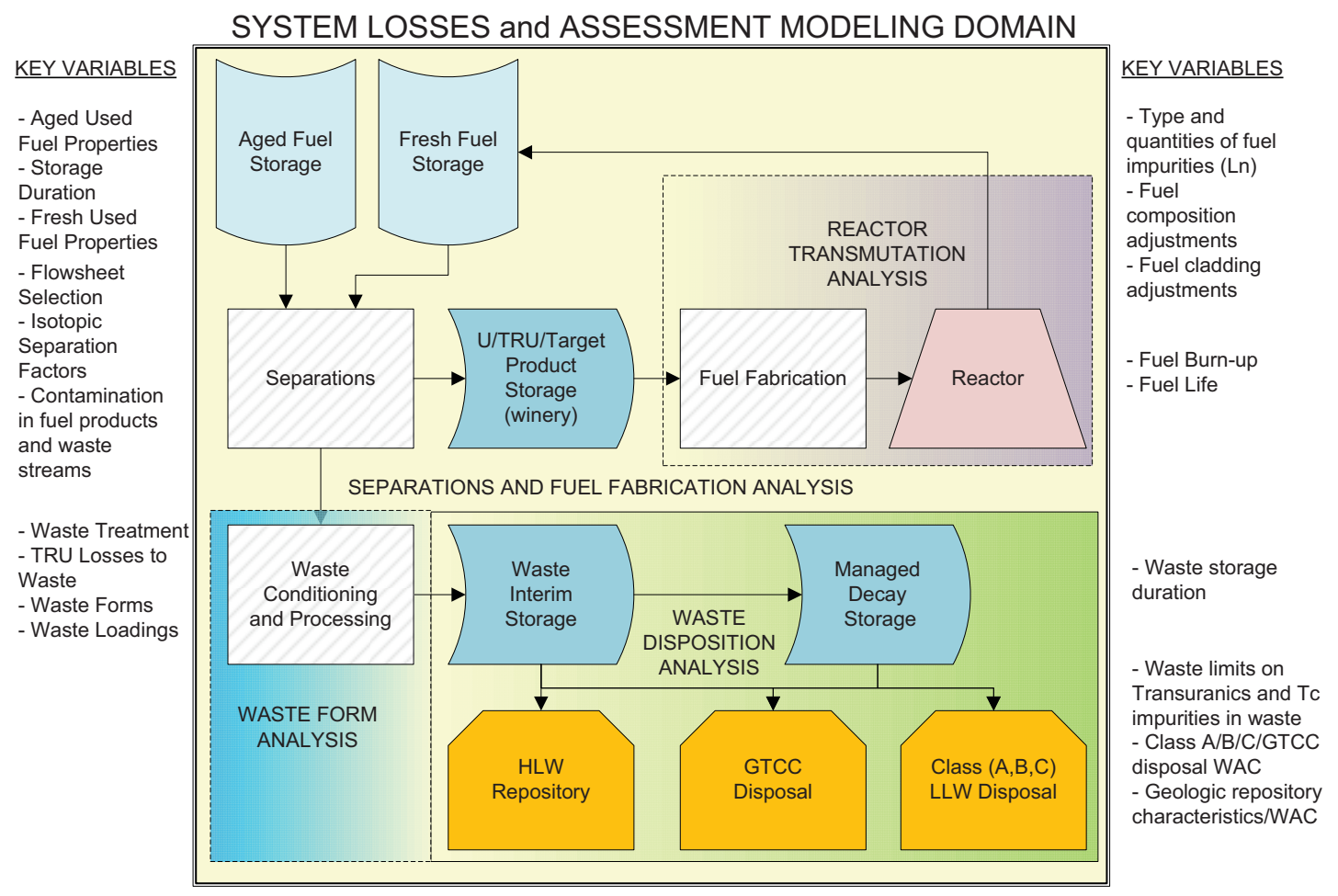

Figure 6-1. System Losses and Assessment Model.

No decisions have yet been made on the preferred SLAM software platform. A range of software will be considered (e.g., continue with Excel, DPL, Aspen Plus, Maple, MATLAB ${ }^{\circledR}$, PowerSim $\bigcirc$, VenSim ${ }^{\circledR}$, others) after a requirements process has been completed. Future requirements will be based on the need for "value-added" improvements to provide "value-added" results.

\subsubsection{System Losses and Assessment Modeling Outputs}

In this section we explore ideas on the types of output that could be used to evaluate system trade-offs. There are many ways to represent tradeoffs between system parameters and various software programs that could be used to produce the output. Output could easily be produced using Excel to produce simple 2 or 3-dimensional outputs. Enhanced outputs (e.g., trade-off surfaces) could be produced by more sophisticated mathematical software (Maple, MATLAB $\AA$ ). The following three examples were created to visualize trends and trade-off space as a function of key parameter change. Note that the charts are provided for illustration purposes only. 
In Figure 6-2 the cost performance is plotted as a function of losses of TRU to waste and purity of refabricated fast reactor fuel. This chart shows that as the composition of TRU in the waste stream increases, the disposal cost is expected to increase, driving up the overall cost. Additionally, low-purity reactor fuel may negatively affect reactor, reprocessing, refabrication, and repository performances. Costs would be expected to increase to meet both high separation efficiencies and high product purity. The exploration of this parameter space will tell us in more detail how sensitive the cost $\mathrm{s}$ to these parameter changes and at what values the tradeoffs lie.

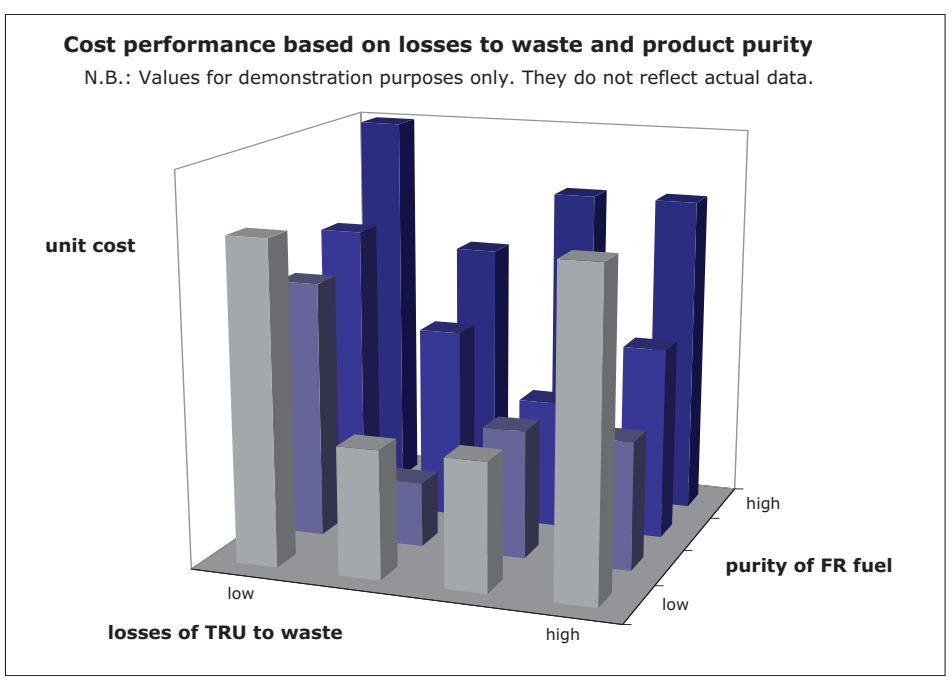

Figure 6-2. Cost performance based on losses to waste and product purity.

In Figure 6-3, cost performance is shown as a function of time that spent fuel spends in interim storage before being recycled. The overall performance is broken down by cost components (storage, recycle, repository, and fuel fabrication). With this output we can follow the evolution of the cost composition as a function of time, and the tradeoffs between partitioning used fuel early (before actinide build-up and before long-term storage expenditures) or after hundreds of years of storage (after heat-emitting fission products decay out, driving down repository cost).

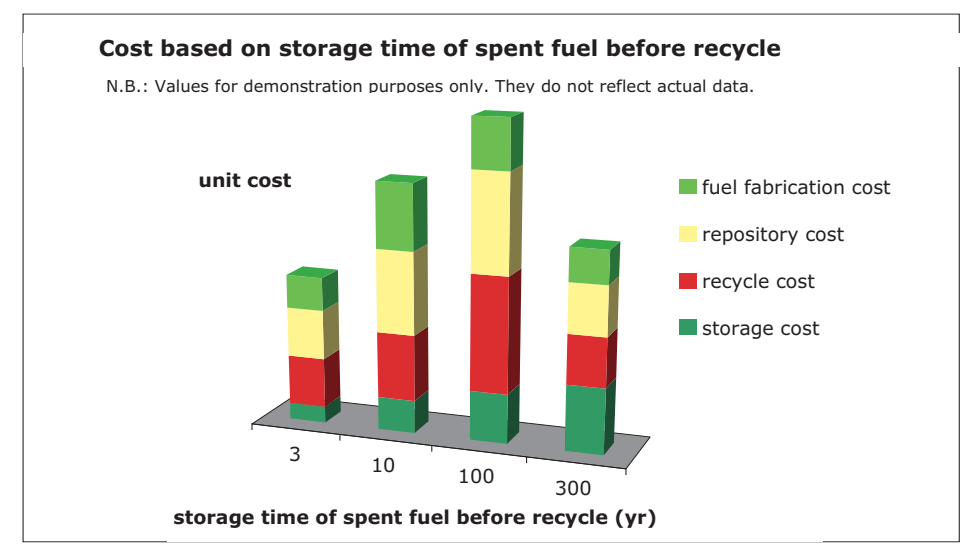

Figure 6-3. Cost based on interim storage time of spent fuel before recycle. 
Figure 6-4 shows the inventory of different types of waste as a function of losses to waste. This output illustrates the relative composition of waste by mass or volume as a function of the losses to waste. Given the use of appropriate software, this output could be extended to also include a third dimension for the purity of fuel.

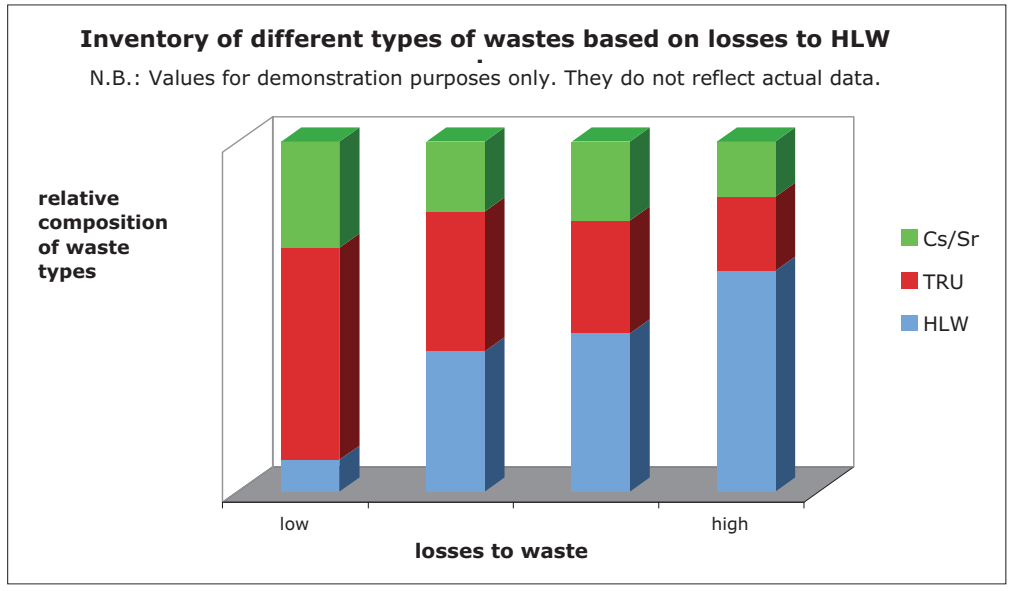

Figure 6-4. Waste inventory based on losses to HLW.

Several standard outputs could be automatically generated by the System Losses and Assessment Model to enable quick analysis of system tradeoffs. The outputs would be designed with the flexibility to show inflection points on surfaces, or show surfaces that evolve with time. A range of system performance measures can be explored, such as repository performance, fuel performance, and electricity generation, all as a function of system parameters. Scenario analysis should allow quick comparisons between different technologies utilizing the same parameter space.

\subsection{Supporting Campaign Work Scope}

The FY-09 System Losses and Assessment project will carry-over activities from Phase 1 into FY-10. We will continue to refine impurity and loss estimates, as well as impurity limits in fuel, by incorporating results of ongoing R\&D, and continue work on the enhanced system losses model.

We can integrate collaborative work from the Fuels, Separations/Waste Form, Systems, and Transmutation activities with this study, and identify processing strategies from a more holistic perspective to see if there are ways to reduce losses (e.g., co-process commercial fuel with other nuclear material and/or non-commercial spent fuel).

If prioritized, FY-10 could include work on the Phase 2 Baseline (2-tier thermal recycle, if prioritized for FY-10), including MOX composition ranges to be considered, impurity interactions with Zr cladding materials, and Actinide target design consideration (e.g., use in Fast Reactors only or in LWRs, inert matrix burner versus burner + breeder). Work may also include the screening of other separation processes (e.g., examples).

Additional collaborative work scope provided by the Campaigns as input to the System Losses and Assessment project are summarized in the following sections.

\subsubsection{Aqueous Separations/Waste Forms Development and Modeling}

The Separations Campaign has supported development of steady state process models based on fundamental chemical and thermodynamic principles to provide the tools to develop advance process flowsheets and predict process throughputs. The modeling effort has focused on enhancing the Argonne Model for Universal Solvent Extraction (AMUSE) and on development of a steady-state plant model based on the UREX+ processes. The AMUSE code calculates multistage countercurrent flowsheets based 
on the distribution ratios (D-values) of components. The D-values are based on the input compositions and conditions of the aqueous and organic phases. Figure 6-5 illustrates the relationship between the two sections and the user inputs that are required for both sections. The accuracy of the D-value calculations over a wide-range of aqueous phase compositions is due to chemically correct models that use the thermodynamic activities of the major aqueous-phase species.

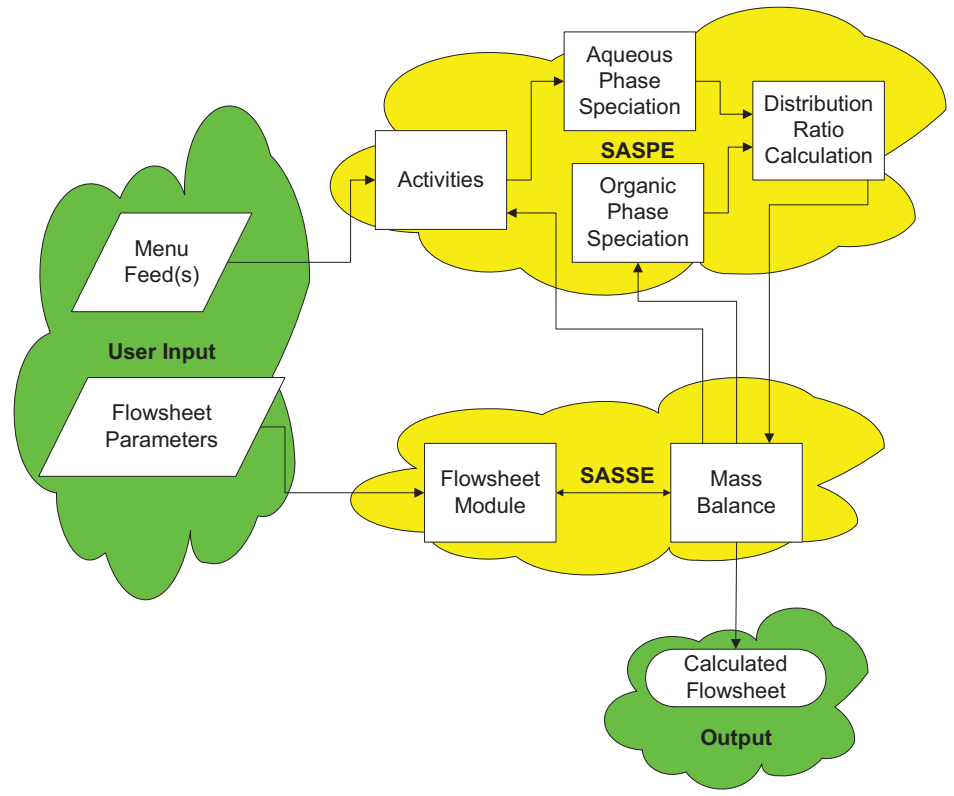

Figure 6-5. Simple schematic of AMUSE operations.

AMUSE enables the design and detailed evaluation of proposed flowsheets to (1) determine that each feed component will reach its design composition in the raffinate and product streams, (2) provide the compositions of the organic and aqueous solutions in each stage of the flowsheet at steady state, and (3) identify key points for process monitoring and control. AMUSE can readily calculate solvent extraction flowsheets for PUREX, UREX, CCD-PEG and TRUEX. With input of appropriate D-values, flowsheets for many other processes including FPEX and TALSPEAK can be generated and evaluated. Sensitivity analysis can define the effects of flow rate variations, compositional variations, stage loss, other-phase carryover, temperature excursions, and equipment type.

Preliminary Aspen Plus ${ }^{\circledR}$ models have been developed for the UREX+1a and UREX+3a. Figure 6-6 shows a high level diagram of the UREX+3a model. Models of the major unit operations within a plant were developed. The unit operation models are in turn composed of several Aspen Plus model blocks coupled together. Rigorous solvent extraction calculations are performed by coupling Aspen Plus directly with the AMUSE solvent extraction model. The plant operations modeled include:

- Head end operations

- Solvent extraction

- $\mathrm{U} / \mathrm{Tc}$ ion-exchange

- Product calcination

- Nitric acid recovery

- Organic recovery

- Off-gas treatment

- Waste water treatment. 


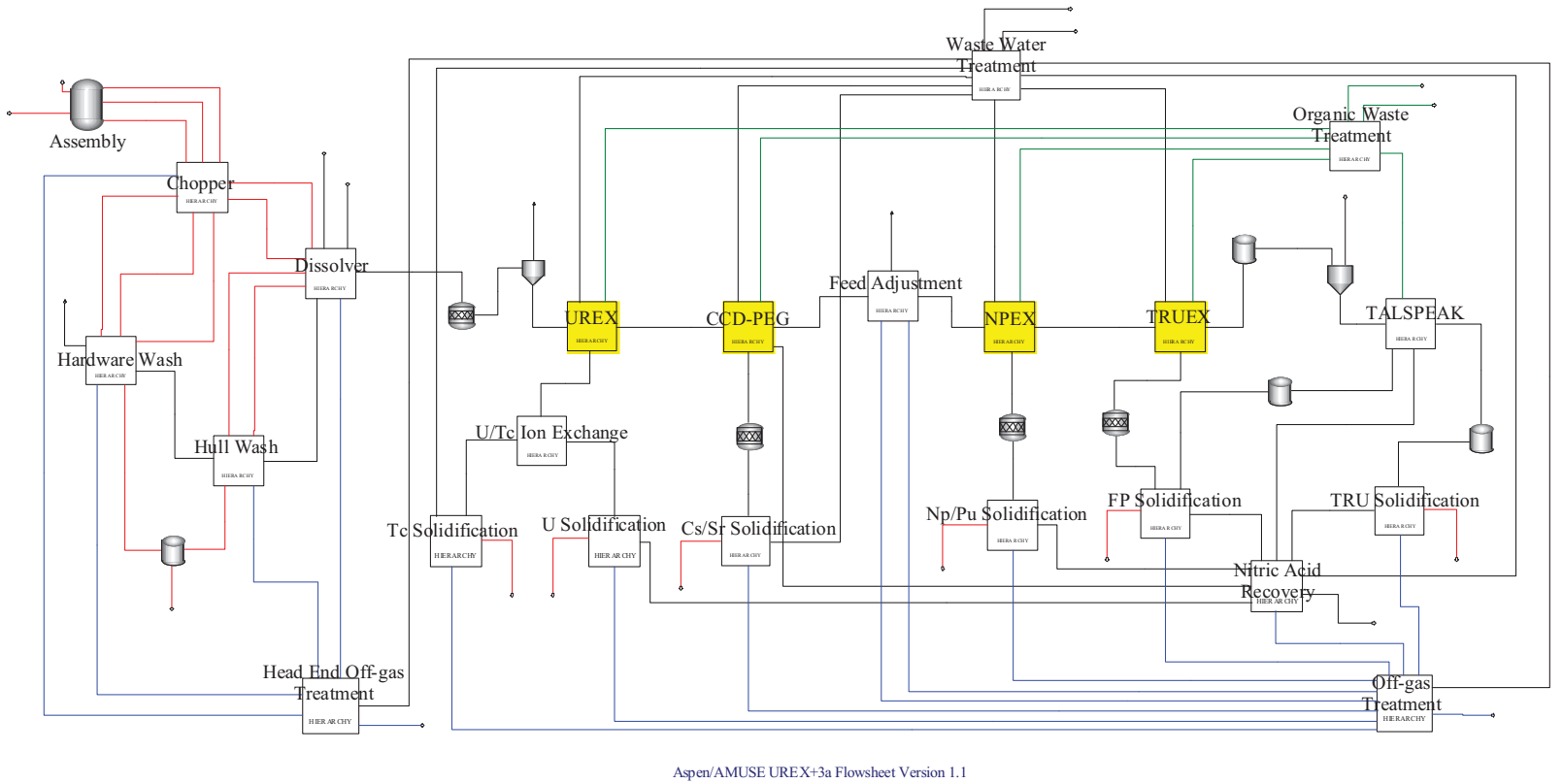

Figure 6-6. Top Level UREX+3 Flowsheet.

Future work is needed to characterize and define aqueous separations process requirements for existing and future flowsheets to meet a wide range of process goals. These flowsheets need to be evaluated via systems analysis models to determine fuel cycle inter-relations. Process impacts of minor transition metal fission product levels needed to meet recycle fuel specs, with or without minor actinides/lanthanides included in the fuel, and must also be evaluated. This effort would be coordinated between INL and ANL for modeling efforts via AMUSE for elemental yield predictions and also ASPEN ${ }^{\circ}$ code for process integration. An assessment of potential sources of all elements during separation (corrosion/erosion or chemical addition) should also be started.

A better understanding of separations support in the area of a totally integrated nuclear material management plan is also needed to identify (1) where there are synergistic SNM material processing needs across all of the DOE programs, (2) new co-processing strategies that could help disposition orphan nuclear material for less cost and risk (3) the integration of R\&D separations with material management/dispositioning needs, (4) strategies to maintain and grow the technical core competency and infrastructure need to support nuclear power.

\subsubsection{EChem Separations/Waste Forms Development and Modeling}

The current plan for Fuel Cycle R\&D activities for EChem Separations/Waste Forms is to continue with previous activities, but with an emphasis on development of technical issues independent of specific flowsheets. Several of the activities stated below will support reducing the uncertainty in the assumptions regarding impurity levels and loss quantities used in this system study, the EChem activities will include the development of:

- A fundamental understanding of the thermodynamics and kinetics of each separation process.

- Off-gas pathways in the EChem process for iodine, tritium, and krypton.

- Electrorefiner process monitoring devices for actinide tracking.

- U/TRU product recovery by electrodeposition.

- U/TRU product processes to separate salt from metal. 
- $\quad$ Salt recycle technology (e.g., U/TRU drawdown, fission product removal).

- Advance waste forms for fission products removed from salt.

- Technetium distribution and limits in metal alloy waste form.

- Capabilities to enable science-based R\&D coupled with modeling and simulation.

Several of the above activities will support reducing the uncertainty in the assumptions regarding impurity levels and loss quantities used in this system study.

\subsubsection{EChem Modeling Efforts}

Electrochemical separation is a series of non-steady state batch processes in which the molten salt electrolyte compositions in the reduction and the refining cells vary with time. The composition of these salts is temporal, and therefore affects the timing of subsequent processes, such as transport of TRU to a liquid cadmium cathode and transfer of salt to the actinide drawdown and fission product ion exchange processes. To capture both the dynamic and batch characteristics of electrochemical separations, a mathematical process model is being developed. The model, as envisioned, will provide electrolyte composition and inventory in each unit operation and mass flows between them, which will allow optimization of process parameters to maximize throughput and minimize high-level waste generation. It will also allow changes to specific unit operations, since some operations, such as actinide drawdown and oxide reduction, are still under active developments and further innovations on the unit operation concepts are expected. The developed model will capture state-of-art unit operation dynamics by combining the first principles of thermodynamics and mass transfer, supported by the available experimental data, in a computationally efficient manner.

The Separations Campaign has supported development of dynamic process models based on fundamental chemical and thermodynamic principles to provide the tools to develop advance process flowsheets and predict process throughputs. Since most of the electrochemical processes are not steady state, the unit operation models using commercial software application (e.g., ASPEN $\left.{ }^{\circledR}\right)$ use rule-based separation logic rather than kinetic or thermodynamic-based calculations. The rules are based on experience and from these rules mass flow can be predicted. However, this method does not provide an effective method to optimize the process or evaluate alternative processing strategies. To provide this capability dynamic modeling methods need to be developed to supplement and eventually replace the rule based logic.

The following is a description of the features of some of the initial unit process models:

Electrorefining Process. The transuranics actinides and active metal fission products in the spent fuel in the electrorefiner anode convert to chlorides and accumulate in the $\mathrm{LiCl}-\mathrm{KCl}$ electrolyte. The $\mathrm{Cl}$ needed to form the salts comes from reaction with $\mathrm{UCl}_{3}$ and the uranium is reduced to metal at the anode. The electrorefining process model calculates changes in the molten salt electrolyte composition in the unit as additional batches of spent fuel are treated. When certain limits are reached, such as total salt volume, concentration of fission products in the salt, or concentration of sodium in the salt, the operational logic of the electrorefining unit model determines the amount of molten salt electrolyte to be withdrawn while adding $\mathrm{LiCl}$ and/or $\mathrm{KCl}$ to the electrolyte in order to maintain the minimum volume and reduce the concentration of sodium and fission products. The process model for electrorefining also determines the type of cathode to be produced, depending on the ratio of actinide chlorides in the molten-salt electrolyte. The solid cathode operation is a simple process model since the main product deposited to the cathode is uranium. On the other hand, liquid cathode operation presents a rather complicated product deposition mechanism, which is the focus of current modeling efforts.

Actinide Drawdown Process. The actinide drawdown process separates the actinides (U, Np, $\mathrm{Pu}, \mathrm{Am}$, $\mathrm{Cm})$ from the salt. In the electro-refiner (ER) salt, they are present in the form of chlorides $\left(\mathrm{UCl}_{3}, \mathrm{PuCl}_{3}\right.$, etc.). Actinide drawdown is calculated based on a simple assumption that a specified percentage of the actinides, which will be determined by experiments, can be removed from the salt. The technology for 
achieving this drawdown is currently in the early testing phase, but will likely involve either electrolysis or chemical reduction with an active metal such as lithium or calcium.

Partitioned-Metal Fission Product Ion Exchange Process and Ceramic Waste Process. A specified amount of zeolite is immersed in a molten pool of salt and allowed to reach equilibrium by exchanging cations with the salt via an ion exchange process. It has been found that fission products tend to have a higher affinity for the zeolite than does lithium and potassium. Thus, most of the $\mathrm{LiCl}-\mathrm{KCl}$ can be recycled to the electrorefiner, while the fission products are concentrated in the zeolite. The current ion exchange process model uses a published equilibrium model to calculate the final compositions of salt-loaded zeolite and the remaining salt in the bulk. Since experimental ion exchange studies are still in progress, parameters for some cations are assumed to be the same as parameters for similar cations. The operation logic is to recycle as much as possible while it meets the constraint on the salt volume limit of electrorefiner. The amount of bulk salt that cannot be recycled due to the salt volume constraint is sent, along with the saltabsorbed zeolite, to the fission product ceramic waste process model, in which they are mixed with zeolite and glass in the mass ratios characteristic of the glass-bonded sodalite ceramic waste form.

As noted before, some unit operations in the electrochemical separations process are not yet included in the process model. Specifically, head-end operation of fuel chopping, off-gas treatment processes associated with fuel chopping, chlorination of the heavy metal recovered from drawdown to replenish the actinide chloride concentration in the electrorefiner salt, and processing of the metal waste have not yet been modeled. Models for each of these processes will be developed as funding allows so that a comprehensive model can be created that will allow optimization of all of the recycle streams and minimization of all the waste forms. Also, modeling the mechanisms for carryover of impurities during specific unit operations will be included.

\subsubsection{Fuel Fabrication (Oxide)}

The Transmutation Fuels Campaign is working to reduce the number of powder preparation processes required to form oxide fuel pellets and developing new approaches to pellet sintering to minimize the dust loss and required sintered pellet recycle losses in the oxide fuel fabrication process. Materials to replace existing binders and lubricants or eliminate their need in the process are also beginning to move forward.

Oxide fuel feed conditioning development is also essential, but cannot reasonably begin until separated product source materials become available. (This is an open issue as no plan is currently in place to establish the aqueous separations infrastructure capable of supplying separated product source materials, and no hot cell space is currently available to do the required testing if/when source material becomes available.)

An assessment of potential sources of all elements during fuel fabrication or fuel irradiation (corrosion/erosion or chemical addition) should be started.

The relative impact of initial lanthanides versus lanthanides produced in-situ requires continued examination.

\subsubsection{Fuel Fabrication (Metal)}

The Transmutation Fuels Campaign effort is working to replace the metal casting technology used in the 1960s with new bottom-pour technology with reusable molds. These changes, if successful, would eliminate most of the sources of scrap in the metal fuel fabrication process. Development of a formed metal fuel is being discussed, but such development has not yet been initiated.

Fuel cladding development for both metal and oxide fuel is being pursued in parallel with fuel development. Cladding composition development for long life and use of a highly corrosion-resistant inner cladding sleeves or coatings are being investigated with the goal of significantly increasing cladding longevity and eliminating cladding failure as a limitation on fuel burnup. 


\subsubsection{Transmutation Fuels Campaign Goals}

The Transmutation Fuels Campaign is working to transform the metal, ceramic, and dispersion fuel systems for transmutation fuels. The Transmutation Fuels Campaign is responsible for developing and qualifying fuel form(s) that can be used in destroying the TRU elements in the spent nuclear fuel (SNF). Transmutation fuel is generically defined as fuel forms containing TRU elements and encased in a cladding material that can sustain high-burnups. The TRU elements targeted for destruction are Plutonium $(\mathrm{Pu})$, Neptunium $(\mathrm{Np})$, Americium $(\mathrm{Am})$, and Curium $(\mathrm{Cm})$. Note that if $\mathrm{Cm}$ can be easily separated from the other TRU elements, the preferred method to deal with $\mathrm{Cm}$ is to let it decay to $\mathrm{Pu}$ and then transmute the decay product. However, a simple partitioning technology does not currently exist; therefore, it is assumed that $\mathrm{Cm}$ will be included in the transmutation fuel.

For the baseline approach, the Transmutation Fuels Campaign develops and qualifies transmutation fuels for fast reactors. The transmutation fuel can be designed to contain all the TRU elements together to be used in a fast reactor with a homogeneous core. Depending upon the separations and partitioning strategy, the transmutation objectives can also be achieved by two different types of fuels that can be used in a heterogeneous design. The driver fuel can be designed to contain Pu and perhaps Np blended with U. Minor actinides (primarily Am and possibly Np and Cm, depending upon the partitioning strategy) can be incorporated into secondary fuel (also referred to as minor actinide targets).

Achieving the goals of the Transmutation Fuels Campaign involves a variety of major thrusts that approach metal, oxide, carbide, and dispersion fuel and cladding issues from multiple directions. The following major thrusts are being pursued:

1. Innovative Fuel Design. A task looking at new methods to design composite dispersion fuels with microstructural properties targeted to provide specific desired performance characteristics.

2. Innovative Fabrication Techniques. Improving microstructures, minimizing unit processes, and evaluating strategic additives to improve fuel irradiation behavior.

3. Feedstock Preparation and Characterization. The development of high purity feed materials for use in the preparation of fuels and materials for irradiation testing. This task includes characterization and continued improvement of feedstock conditioning methods.

4. Characterization of Fresh Fuel Samples. Detailed characterization efforts to determine exact characteristics of as-fabricated fuel materials prior to irradiation with emphasis on microstructures, impurities distribution, and localized properties.

5. Cladding Materials Development. Development of innovative cladding materials to achieve high burnup in the fuels regardless of lanthanide content. Task includes microstructural design, effects of additives on clad performance, and sample preparation for irradiation testing.

6. Irradiation Experiments. Focuses on providing irradiation support for fabricated sample materials in an appropriate irradiation spectrum, including international testing where appropriate.

7. Post Irradiation Examination. Focuses on the examination of irradiated fuel samples and also legacy samples from earlier test programs to obtain useful data for fuel and cladding development and design. Includes the data analysis functions.

8. Out of Pile Testing. Experimental design for assessing targeted phenomenology using external neutron sources, ion beam irradiations, or thermal and/or stress gradient simulations outside a reactor.

9. Phase Field Theory development for Fuels and Cladding. This task involves developing the theoretical basis for closure of phase field equations concurrently with the transport equations defining behavior of fuels and cladding materials in reactor service. 
10. Innovative and Additional Characterization Techniques. Development of the new techniques necessary to measure fuel properties as the micron and submicron scale to better predict behavior.

11. Design of Instrumented Irradiation Experiments. Design task for test trains that are capable of providing irradiation data feedback to the Transmutation Fuels Campaign during the irradiation testing of fuels.

12. In-Pile Instrumentation Development. Task aimed at developing new and novel instrumentation techniques to obtain data while fuel is being irradiated. Early focus is on instruments that can provide short-term data on the fuel as it initially changes due to irradiation.

13. Fuel Fabrication Simulator. Task aimed at developing a mechanistic model that simulates fuel fabrication processes at large scale to determine issues and opportunities for improvement.

14. Fuel Development and Design Interfaces. Task aimed at working with separations and reactor Campaigns to optimize nuclear material, fuel product, data transfer, NMC\&A, and records interfaces that may affect fuel design or manufacturing approaches.

\subsubsection{Fuel Performance}

Neutron capture and atom displacement analyses will be required for whatever cases are to be considered. An element-by-element treatment of sources and sinks will be required, with the objective to determine overall mass balance and fuel performance penalties from neutron capture and atom displacement.

Finally, fuel performance impurity impact mitigation options require analysis for whatever cases are to be considered (increase TRU content in fuel, lower fuel residence time, etc.).

\subsubsection{Waste Management}

The Separations Campaign is planning to include a focus on alternative waste forms, compared to borosilicate glass that has been assumed in most prior HLW repository loading studies. Alternative waste forms such as glass ceramics, monozites, cermets, Vycor, and Epsilon metal may have capabilities for higher waste loadings than borosilicate glass, and still maintain acceptable durability. Higher waste loadings can increase the repository loading, perhaps to values higher than assumed thus far in the losses study.

\subsubsection{Integration}

The SLAM model and the information gained from the other areas above must be integrated. 


\section{REFERENCES}

Bathke, C., et al, 2009, The Attractiveness of Materials in Advanced Nuclear Fuel Cycles for Various Proliferation and Theft Scenarios, Proceedings of GLOBAL 2009, Paris, France, Paper 9544, September 6-11, 2009.

Bays, S., Piet S., et al, 2009, Transmutation Dynamics: Impacts of Multi-Recycling on Fuel Cycle Performances, Advanced Fuel Cycle Initiative, AFCI-SYSA-PMO-MI-DV-2009-000185, INL/EXT-09-16857, September 2009.

Bjornard, T., et al, 2009, Safeguards-by-Design: Early Integration of Physical Protection and Safeguardability into Design of Nuclear Facilities, Proceedings of GLOBAL 2009, Paris, France, Paper 9518, September 6-11, 2009.

DOE 2009, Management of Nuclear Materials, DOE Order 410.2, U.S. Department of Energy, August 17 , 2009, http://www.directives.doe.gov/pdfs/doe/doetext/neword/410/04102.pdf, Web page accessed September 25, 2009.

DSARR 2009, Dynamic Systems Analysis Report for Nuclear Fuel Recycle, AFCI Systems Analysis Campaign, GNEP-SYSA-AI-SS-RT-208-000264, May 31, 2008.

Global Nuclear Energy Partnership, 2007, "Product Solidification, Waste Solidification, and Off-Gas Unit Operations Mass Balance Basis, Advanced Fuel Cycle Facility Project," GNEP-AFCF-WAST-PC-RT-2007-000332, Rev Draft A, September 27, 2007.

Gombert, Dirk, et al, 2007, “Global Nuclear Energy Partnership Integrated Waste Management Strategy Waste Treatment Baseline Study,” GNEP-WAST-AI-RT-2007-000324, September 2007.

Gombert, D, et.al., 2008, "Combined Waste Form Cost Trade Study," GNEP-SYSA-PMO-MI-DV-2009000003, November 2008.

Goodman, M., Scheinman, A., Sprinkle, J., A Nonproliferation Impact Assessment of the GNEP Alternatives, Los Alamos National Laboratory, LA-UR-09-03011, Proceedings of GLOBAL 2009, Paris, France, Paper 9476, September 6-11, 2009.

Hoffman, E.A., 2009, “ANL AFCI Transmutation Studies,” ANL-AFCI-271, August 31, 2009.

Jones, R. L. Jr., 2007a, "Engineering Alternative Studies for Separations, Waste Generation Forecast and Characterization Study,” WH-G-ESR-G-00022, Revision 0, Savannah River Site, June 2007.

Jones, R. L. Jr., 2007b, "Engineering Alternative Studies for Separations, Waste Generation Forecast and Characterization Study - 800 MT/year UREX+1A," WH-G-ESR-G-00051, Revision B, Savannah River Site, July 2007.

Shropshire, D. E., Williams, K., et al., 2008, Advanced Fuel Cycle Cost Basis, INL/EXT-07-12107, March 2008.

Shropshire, D., Williams, K., Hoffman, E., et al, 2009, “Advanced Fuel Cycle Economic Analysis of Symbiotic Light-Water Reactor and Fast Burner Reactor Systems,” INL/EXT-09-15254, January 2009.

Soelberg, N., et al, 2009, "Heat Management Strategy Trade Study," Advanced Fuel Cycle Initiative, AFCI-SYSA-PMO-MI-DV-2009-000169, INL/EXT-09-16708, September 2009. 


\section{Appendix A}

\section{Data from Transmutation Reactivity Screening Analysis}




\section{Appendix A \\ Data from Transmutation Reactivity Screening Analysis}

\section{A-1. Fuel and Reactor Choice (Fast versus Thermal Spectrum Reactors)}

Although it is possible from the physics standpoint to repeatedly recycle $\mathrm{Pu}, \mathrm{NpPu}, \mathrm{NpPuAm}$, or even all TRU elements in either thermal or fast reactors (Bays 2009), there are important fundamental differences.

A nuclear fuel ultimately requires that the production of neutrons by fission is balanced by neutron absorption, which includes neutrons causing fission, neutrons being captured, and neutrons leaking from the reactor. So to understand types of reactors, we discuss the probability of a neutron causing fission, probability of neutron being captured, and the overall neutron balance.

Figure A1-1 shows the 1-group fission cross section, which is a measure of the likelihood of fission occurring. The isotopes on the left are called "fertile." They cannot directly sustain a fission reaction in a thermal reactor; the probability of fission is low in either thermal or fast reactors as shown in the figure. The isotopes on the right are called "fissile." They can sustain a fission reaction in either a thermal or fast reactor; their fission probabilities are higher than the fertile isotopes. Note also that their fission probability is quite higher in thermal than fast. This means that more neutrons must be active in a fast reactor to achieve the same power output as a thermal reactor, as fission probability times the number of neutrons determines power.

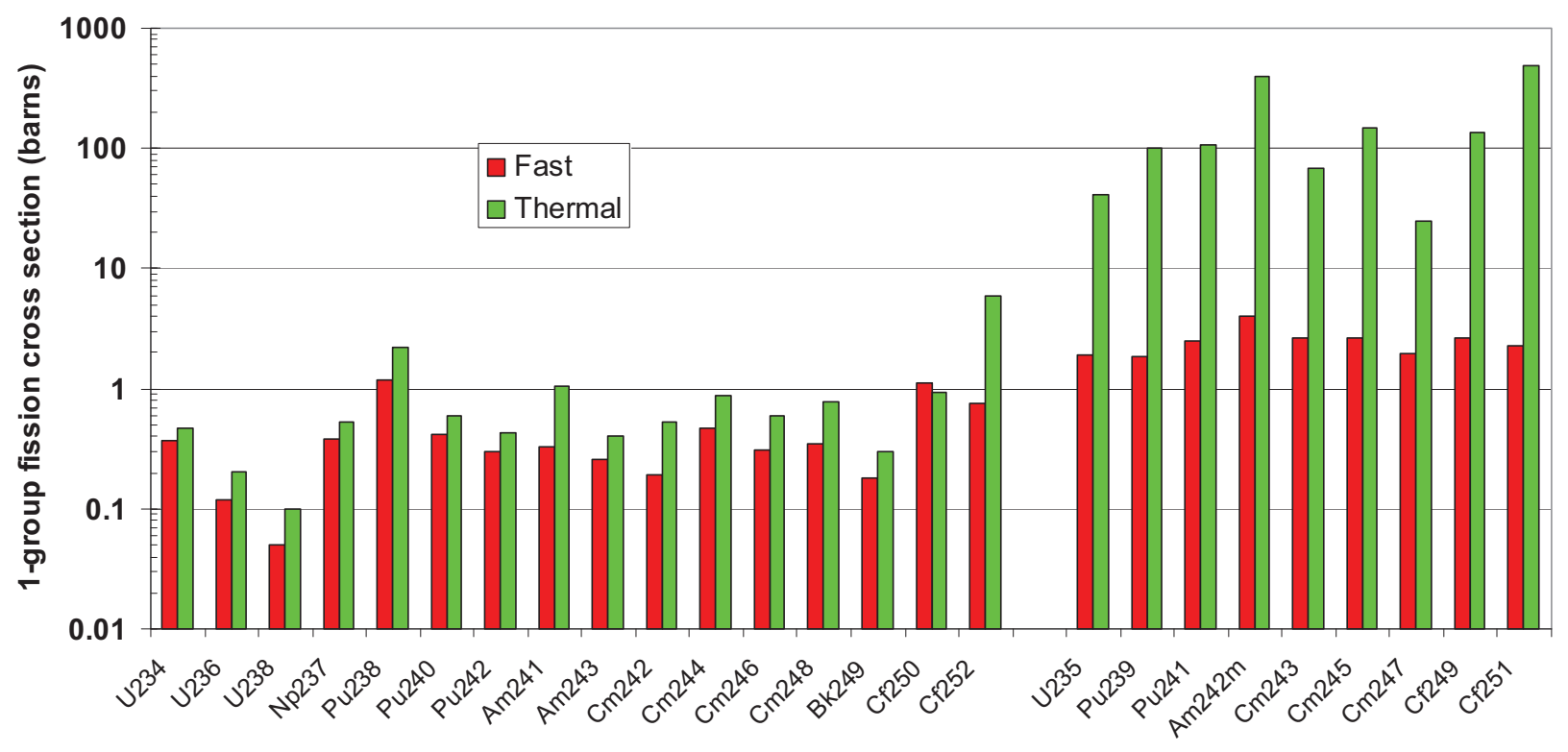

Figure A1-1. Probability of fission with fertile (left) and fissile (right) isotopes. 
Figure A1-2 shows the probability of an isotope capturing a neutron. This "wastes" the neutron in the sense that the neutron is gone without producing another fission. Upon absorbing a neutron, the isotope turns into another actinide isotope. Often, a fertile isotope turns into a fissile isotope and a fissile isotope turns into a fertile one. The figure shows that there is no consistent pattern between fertile and fissile isotopes, but all the capture probabilities in fast reactors are much lower than in thermal reactors. This is why fast reactors are considered more neutron-efficient in the sense that the probability of neutrons causing fission instead of being "wasted" via neutron capture is much higher.

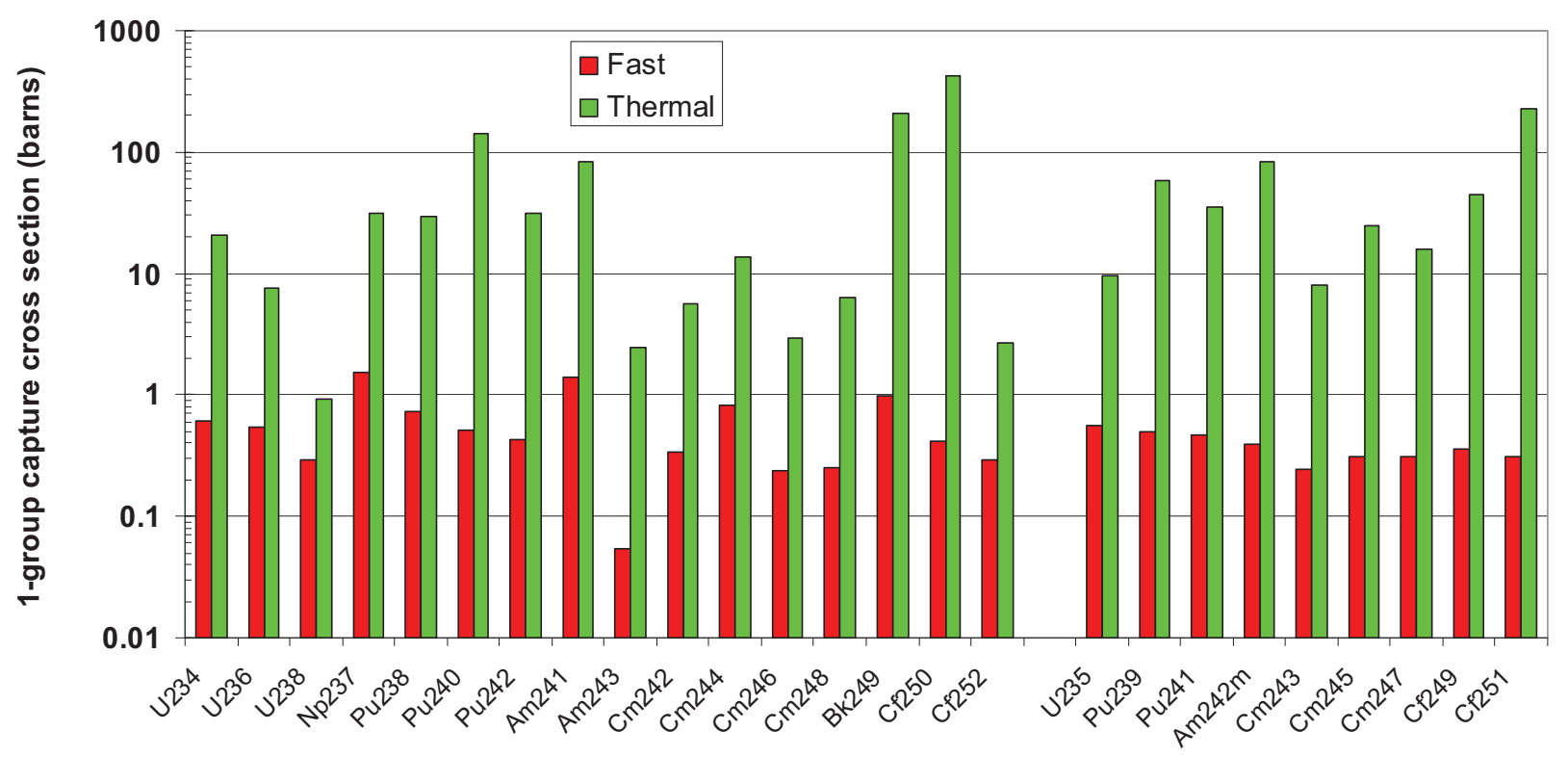

Figure A1-2. Probability of neutron capture with fertile (left) and fissile (right) isotopes.

When an isotope fissions, it produces 2.5-3.5 neutrons, this parameter of neutrons per fission is called "nu." Ignoring neutron leakage, the condition for neutron balance is that the ratio of nu times fission (production) divided by fission+capture (loss) is greater than 1 . Since several percent of neutrons will leak or be captured by non-fuel materials, this ratio must be several percent higher than 1. Figure A1-3 shows this ratio. All of the fissile isotopes have ratios over 1.8, and therefore can sustain fission in either thermal or fast reactors. Of fertile isotopes, only $\mathrm{Cf}-252$ has a ratio over 1 and cannot sustain fission in a thermal reactor. (Cf-252 is a rare, short-lived isotope that is extremely difficult to handle and is not a practical fuel.) Some of the fertile isotopes do have a ratio over 1 in a fast spectrum. 


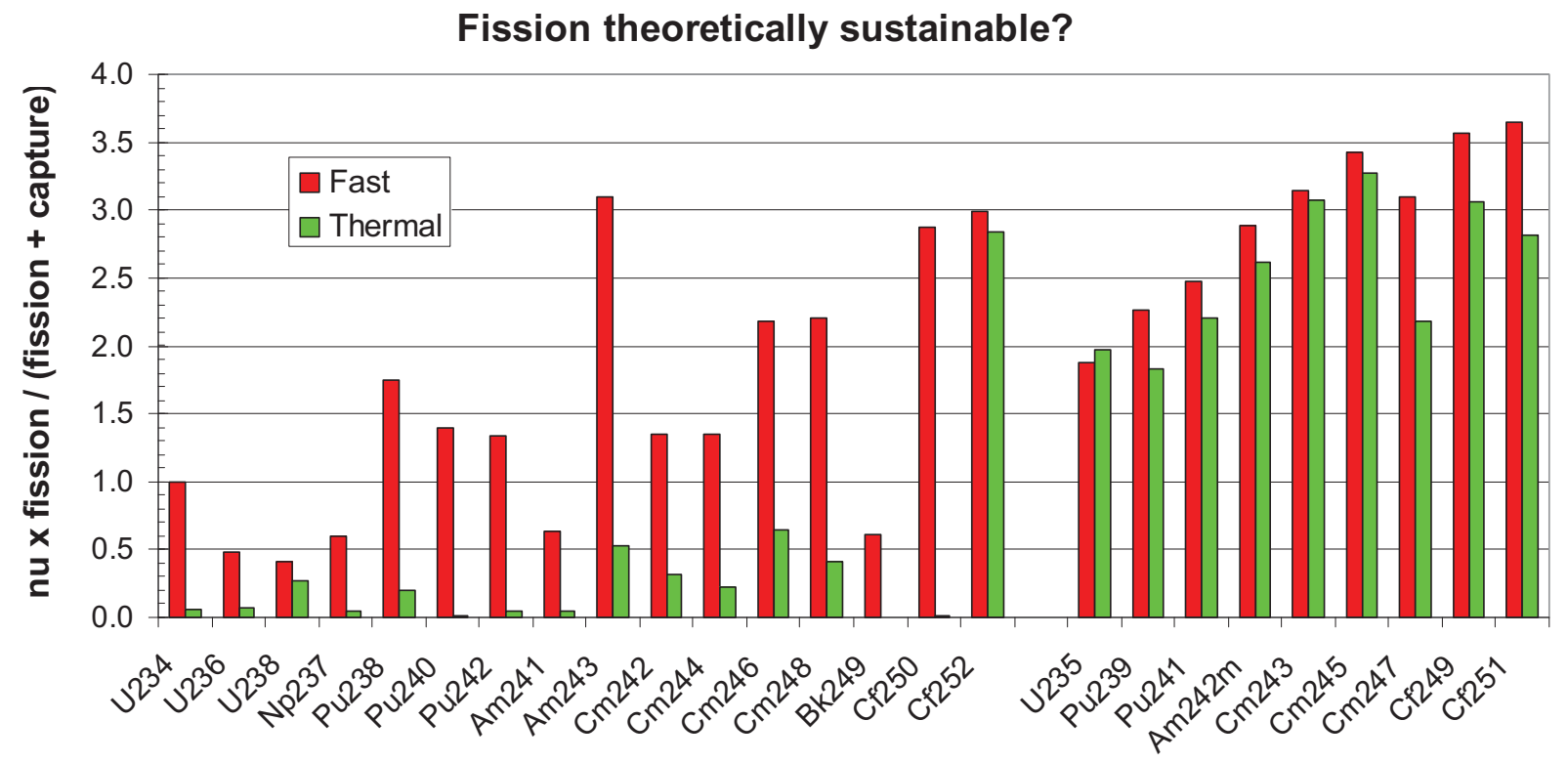

Figure A1-3. Best-case neutron production divided by best-case neutron loss with fertile (left) and fissile (right) isotopes.

Fissile isotopes are more valuable as fuel and can sustain fission in either fast or thermal reactors. The most important fissile isotopes because of their availability are U-235 (only fissile isotope in nature), $\mathrm{Pu}-239$, and $\mathrm{Pu}-241$. U-235 and $\mathrm{Pu}-239$ are long-lived, but Pu-241 has a half-life of 14.4 years, so plutonium-based fuels are perishable. Because there is only one fissile isotope in nature and it is a small fraction of its element (U-235 at $0.7 \%$ of natural uranium), all fuel cycles involve one or both of the two fertile isotopes that occur in nature, U-238 (99.3\% of natural uranium) or Th-232 (100\% of natural thorium). These fertile isotopes then transmute to fissile isotopes, Pu-239 from U-238 or U-233 from Th238. This transmutation of fertile to fissile is true whether material is recycled or not (e.g., the current conventional once-through uranium fuel cycle starts with fuel that is $\sim 4.3 \%$ enriched in U-235 [hence $95.7 \% \mathrm{U}-238]$ ), but by the time the fuel is removed from the reactor a significant fraction of fissions is coming from Pu-239 that was created from the initial U-238. U-Pu fuel cycles (built on U-238 to Pu-239) have received the most attention in large part because the alternative Th-U fuel cycle (built on Th-232 to U-233) requires chemical engineering for two natural resource elements (Th for Th-232 and U for U-235) instead of one ( $U$ for both U-238 and U-235). Nonetheless, Th-U remains an option and all the issues posed in this study for the U-Pu fuel cycles have analogs in the Th-U option space. We have done no quantitative estimates for fuel impurity ramifications in the Th-U option space, but there is little reason to believe that they would be radically different than for U-Pu

\section{A-2. Transmutation Reactivity Screening Analysis}

The fission product production, neutron capture, and differential reactivity were examined for fast reactor metal fuel $(\mathrm{CR}=0.50)$, fast reactor oxide fuel $(\mathrm{CR}=0.50)$, and LWR MOX-Pu. Differential reactivity was calculated elsewhere (Hoffman 2009) to include both neutron capture and displacement of fuel atoms by non-fuel atoms. Current Transmutation Fuels Campaign working limits were extended by chemical element analogy to all elements from $\mathrm{H}$ to Th and Fuel limits for groups of elements were evenly divided among elements in that group for exploratory assessments. The fission yield of elements Se through Dy is sufficiently high that they must be removed before subsequent recycle. The tolerable fraction of these fission products remaining in recycled fuel is lower than $0.1 \%$ for some individual elements; rebalancing the group-element-allocation assumption will even out this result in future work. Work described 
elsewhere (Hoffman 2009) suggests that the upper-bound reactivity impact of impurities (if kept at Transmutation Fuels Campaign working limits) is below 1\% in fast reactors and below 4\% for LWR MOX-Pu. Much of these impacts would be easily overcome, especially the portion caused by fuel atom displacement.

\section{A-2.1 Modification and Interpretation of Transmutation Fuels Campaign Limits for Transmutation Purposes}

The current Transmutation Fuels Campaign working limits on impurities in fast reactor fuels require modification and interpretation before they can be used in system and transmutation analysis because (a) they are defined for TRU feed rather than the fuel itself, (b) they do not cover all elements (i.e., some elements are not explicitly limited), and (c) because most limits are specified for groups of chemically similar elements rather than individual elements. For exploratory analysis, it is inappropriate to include zero amounts of elements without specified limits and elements that are chemically similar are not necessarily neutronically similar. So, the current Transmutation Fuels Campaign working limits were extended by chemical element analogy to all elements from $\mathrm{H}$ to Th and those limits for groups of elements were evenly divided among elements in that group for exploratory assessments.

There are five steps involved in converting the fuel impurity limits into data that may be used in the transmutation analysis.

1. Obtain Transmutation Fuels Campaign working limits

2. Allocate limits for grouped elements (e.g., all lanthanides) to individual elements

3. Extend limits to all chemical elements

4. Convert limits on feedstock to fuel

5. Multiply adjusted limits by weighting factors (differential reactivity and neutron capture cross sections).

Table A2-1 lists the working limits from the Transmutation Fuels Campaign, but reorganized into atomic number order. Cells shaded green are not limited. Most of the limited elements are covered by "group limits" such as the metal fuel limit on $\mathrm{C}+\mathrm{N}+\mathrm{O}+\mathrm{Si}$, which together must stay below $2000 \mathrm{ppm}$. Note that the sum of individual element limits does not match the "total impurity" limit also provided.

Transmutation/fuel value analysis has no mechanism to use the total impurity limit values, except as a sanity check against the sum of individual limits.

Table A2-1. Working Transmutation Fuels Campaign limits on TRU feedstock into fuel fabrication.

\begin{tabular}{|c|c|c|c|c|c|}
\hline & Fuel & Oxide & Metal & Oxide & Metal \\
\hline & & \multicolumn{2}{|c|}{$\begin{array}{l}\text { Limit (ppm of TRU } \\
\text { feedstock) }\end{array}$} & \multicolumn{2}{|c|}{ Rationale for Transmutation Fuels Campaign Limit } \\
\hline 1 & $\mathrm{H}$ & & & & \\
\hline 2 & $\mathrm{He}$ & & & & \\
\hline 3 & $\mathrm{Li}$ & Unknown & & \multicolumn{2}{|c|}{ Value lass than $\mathrm{Na}, \mathrm{K}$ is not understood. Input needed. } \\
\hline 4 & $\mathrm{Be}$ & Limit $\mathrm{O} 1$ & & See Al & \\
\hline 5 & $\mathrm{~B}$ & 40 & & & \\
\hline 6 & $\mathrm{C}$ & Limit $\mathrm{O} 2$ & Limit M1 & \multirow{2}{*}{$\begin{array}{l}\text { Restricted to prevent } \\
\text { issues with control of } \\
\text { O:M ratio during } \\
\text { fabrication }\end{array}$} & \multirow{3}{*}{$\begin{array}{l}\text { Restricted to minimize } \\
\text { interaction with fuel alloy } \\
\text { components. Si is especially } \\
\text { problematic in combination } \\
\text { with } \mathrm{Zr} \text {. }\end{array}$} \\
\hline 7 & $\mathrm{~N}$ & Limit O2 & Limit M1 & & \\
\hline 8 & $\mathrm{O}$ & & Limit M1 & & \\
\hline
\end{tabular}




\begin{tabular}{|c|c|c|c|c|c|}
\hline & Fuel & Oxide & Metal & Oxide & Metal \\
\hline & & \multicolumn{2}{|c|}{$\begin{array}{l}\text { Limit (ppm of TRU } \\
\text { feedstock) }\end{array}$} & \multicolumn{2}{|c|}{ Rationale for Transmutation Fuels Campaign Limit } \\
\hline 9 & $\mathrm{~F}$ & Limit $\mathrm{O} 3$ & Limit M2 & $\begin{array}{l}\text { Halogens are restricted } \\
\text { to prevent fuel cladding } \\
\text { corrosion }\end{array}$ & $\begin{array}{l}\text { Halogens are restricted to } \\
\text { prevent fuel cladding } \\
\text { corrosion }\end{array}$ \\
\hline 10 & $\mathrm{Ne}$ & & & & \\
\hline 11 & $\mathrm{Na}$ & Limit O4 & & \multicolumn{2}{|c|}{$\begin{array}{l}\text { Reactive metals that form compounds oxides, which can } \\
\text { melt or decompose at temperatures below the fuel } \\
\text { sintering temperature causing issues in fabrication. }\end{array}$} \\
\hline 12 & $\mathrm{Mg}$ & Limit $\mathrm{O} 1$ & & \multicolumn{2}{|c|}{$\begin{array}{l}\text { Aluminum is a liquid metal embrittlement agent on fuel } \\
\text { cladding. Others displace fissile content. }\end{array}$} \\
\hline 13 & $\mathrm{Al}$ & Limit 01 & Limit M3 & & $\begin{array}{l}\text { Transition metals form } \\
\text { undesirable intermetallics in } \\
\text { the fuel and affect the total } \\
\text { impurities displacing fissile } \\
\text { content. }\end{array}$ \\
\hline 14 & $\mathrm{Si}$ & Limit 01 & Limit M1 & & Same as $\mathrm{C}, \mathrm{N}, \mathrm{O}$ \\
\hline 15 & $\mathrm{P}$ & Limit O5 & & \multicolumn{2}{|c|}{$\begin{array}{l}\text { Elements form unstable low melting point compounds } \\
\text { increasing the difficulty in fabrication. }\end{array}$} \\
\hline 16 & $\mathrm{~S}$ & Limit $\mathrm{O5}$ & & & \\
\hline 17 & $\mathrm{Cl}$ & Limit $\mathrm{O} 3$ & Limit M2 & See $F$ (Halogen limit) & See F (Halogen limit) \\
\hline 18 & $\mathrm{Ar}$ & & & & \\
\hline 19 & $\mathrm{~K}$ & Limit $\mathrm{O} 4$ & & See $\mathrm{Na}$ & \\
\hline 20 & $\mathrm{Ca}$ & Limit 01 & & See Al & \\
\hline 21 & $\mathrm{Sc}$ & & & & \\
\hline 22 & $\mathrm{Ti}$ & Limit O6 & & \multicolumn{2}{|c|}{$\begin{array}{l}\text { Transition metals form undesirable oxides in the fuel and } \\
\text { affect the total impurities displacing fissile content. }\end{array}$} \\
\hline 23 & V & Limit $\mathrm{O} 6$ & & See Ti & \\
\hline 24 & $\mathrm{Cr}$ & Limit $\mathrm{O} 7$ & Limit M3 & $\begin{array}{l}\text { Transition metals form } \\
\text { undesirable } \\
\text { intermetallics in the fuel } \\
\text { and affect the total } \\
\text { impurities displacing } \\
\text { fissile content. }\end{array}$ & See Al \\
\hline 25 & $\mathrm{Mn}$ & Limit $\mathrm{O} 6$ & Limit M3 & See Ti & See Al \\
\hline 26 & $\mathrm{Fe}$ & Limit $\mathrm{O} 7$ & Limit M3 & See $\mathrm{Cr}$ & See Al \\
\hline 27 & Co & Limit 06 & & See Ti & \\
\hline 28 & $\mathrm{Ni}$ & Limit $\mathrm{O} 7$ & Limit M3 & See $\mathrm{Cr}$ & See Al \\
\hline 29 & $\mathrm{Cu}$ & Limit $\mathrm{O} 6$ & & See Ti & \\
\hline
\end{tabular}




\begin{tabular}{|c|c|c|c|c|c|}
\hline & Fuel & Oxide & Metal & Oxide & Metal \\
\hline & & \multicolumn{2}{|c|}{$\begin{array}{l}\text { Limit (ppm of TRU } \\
\text { feedstock) }\end{array}$} & \multicolumn{2}{|c|}{ Rationale for Transmutation Fuels Campaign Limit } \\
\hline 30 & $\mathrm{Zn}$ & Limit O8 & Limit M3 & $\begin{array}{l}\text { Low melting point metals } \\
\text { that form oxides, which } \\
\text { decompose at } \\
\text { temperatures below the } \\
\text { fuel sintering } \\
\text { temperature causing } \\
\text { issues in fabrication. }\end{array}$ & See Al \\
\hline 31 & $\mathrm{Ga}$ & 200 & & \multicolumn{2}{|c|}{$\begin{array}{l}\text { Liquid metal embrittlement agent. Control for separation } \\
\text { of WG Pu MOX only. }\end{array}$} \\
\hline 32 & $\mathrm{Ge}$ & & & & \\
\hline 33 & As & & & & \\
\hline 34 & $\mathrm{Se}$ & & & & \\
\hline 35 & $\mathrm{Br}$ & & Limit M2 & & See F (Halogen limit) \\
\hline 36 & $\mathrm{Kr}$ & & & & \\
\hline 37 & $\mathrm{Rb}$ & & & & \\
\hline 38 & $\mathrm{Sr}$ & 1000 & & \multicolumn{2}{|c|}{$\begin{array}{l}\text { Tramp fission product. Carryover limited to minimize } \\
\text { displacement of fissile content. }\end{array}$} \\
\hline 39 & $\mathrm{Y}$ & & & & \\
\hline 40 & $\mathrm{Zr}$ & & & & \\
\hline 41 & $\mathrm{Nb}$ & & & & \\
\hline 42 & Mo & Limit $\mathrm{O6}$ & Limit M3 & See Ti & See Al \\
\hline 43 & Tc & & & & \\
\hline 44 & $\mathrm{Ru}$ & 1000 & & \multicolumn{2}{|c|}{$\begin{array}{l}\text { Tramp fission product. Carryover limited to minimize } \\
\text { displacement of fissile content. }\end{array}$} \\
\hline 45 & $\mathrm{Rh}$ & & & & \\
\hline 46 & $\mathrm{Pd}$ & & & & \\
\hline 47 & $\mathrm{Ag}$ & Limit 06 & & See $\mathrm{Ti}$ & \\
\hline 48 & $\mathrm{Cd}$ & Limit O8 & 200 & $\begin{array}{l}\text { Low melting point metals } \\
\text { that form oxides which } \\
\text { decompose at } \\
\text { temperatures below the } \\
\text { fuel sintering } \\
\text { temperature causing } \\
\text { issues in fabrication }\end{array}$ & $\begin{array}{l}\text { Limited carryover from } \\
\text { electrochemical separations }\end{array}$ \\
\hline 49 & $\ln$ & & & & \\
\hline 50 & $\mathrm{Sn}$ & Limit $\mathrm{O} 8$ & & See $\mathrm{Zn}$ & \\
\hline 51 & $\mathrm{Sb}$ & & & & \\
\hline 52 & $\mathrm{Te}$ & & & & \\
\hline 53 & 1 & & Limit M2 & & See F (Halogen limit) \\
\hline 54 & $\mathrm{Xe}$ & & & & \\
\hline 55 & Cs & & & & \\
\hline 56 & $\mathrm{Ba}$ & & & & \\
\hline 57 & $\mathrm{La}$ & Limit O9 & Limit M4 & Elements form oxide & Concentrations of rare earth \\
\hline
\end{tabular}




\begin{tabular}{|c|c|c|c|c|c|}
\hline & Fuel & Oxide & Metal & Oxide & Metal \\
\hline & & \multicolumn{2}{|c|}{$\begin{array}{l}\text { Limit (ppm of TRU } \\
\text { feedstock) }\end{array}$} & \multicolumn{2}{|c|}{ Rationale for Transmutation Fuels Campaign Limit } \\
\hline 58 & $\mathrm{Ce}$ & Limit 09 & Limit M4 & \multirow{3}{*}{$\begin{array}{l}\text { hydrates and oxides that } \\
\text { make control of O:M } \\
\text { ratio difficult in pellet } \\
\text { sintering. }\end{array}$} & \multirow{3}{*}{$\begin{array}{l}\text { elements form low melting } \\
\text { eutectics with fuel cladding. } \\
\text { Rare earth feedstock } \\
\text { impurities are more } \\
\text { detrimental to fuel due to their } \\
\text { lack of dispersion. }\end{array}$} \\
\hline 59 & $\operatorname{Pr}$ & Limit O9 & Limit M4 & & \\
\hline 60 & $\mathrm{Nd}$ & Limit O9 & Limit M4 & & \\
\hline 61 & $\mathrm{Pm}$ & & & & \\
\hline 62 & Sm & Limit $\mathrm{O} 10$ & Limit M4 & \multirow{3}{*}{$\begin{array}{l}\text { Restricted as thermal } \\
\text { neutron resonance } \\
\text { absorbers (poisons). }\end{array}$} & \multirow[t]{10}{*}{ See La (lanthanide limit) } \\
\hline 63 & $\mathrm{Eu}$ & Limit $\mathrm{O} 10$ & Limit M4 & & \\
\hline 64 & $\mathrm{Gd}$ & Limit 010 & Limit M4 & & \\
\hline 65 & $\mathrm{~Tb}$ & & Limit M4 & & \\
\hline 66 & Dy & Limit $\mathrm{O} 10$ & Limit M4 & See Sm & \\
\hline 67 & Ho & & Limit M4 & & \\
\hline 68 & $\mathrm{Er}$ & & Limit M4 & & \\
\hline 69 & $\mathrm{Tm}$ & & Limit M4 & & \\
\hline 70 & $\mathrm{Yb}$ & & Limit M4 & & \\
\hline 71 & Lu & & Limit M4 & & \\
\hline 72 & $\mathrm{Hf}$ & & 100 & & Limited as an impurity to $\mathrm{Zr}$ \\
\hline 73 & $\mathrm{Ta}$ & Limit O6 & & See Ti & \\
\hline 74 & $\mathrm{~W}$ & Limit $\mathrm{O} 6$ & & See Ti & \\
\hline 75 & $\operatorname{Re}$ & & & & \\
\hline 76 & Os & & & & \\
\hline 77 & Ir & & & & \\
\hline 78 & $\mathrm{Pt}$ & & & & \\
\hline 79 & $\mathrm{Au}$ & & & & \\
\hline 80 & $\mathrm{Hg}$ & & & & \\
\hline 81 & $\mathrm{TI}$ & & & & \\
\hline 82 & $\mathrm{~Pb}$ & Limit O8 & & $\begin{array}{l}\text { Low melting point metals } \\
\text { decompose at temperatur } \\
\text { temperature causing issue }\end{array}$ & $\begin{array}{l}\text { nat form oxides, which } \\
\text { s below the fuel sintering } \\
\text { s in fabrication. }\end{array}$ \\
\hline 83 & $\mathrm{Bi}$ & & & & \\
\hline 84 & Po & & & & \\
\hline 85 & At & & & & \\
\hline 86 & $\mathrm{Rn}$ & & & & \\
\hline 87 & $\mathrm{Fr}$ & & & & \\
\hline 88 & $\mathrm{Ra}$ & & & & \\
\hline 89 & $A c$ & & & & \\
\hline 90 & Th & & & & \\
\hline 91 & $\mathrm{~Pa}$ & & & & \\
\hline 92 & $U$ & & & & \\
\hline 93 & $\mathrm{~Np}$ & & & & \\
\hline
\end{tabular}




\begin{tabular}{|c|c|c|c|c|c|c|}
\hline & Fuel & Oxide & Metal & \multicolumn{2}{|c|}{ Oxide } & Metal \\
\hline & & \multicolumn{2}{|c|}{$\begin{array}{l}\text { Limit (ppm of TRU } \\
\text { feedstock) }\end{array}$} & \multicolumn{3}{|c|}{ Rationale for Transmutation Fuels Campaign Limit } \\
\hline 94 & $\mathrm{Pu}$ & & & & & \\
\hline 95 & Am & & & & & \\
\hline 96 & $\mathrm{Cm}$ & & & & & \\
\hline 97 & $\mathrm{Bk}$ & & & & & \\
\hline 98 & $\mathrm{Cf}$ & & & & & \\
\hline \multicolumn{2}{|c|}{$\begin{array}{l}\text { Total of } \\
\text { above } \\
\text { limits }\end{array}$} & 13,540 & 6,600 & & & \\
\hline \multicolumn{2}{|c|}{$\begin{array}{l}\text { Total } \\
\text { impurity } \\
\text { limit per } \\
\text { Transmuta- } \\
\text { tion Fuels } \\
\text { Campaign } \\
\end{array}$} & 10,000 & 10,000 & & & \\
\hline \multicolumn{7}{|c|}{ Oxide "group" limits } \\
\hline \multicolumn{5}{|c|}{$\mathrm{O} 1=\mathrm{Be}, \mathrm{Mg}, \mathrm{Al}, \mathrm{Si}, \mathrm{Ca}$} & 2000 & None $>500$ \\
\hline \multicolumn{5}{|c|}{$\mathrm{O} 2=\mathrm{C}, \mathrm{N}$} & 700 & \\
\hline \multicolumn{5}{|c|}{$\mathrm{O} 3=\mathrm{F}, \mathrm{Cl}$} & 60 & \\
\hline \multicolumn{5}{|c|}{$\mathrm{O} 4=\mathrm{Na}, \mathrm{K}$} & 1400 & None $>500$ or 1000 , respectively \\
\hline \multicolumn{5}{|c|}{$\mathrm{O} 5=\mathrm{P}, \mathrm{S}$} & 800 & None $>300$ or 600 , respectively \\
\hline \multicolumn{5}{|c|}{$\mathrm{O} 6=\mathrm{Ti}, \mathrm{V}, \mathrm{Mn}, \mathrm{Co}, \mathrm{Cu}, \mathrm{Mo}, \mathrm{Ag}, \mathrm{Ta}, \mathrm{W}$} & 2000 & None $>500$ or 1000 , respectively \\
\hline \multicolumn{5}{|c|}{$\mathrm{O} 7=\mathrm{Cr}, \mathrm{Fe}, \mathrm{Ni}$} & 1500 & None $>300$ \\
\hline \multicolumn{5}{|c|}{$\mathrm{O} 8=\mathrm{Zn}, \mathrm{Cd}, \mathrm{Sn}, \mathrm{Pb}$} & 440 & None $>100$ or 200 , respectively \\
\hline \multicolumn{5}{|c|}{$\mathrm{O} 9=\mathrm{La}, \mathrm{Ce}, \mathrm{Pr}, \mathrm{Nd}, \mathrm{Sm}$} & 2000 & \\
\hline \multicolumn{5}{|c|}{$\mathrm{O} 10=\mathrm{Sm}, \mathrm{Eu}, \mathrm{Gd}, \mathrm{Dy}$} & 400 & \\
\hline \multicolumn{7}{|c|}{ Metal "group" limits } \\
\hline \multicolumn{5}{|c|}{$\mathrm{M} 1=\mathrm{C}, \mathrm{N}, \mathrm{O}, \mathrm{Si}$} & 2000 & \\
\hline \multicolumn{5}{|c|}{$\mathrm{M} 2=\mathrm{Br}, \mathrm{Cl}, \mathrm{F}, \mathrm{I}$ (halogens) } & 300 & \\
\hline \multicolumn{5}{|c|}{$\begin{array}{l}\mathrm{M} 3=\mathrm{Al}, \mathrm{Cr}, \mathrm{Mn}, \mathrm{Fe}, \mathrm{Ni}, \mathrm{Zn}, \mathrm{Mo} \text { (transition } \\
\text { metals) }\end{array}$} & 1500 & \\
\hline \multicolumn{5}{|c|}{$\begin{array}{l}\text { M4 = La, Ce, Pr, Nd, Sm, Eu, Gd, Tb, Dy, Ho, Er, } \\
\text { Tm, Yb, Lu (lanthanides) }\end{array}$} & 2500 & \\
\hline
\end{tabular}

Table A2-2 takes the second and third steps-(2) allocating the limit for grouped element evenly among those elements and (3) extending limits to other elements. The color scheme in the table has changed. Black text means the limit comes directly from Table A2-1; red text means the limit is the result of allocation of a group limit. The shade of some cells is color coded: purple for inert gases, pink for Group 1A/2A, and blue for halogens, orange for lanthanides. The two columns for "Step 3" have an assumed limit for all elements from $\mathrm{H}$ to Bi except for inert gases and oxygen for oxide fuel. Recall that two of the elements from $\mathrm{H}$ to Bi do not appear in nature: Tc and Pm. The only source of these elements in TRU feed would be recycling of fission products. 
Table A2-2. Fuel TRU feed limits with group limits allocated among elements.

\begin{tabular}{|c|c|c|c|c|c|}
\hline & Element & $\begin{array}{c}\text { Step } 2 \\
\text { Oxide with } \\
\text { Group Limits } \\
\text { Allocated }\end{array}$ & $\begin{array}{c}\text { Step } 3 \\
\text { Oxide with } \\
\text { Assumptions } \\
\text { Made for Non- } \\
\text { limited } \\
\text { Elements }\end{array}$ & $\begin{array}{c}\text { Step } 2 \\
\text { Metal with } \\
\text { Group Limits } \\
\text { Allocated }\end{array}$ & $\begin{array}{c}\text { Step } 3 \\
\text { Metal with } \\
\text { Assumptions } \\
\text { Made for Non- } \\
\text { limited } \\
\text { Elements }\end{array}$ \\
\hline 1 & $\mathrm{H}$ & 0 & 10 & 0 & 10 \\
\hline 2 & $\mathrm{He}$ & 0 & 0 & 0 & 0 \\
\hline 3 & $\mathrm{Li}$ & 0 & 700 & 0 & 10 \\
\hline 4 & $\mathrm{Be}$ & 400 & 400 & 0 & 10 \\
\hline 5 & $B$ & 40 & 40 & 0 & 10 \\
\hline 6 & C & 350 & 350 & 500 & 500 \\
\hline 7 & $\mathrm{~N}$ & 350 & 350 & 500 & 500 \\
\hline 8 & 0 & 0 & 0 & 500 & 500 \\
\hline 9 & $\mathrm{~F}$ & 30 & 30 & 75 & 75 \\
\hline 10 & $\mathrm{Ne}$ & 0 & 0 & 0 & 0 \\
\hline 11 & $\mathrm{Na}$ & 700 & 700 & 0 & 10 \\
\hline 12 & $\mathrm{Mg}$ & 400 & 400 & 0 & 10 \\
\hline 13 & $\mathrm{Al}$ & 400 & 400 & 214 & 214 \\
\hline 14 & $\mathrm{Si}$ & 400 & 400 & 500 & 500 \\
\hline 15 & $\mathrm{P}$ & 400 & 400 & 0 & 10 \\
\hline 16 & $S$ & 400 & 400 & 0 & 10 \\
\hline 17 & $\mathrm{Cl}$ & 30 & 30 & 75 & 75 \\
\hline 18 & $\mathrm{Ar}$ & 0 & 0 & 0 & 0 \\
\hline 19 & $\mathrm{~K}$ & 700 & 700 & 0 & 10 \\
\hline 20 & $\mathrm{Ca}$ & 400 & 400 & 0 & 10 \\
\hline 21 & Sc & 0 & 100 & 0 & 10 \\
\hline 22 & $\mathrm{Ti}$ & 222 & 222 & 0 & 10 \\
\hline 23 & $\mathrm{~V}$ & 222 & 222 & 0 & 10 \\
\hline 24 & $\mathrm{Cr}$ & 500 & 500 & 214 & 214 \\
\hline 25 & $\mathrm{Mn}$ & 222 & 222 & 214 & 214 \\
\hline 26 & $\mathrm{Fe}$ & 500 & 500 & 214 & 214 \\
\hline 27 & Co & 222 & 222 & 0 & 214 \\
\hline 28 & $\mathrm{Ni}$ & 500 & 500 & 214 & 214 \\
\hline 29 & $\mathrm{Cu}$ & 222 & 222 & 0 & 214 \\
\hline 30 & $\mathrm{Zn}$ & 110 & 110 & 214 & 214 \\
\hline 31 & $\mathrm{Ga}$ & 200 & 200 & 0 & 214 \\
\hline 32 & $\mathrm{Ge}$ & 0 & 200 & 0 & 214 \\
\hline 33 & As & 0 & 200 & 0 & 214 \\
\hline 34 & $\mathrm{Se}$ & 0 & 200 & 0 & 214 \\
\hline 35 & $\mathrm{Br}$ & 0 & 10 & 75 & 75 \\
\hline 36 & $\mathrm{Kr}$ & 0 & 0 & 0 & 0 \\
\hline 37 & $\mathrm{Rb}$ & 0 & 700 & 0 & 100 \\
\hline 38 & $\mathrm{Sr}$ & 1000 & 1,000 & 0 & 100 \\
\hline 39 & $Y$ & 0 & 10 & 0 & 100 \\
\hline 40 & $\mathrm{Zr}$ & 0 & 10 & 0 & 10 \\
\hline 41 & $\mathrm{Nb}$ & 0 & 10 & 0 & 214 \\
\hline
\end{tabular}




\begin{tabular}{|c|c|c|c|c|c|}
\hline & Element & $\begin{array}{c}\text { Step } 2 \\
\text { Oxide with } \\
\text { Group Limits } \\
\text { Allocated }\end{array}$ & $\begin{array}{c}\text { Step } 3 \\
\text { Oxide with } \\
\text { Assumptions } \\
\text { Made for Non- } \\
\text { limited } \\
\text { Elements } \\
\end{array}$ & $\begin{array}{c}\text { Step } 2 \\
\text { Metal with } \\
\text { Group Limits } \\
\text { Allocated }\end{array}$ & $\begin{array}{c}\text { Step } 3 \\
\text { Metal with } \\
\text { Assumptions } \\
\text { Made for Non- } \\
\text { limited } \\
\text { Elements } \\
\end{array}$ \\
\hline 42 & Mo & 222 & 222 & 214 & 214 \\
\hline 43 & Tc & 0 & 10 & 0 & 214 \\
\hline 44 & $\mathrm{Ru}$ & 1000 & 1,000 & 0 & 214 \\
\hline 45 & $\mathrm{Rh}$ & 0 & 10 & 0 & 214 \\
\hline 46 & $\mathrm{Pd}$ & 0 & 10 & 0 & 214 \\
\hline 47 & $\mathrm{Ag}$ & 222 & 222 & 0 & 214 \\
\hline 48 & $\mathrm{Cd}$ & 110 & 110 & 200 & 200 \\
\hline 49 & $\ln$ & 0 & 10 & 0 & 200 \\
\hline 50 & Sn & 110 & 110 & 0 & 200 \\
\hline 51 & $\mathrm{Sb}$ & 0 & 10 & 0 & 200 \\
\hline 52 & $\mathrm{Te}$ & 0 & 10 & 0 & 200 \\
\hline 53 & lodine & 0 & 10 & 75 & 75 \\
\hline 54 & $\mathrm{Xe}$ & 0 & 0 & 0 & 0 \\
\hline 55 & $\mathrm{Cs}$ & 0 & 200 & 0 & 100 \\
\hline 56 & $\mathrm{Ba}$ & 0 & 100 & 0 & 100 \\
\hline 57 & $\mathrm{La}$ & 500 & 500 & 167 & 167 \\
\hline 58 & $\mathrm{Ce}$ & 500 & 500 & 167 & 167 \\
\hline 59 & $\mathrm{Pr}$ & 500 & 500 & 167 & 167 \\
\hline 60 & $\mathrm{Nd}$ & 500 & 500 & 167 & 167 \\
\hline 61 & $\mathrm{Pm}$ & 0 & 500 & 167 & 167 \\
\hline 62 & $\mathrm{Sm}$ & 100 & 100 & 167 & 167 \\
\hline 63 & $\mathrm{Eu}$ & 100 & 100 & 167 & 167 \\
\hline 64 & $\mathrm{Gd}$ & 100 & 100 & 167 & 167 \\
\hline 65 & $\mathrm{~Tb}$ & 0 & 100 & 167 & 167 \\
\hline 66 & Dy & 100 & 100 & 167 & 167 \\
\hline 67 & $\mathrm{Ho}$ & 0 & 100 & 167 & 167 \\
\hline 68 & $\mathrm{Er}$ & 0 & 100 & 167 & 167 \\
\hline 69 & $\mathrm{Tm}$ & 0 & 100 & 167 & 167 \\
\hline 70 & $\mathrm{Yb}$ & 0 & 100 & 167 & 167 \\
\hline 71 & $\mathrm{Lu}$ & 0 & 100 & 167 & 167 \\
\hline 72 & $\mathrm{Hf}$ & 0 & 10 & 100 & 100 \\
\hline 73 & $\mathrm{Ta}$ & 222 & 222 & 0 & 10 \\
\hline 74 & W & 222 & 222 & 0 & 10 \\
\hline 75 & $\mathrm{Re}$ & 0 & 10 & 0 & 10 \\
\hline 76 & Os & 0 & 10 & 0 & 10 \\
\hline 77 & Ir & 0 & 10 & 0 & 10 \\
\hline 78 & $\mathrm{Pt}$ & 0 & 10 & 0 & 10 \\
\hline 79 & $\mathrm{Au}$ & 0 & 10 & 0 & 10 \\
\hline 80 & $\mathrm{Hg}$ & 0 & 10 & 0 & 10 \\
\hline 81 & $\mathrm{TI}$ & 0 & 10 & 0 & 10 \\
\hline 82 & $\mathrm{~Pb}$ & 110 & 110 & 0 & 10 \\
\hline 83 & $\mathrm{Bi}$ & 0 & 10 & 0 & 10 \\
\hline
\end{tabular}




\begin{tabular}{|c|c|c|c|c|}
\hline Element & $\begin{array}{c}\text { Step } 2 \\
\text { Oxide with } \\
\text { Group Limits } \\
\text { Allocated }\end{array}$ & $\begin{array}{c}\text { Step } 3 \\
\text { Oxide with } \\
\text { Assumptions } \\
\text { Made for Non- } \\
\text { limited } \\
\text { Elements }\end{array}$ & $\begin{array}{c}\text { Step } 2 \\
\text { Metal with } \\
\text { Group Limits } \\
\text { Allocated }\end{array}$ & $\begin{array}{c}\text { Step } 3 \\
\text { Metal with } \\
\text { Assumptions } \\
\text { Made for Non- } \\
\text { limited } \\
\text { Elements }\end{array}$ \\
\hline $\begin{array}{l}\text { Total of above } \\
\text { limits }\end{array}$ & 13,540 & 17,260 & 6,600 & 10,751 \\
\hline $\begin{array}{l}\text { Total impurity } \\
\text { limit per } \\
\text { Transmutation } \\
\text { Fuels Campaign }\end{array}$ & 10,000 & 10,000 & 10,000 & 10,000 \\
\hline
\end{tabular}

Table A2-3 takes the fourth step - convert the limits in units of ppm in TRU feedstock ( $\mu$ g-impurity/ $\mathrm{g}$-TRU) to ppm fuel ( $\mu \mathrm{g}$-impurity/g-fuel). This requires an estimate of the TRU content in final fuel, which depends on the TRU conversion ratio. For this study, the nominal CR was 0.50. In the AFCI Transmutation Library, for FR-oxide at $\mathrm{CR}=0.50$, the first recycle is $33.1 \% \mathrm{TRU}$, which must climb to $37.8 \%$ at equilibrium as the recycled TRU isotopes evolve. We used a constant value of $35 \%$. For FR-metal at $\mathrm{CR}=0.50$, the first recycle is $29.4 \%$ TRU climbing to $33.3 \%$ for equilibrium recycle. We used a constant value of $31 \%$.

The underlying assumption by the Transmutation Fuels Campaign is that the $\mathrm{U}$ to be mixed with TRU is much more pure so that the impurities in the final product are dominated by impurities in the TRU feed, not $U$ feed, and the even more basic assumption that the $U$ and TRU feeds are separate. This means that the TRU feed impurity limits are a function of the assumed CR, and hence the assumed TRU/U mixture. E. Shaber ${ }^{\mathrm{e}}$ clarified that the working limits are based on the assumption of $40 \% \mathrm{TRU}$, so that the current application of those limits is slightly conservative (i.e., there would be somewhat more "pure" uranium to dilute impure TRU than assumed by the Transmutation Fuels Campaign).

Table A2-3 also contains two MOX-Pu columns for comparison. One is use of the procedure noted above, but applied to MOX-Pu instead of FR-oxide. MOX-Pu has about 10\% TRU versus 35\% TRU in FR-oxide, so in units of ppm-impurity/fuel the impurity limits are 3.5 times lower than for FR-oxide. The second MOX-Pu column is an industrial cross-check (Meyer 2000).

The values in Table A2-3 were used in subsequent calculations of fuel value.

\footnotetext{
${ }^{\mathrm{e}}$ Based on technical discussions between Eric Shaber and Steve Piet.
} 
Table A2-3. Modified limits on fuel impurities.

\begin{tabular}{|c|c|c|c|c|c|}
\hline & & \multirow{2}{*}{$\begin{array}{c}\text { FR Oxide Fuel (ug/g- } \\
\text { fuel) if } 35 \% \text { TRU } \\
\\
\text { Modified } \\
\text { Transmutation Fuels } \\
\text { Campaign Limits } \\
\end{array}$} & \multicolumn{2}{|c|}{ MOX Fuel (ug/g-fuel) if $10 \%$ TRU } & \multirow{2}{*}{$\begin{array}{c}\text { FR Metal Fuel } \\
\text { (ug/g-fuel) if 31\% TRU } \\
\\
\text { Modified Transmutation } \\
\text { Fuels Campaign Limits }\end{array}$} \\
\hline & & & $\begin{array}{c}\text { Modified } \\
\text { Transmutation } \\
\text { Fuels Campaign } \\
\text { Limits }\end{array}$ & $\begin{array}{l}\text { LWR MOX Spec } \\
\text { from } 2001 \text { Report } \\
\text { (for comparison) }\end{array}$ & \\
\hline 1 & $\mathrm{H}$ & 4 & 1 & 0 & 3 \\
\hline 2 & $\mathrm{He}$ & 0 & 0 & 0 & 0 \\
\hline 3 & $\mathrm{Li}$ & 245 & 70 & 0 & 3 \\
\hline 4 & $\mathrm{Be}$ & 140 & 40 & 0 & 3 \\
\hline 5 & $\mathrm{~B}$ & 14 & 4 & 20 & 3 \\
\hline 6 & $\mathrm{C}$ & 123 & 35 & 100 & 155 \\
\hline 7 & $\mathrm{~N}$ & 123 & 35 & 75 & 155 \\
\hline 8 & $\mathrm{O}$ & 0 & 0 & 0 & 155 \\
\hline 9 & $\mathrm{~F}$ & 11 & 3 & 15 & 23 \\
\hline 10 & $\mathrm{Ne}$ & 0 & 0 & 0 & 0 \\
\hline 11 & $\mathrm{Na}$ & 245 & 70 & 0 & 3 \\
\hline 12 & $\mathrm{Mg}$ & 140 & 40 & 20 & 3 \\
\hline 13 & $\mathrm{Al}$ & 140 & 40 & 250 & 66 \\
\hline 14 & $\mathrm{Si}$ & 140 & 40 & 250 & 155 \\
\hline 15 & $\mathrm{P}$ & 140 & 40 & 0 & 3 \\
\hline 16 & $S$ & 140 & 40 & 0 & 3 \\
\hline 17 & $\mathrm{Cl}$ & 11 & 3 & 25 & 23 \\
\hline 18 & $\mathrm{Ar}$ & 0 & 0 & 0 & 0 \\
\hline 19 & $\mathrm{~K}$ & 245 & 70 & 0 & 3 \\
\hline 20 & $\mathrm{Ca}$ & 140 & 40 & 20 & 3 \\
\hline 21 & $\mathrm{Sc}$ & 35 & 10 & 0 & 3 \\
\hline 22 & $\mathrm{Ti}$ & 78 & 22 & 20 & 3 \\
\hline 23 & $\mathrm{~V}$ & 78 & 22 & 0 & 3 \\
\hline 24 & $\mathrm{Cr}$ & 175 & 50 & 20 & 66 \\
\hline 25 & $\mathrm{Mn}$ & 78 & 22 & 0 & 66 \\
\hline 26 & $\mathrm{Fe}$ & 175 & 50 & 500 & 66 \\
\hline 27 & $\mathrm{Co}$ & 78 & 22 & 0 & 66 \\
\hline 28 & $\mathrm{Ni}$ & 175 & 50 & 20 & 66 \\
\hline 29 & $\mathrm{Cu}$ & 78 & 22 & 0 & 66 \\
\hline 30 & $\mathrm{Zn}$ & 39 & 11 & 20 & 66 \\
\hline 31 & $\mathrm{Ga}$ & 70 & 20 & 0 & 66 \\
\hline 32 & $\mathrm{Ge}$ & 70 & 20 & 0 & 66 \\
\hline 33 & As & 70 & 20 & 0 & 66 \\
\hline 34 & $\mathrm{Se}$ & 70 & 20 & 0 & 66 \\
\hline 35 & $\mathrm{Br}$ & 4 & 1 & 0 & 23 \\
\hline 36 & $\mathrm{Kr}$ & 0 & 0 & 0 & 0 \\
\hline 37 & $\mathrm{Rb}$ & 245 & 70 & 0 & 31 \\
\hline 38 & $\mathrm{Sr}$ & 350 & 100 & 0 & 31 \\
\hline 39 & $\mathrm{Y}$ & 4 & 1 & 10 & 31 \\
\hline 40 & $\mathrm{Zr}$ & 4 & 1 & 0 & 3 \\
\hline 41 & $\mathrm{Nb}$ & 4 & 1 & 0 & 66 \\
\hline 42 & Mo & 78 & 22 & 20 & 66 \\
\hline
\end{tabular}




\begin{tabular}{|c|c|c|c|c|c|}
\hline & & \multirow{2}{*}{$\begin{array}{c}\text { FR Oxide Fuel (ug/g- } \\
\text { fuel) if } 35 \% \text { TRU } \\
\\
\text { Modified } \\
\text { Transmutation Fuels } \\
\text { Campaign Limits } \\
\end{array}$} & \multicolumn{2}{|c|}{ MOX Fuel (ug/g-fuel) if $10 \%$ TRU } & \multirow{2}{*}{$\begin{array}{c}\text { FR Metal Fuel } \\
\text { (ug/g-fuel) if 31\% TRU } \\
\\
\text { Modified Transmutation } \\
\text { Fuels Campaign Limits }\end{array}$} \\
\hline & & & $\begin{array}{c}\text { Modified } \\
\text { Transmutation } \\
\text { Fuels Campaign } \\
\text { Limits } \\
\end{array}$ & $\begin{array}{l}\text { LWR MOX Spec } \\
\text { from 2001 Report } \\
\text { (for comparison) }\end{array}$ & \\
\hline 43 & $\mathrm{Tc}$ & 4 & 1 & 0 & 66 \\
\hline 44 & $\mathrm{Ru}$ & 350 & 100 & 0 & 66 \\
\hline 45 & $\mathrm{Rh}$ & 4 & 1 & 0 & 66 \\
\hline 46 & $\mathrm{Pd}$ & 4 & 1 & 0 & 66 \\
\hline 47 & $\mathrm{Ag}$ & 78 & 22 & 0 & 66 \\
\hline 48 & $\mathrm{Cd}$ & 39 & 11 & 20 & 62 \\
\hline 49 & In & 4 & 1 & 0 & 62 \\
\hline 50 & $\mathrm{Sn}$ & 39 & 11 & 0 & 62 \\
\hline 51 & $\mathrm{Sb}$ & 4 & 1 & 0 & 62 \\
\hline 52 & $\mathrm{Te}$ & 4 & 1 & 0 & 62 \\
\hline 53 & $\mathrm{I}$ & 4 & 1 & 0 & 23 \\
\hline 54 & $\mathrm{Xe}$ & 0 & 0 & 0 & 0 \\
\hline 55 & Cs & 70 & 20 & 0 & 31 \\
\hline 56 & $\mathrm{Ba}$ & 35 & 10 & 0 & 31 \\
\hline 57 & $\mathrm{La}$ & 175 & 50 & 0 & 52 \\
\hline 58 & $\mathrm{Ce}$ & 175 & 50 & 0 & 52 \\
\hline 59 & $\operatorname{Pr}$ & 175 & 50 & 0 & 52 \\
\hline 60 & $\mathrm{Nd}$ & 175 & 50 & 0 & 52 \\
\hline 61 & $\mathrm{Pm}$ & 175 & 50 & 0 & 52 \\
\hline 62 & $\mathrm{Sm}$ & 35 & 10 & 20 & 52 \\
\hline 63 & $\mathrm{Eu}$ & 35 & 10 & 20 & 52 \\
\hline 64 & $\mathrm{Gd}$ & 35 & 10 & 20 & 52 \\
\hline 65 & $\mathrm{~Tb}$ & 35 & 10 & 0 & 52 \\
\hline 66 & Dy & 35 & 10 & 20 & 52 \\
\hline 67 & Ho & 35 & 10 & 0 & 52 \\
\hline 68 & $\mathrm{Er}$ & 35 & 10 & 0 & 52 \\
\hline 69 & $\mathrm{Tm}$ & 35 & 10 & 0 & 52 \\
\hline 70 & $\mathrm{Yb}$ & 35 & 10 & 0 & 52 \\
\hline 71 & $\mathrm{Lu}$ & 35 & 10 & 0 & 52 \\
\hline 72 & Hf & 4 & 1 & 0 & 31 \\
\hline 73 & $\mathrm{Ta}$ & 78 & 22 & 0 & 3 \\
\hline 74 & $\mathrm{~W}$ & 78 & 22 & 20 & 3 \\
\hline 75 & $\mathrm{Re}$ & 4 & 1 & 0 & 3 \\
\hline 76 & Os & 4 & 1 & 0 & 3 \\
\hline 77 & $\mathrm{Ir}$ & 4 & 1 & 0 & 3 \\
\hline 78 & $\mathrm{Pt}$ & 4 & 1 & 0 & 3 \\
\hline 79 & $\mathrm{Au}$ & 4 & 1 & 0 & 3 \\
\hline 80 & $\mathrm{Hg}$ & 4 & 1 & 0 & 3 \\
\hline 81 & $\mathrm{Tl}$ & 4 & 1 & 0 & 3 \\
\hline 82 & $\mathrm{~Pb}$ & 39 & 11 & 0 & 3 \\
\hline 83 & $\mathrm{Bi}$ & 4 & 1 & 0 & 3 \\
\hline & TOTAL & 6,041 & 1,726 & 1,500 & 3,333 \\
\hline
\end{tabular}




\section{A-2.2 Impurity Impact on Fuel Performance}

We looked into the impurities using a combination of fission product yield, cross sections, and differential reactivity coefficients for several reasons. First, is the production of fission products sufficient to require their removal to meet the current Transmutation Fuels Campaign limits? If so, how much of the fission products must be removed in order to meet the limits for the next batch of fresh fuel? What elements dominate neutron capture? What elements dominate differential reactivity? Does it matter if natural sources or fission product source dominate elements?

Figures A2-1 and A2-2 shows the fraction of total fission products in the output fuel from metal and oxide fueled fast reactors at transuranic conversion ratio of 0.50 and LWR with MOX-Pu fuel. (One plot is log, the other plot is linear.) The two fast reactor curves are almost identical, as they are expected to be. The MOX curve varies slightly from the fast reactor curves because the fission yield curves of various fissionable isotopes vary slightly. To the degree that the curves diverge, it is important to assess the fission product mixes of different fuel/reactor combinations instead of simply using a generic set of fission products.

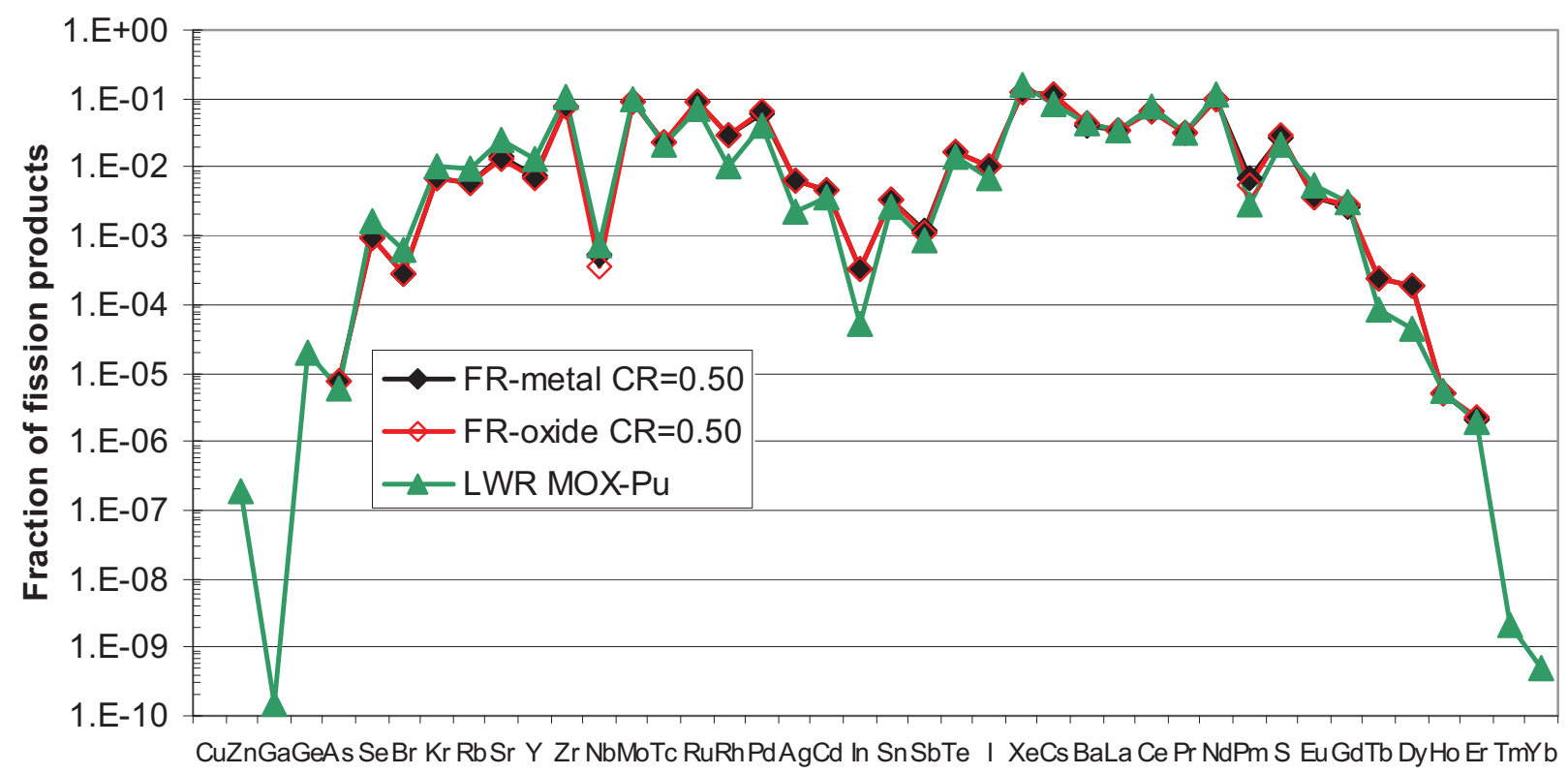

Figure A2-1. Fraction of fission products by chemical element (log plot). 


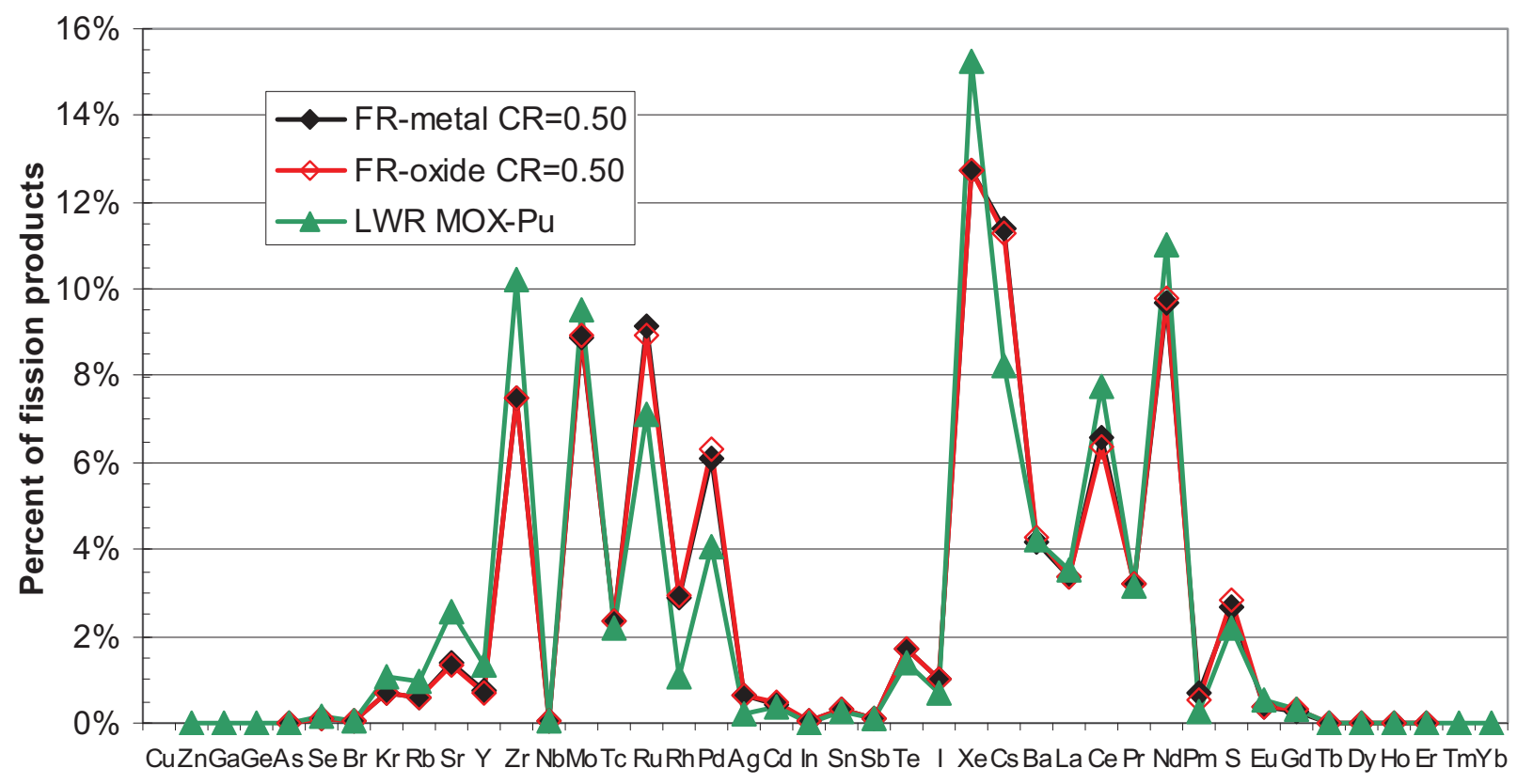

Figure A2-2. Fraction of fission products by chemical element (linear plot).

The Transmutation Fuels Campaign has evolving limits on many, but not all, of the elements from $\mathrm{H}$ to Th. Many of their limits are for a group of elements (e.g., a limit on the total lanthanides). To perform an exploratory assessment, we made three modifications to their current limits as noted in the previous Subsection A1-1. This procedure gave us a set of hypothetical limits for all elements except noble gases.

With one final assumption, it is then possible to examine to what degree fission products should be removed from recycled material to meet the impurity limits of the next recycle. The assumption is that all the impurities not removed reappear in the new fuel without net dilution or concentration. This means that if an impurity is " $\mathrm{X}$ " percent of discharged fuel, and is not chemically removed, it is " $\mathrm{X}$ " percent of the new fuel. This would appear to be a good assumption for the fast reactor fuels that are repeatedly recycled; the U versus TRU composition changes little each recycle. This assumption is probably wrong by an order of magnitude for MOX-Pu if impurities tend to be in Pu versus $\mathrm{U}$, because there is about an order of magnitude concentration increase from used UOX to MOX-Pu. That is, used UOX is about $1 \%$ $\mathrm{Pu}$, but fresh MOX-Pu is about $10 \% \mathrm{Pu}$. So, if impurities flow with $\mathrm{Pu}$ rather than $\mathrm{U}$, then there is a factor of 10 increase in the impurity level in going from UOX to MOX. For example, consider an impurity at X $\mathrm{ppm}$ in used UOX. Its concentration in the Pu stream is 100 times ppm $(=\mathrm{X} / 0.01)$. The $\mathrm{Pu}$ is diluted 10:1 by uranium so that its concentration in the new fuel is 10 times ppm. For simplicity, we ignore this issue and simply assume no net concentration or dilution.

Figure A2-3 shows the result of dividing the assumed tolerable chemical limit by the concentration produced via fission products. (There is no calculated value for noble gases $\mathrm{Kr}$ and $\mathrm{Xe}$.) A number greater than one means that all the fission products could pass into new fuel without any separation, assuming there were no other sources of those elements. A number less than one means that only that fraction of fission products can be tolerated in the new fuel. That is, one minus that fraction is the minimum tolerable separation fraction of that element. 


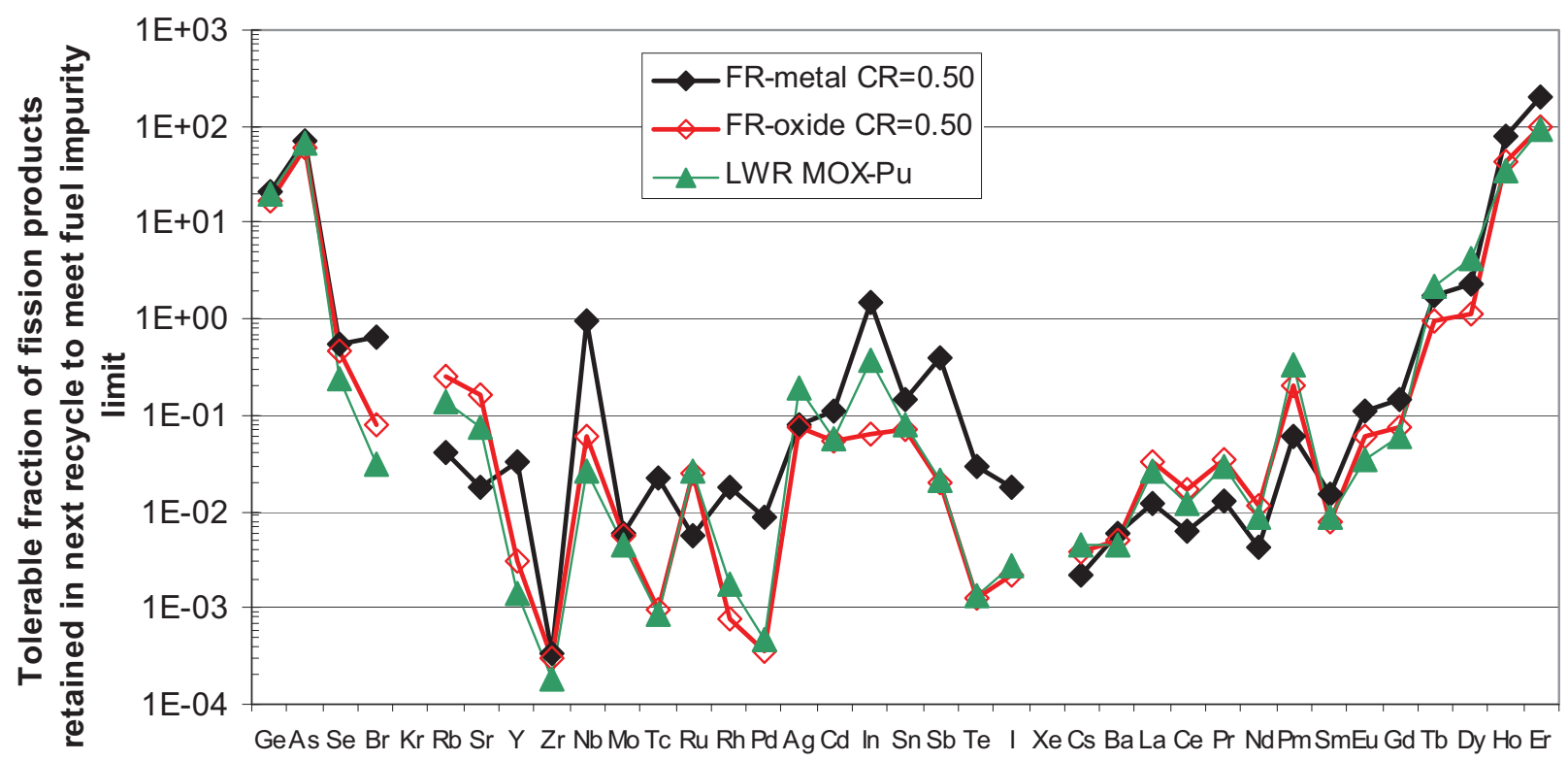

Figure A2-3. Fraction of fission products that can be kept in the next recycle, assuming initially pure material before the preceding irradiation, probably overestimates MOX-Pu tolerance by an order of magnitude.

As an example, consider Europium (Eu). It is $469 \mathrm{ppm}$ in used FR-metal fuel from fission. The calculation path for the limit in the proper units starts with the current specification of $2500 \mathrm{ppm}$ for all the lanthanides in the TRU feedstream. There are 15 lanthanide elements (including yttrium), so the limit assigned to $\mathrm{Eu}$ is $2500 / 15=167 \mathrm{ppm}$. This fuel is $31 \% \mathrm{TRU}$, so dilution by presumably pure uranium brings Eu down to $52 \mathrm{ppm}-\mathrm{Eu}$ in fuel. Since $469 \mathrm{ppm}-\mathrm{Eu}$ is produced and only $52 \mathrm{ppm}-\mathrm{Eu}$ is tolerated, the tolerable fraction of fission-source Eu in recycled material is 0.11 (i.e., at least $89 \%$ of the Eu must be removed). Using this procedure, the required removal fraction varies for the lanthanides from $99.6 \%(\mathrm{Nd})$ to zero ( $\mathrm{Tb}, \mathrm{Dy}, \mathrm{Ho}, \mathrm{Er})$. A rebalancing of the assumed allocation of the $2500 \mathrm{ppm}$-lanthanide limit would tell us what average lanthanide removal fraction would be required. A crude estimate is $93 \%$, naturally less restrictive than the worst case $(\mathrm{Nd})$ and more than $\mathrm{Eu}$.

Of course, this procedure only addresses one recycle. Lanthanide isotopes that absorb a neutron during reirradiation only turn into another lanthanide element, so irradiation does not change the numbers. So, equilibrium will be established during repeated recycle with the net production of lanthanides by fission balanced by net removal of lanthanides during recycling.

Finally, we looked at direct physics impact of impurities in two ways: simple neutron capture and differential reactivity. The neutron capture is determined by multiplying the modified fuel impurity limits times the first group neutron capture cross sections. The differential reactivity coefficients were calculated by displacing fuel atoms by postulated impurity atoms in a detailed reactor physics calculation (Hoffman2009). The differential reactivity impact was calculated by adding to a known "pure" composition (no impurities, only $U$ and TRU elements) a small concentration of each isotope sufficient to produce a significant perturbation (100 micrograms per gram of initial transuranic material). This was done for 300 individual isotopes for metal fuel and oxide fuel fast reactor with transuranic conversion ratio of 0.5 . The result is a set of 300 values in units of percent milli-rho per micrograms per gram of initial TRU, or percent milli-rho per ppm of each isotope in question.

For each isotope of interest, a small amount (100 micrograms) of the isotope was added to the nominal fuel mix in units of micrograms per gram (i.e., ppm). The change in reactivity was noted in detailed 
physics calculations. The results are reported in units of percent milli-rho per microgram of impurity per gram of fuel. This method is described in more detail elsewhere (Hoffman 2009).

The elements Se to $\mathrm{Yb}$ can arise from either fission products or natural sources. The other elements below $\mathrm{Pb}$ are presumably from natural sources. So, in looking at the overall reactivity penalty, Hoffman considered for each element, which had the higher reactivity penalty (fission product isotopic mix or natural isotopic mix) and used whichever gave the higher reactivity penalty.

We examined the impact of impurities by multiplying either 1-group neutron cross sections or differential reactivity by the modified fuel limits. Figure A2-4 shows the contribution of different sets of elements to the total neutron absorption (mass fraction times neutron capture cross section) and to the total differential reactivity, which assumes each element's isotopes match natural abundances. The lanthanides dominate parasitic neutron capture, followed by the transition metals $\mathrm{Nb}$ to $\mathrm{Te}$, and the transition metals $\mathrm{Hf}$ to $\mathrm{Pb}$. Note that the Transmutation Fuels Campaign does not generally have limits for the Hf-Pb set of transition metals, yet they do contribute significantly to total neutron capture, with the assumed values used here.

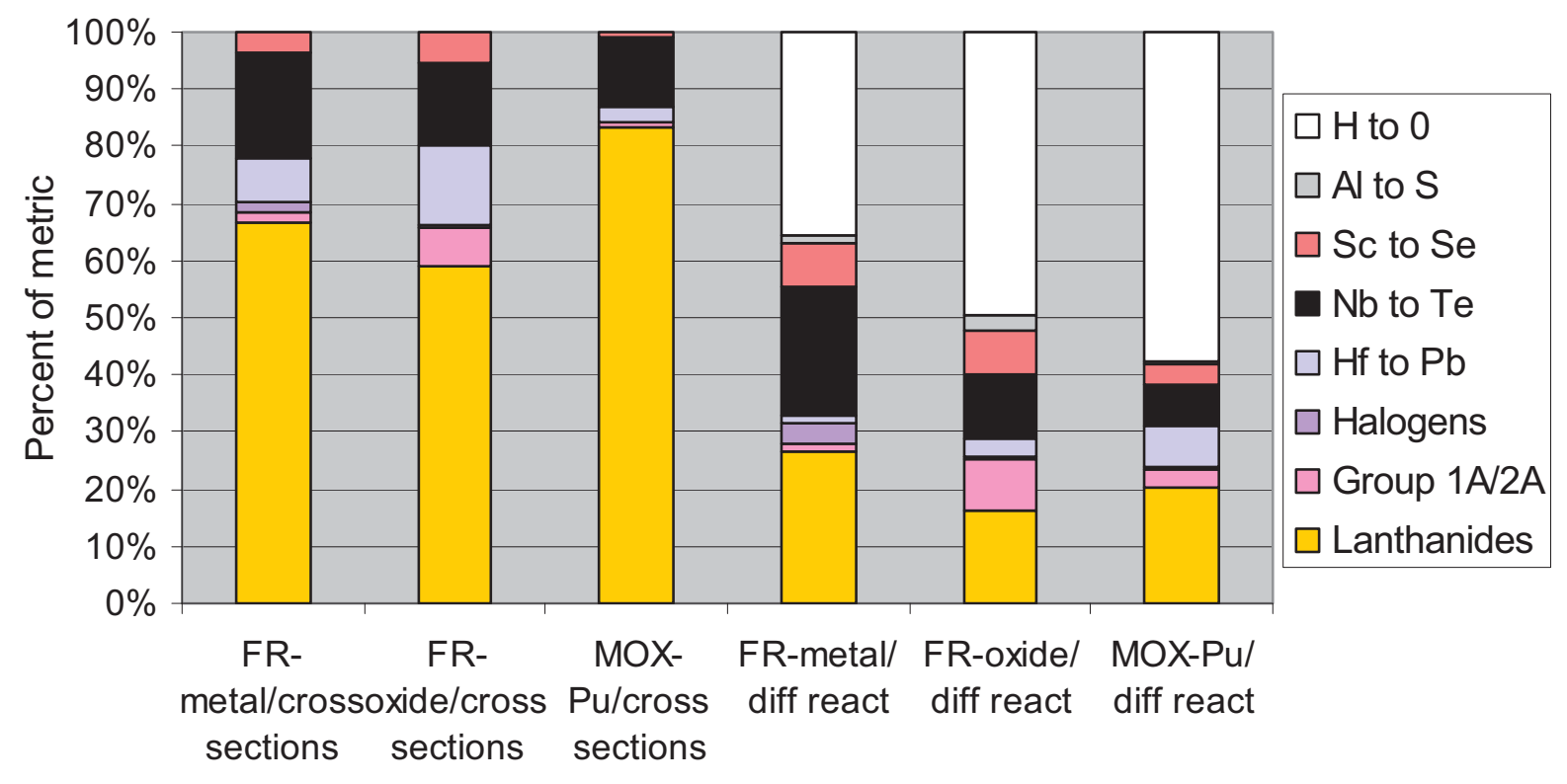

Figure A2-4. Percent weighted cross sections or percent of differential reactivity, assuming all elements have natural isotopic abundances.

The relative contribution to differential reactivity is fundamentally different. As Hoffman points out (Hoffman 2009) the light elements ( $\mathrm{H}$ to $\mathrm{O}$ here) dominate differential reactivity. Few of these have large neutron capture cross sections; the primary impact is fuel atom displacement. Depending on fuel and reactor design, that may or may not be a significant issue. The next important group is the lanthanides, followed by the $\mathrm{Nb}$ to Te transition metals.

The previous analysis assumed natural isotopic abundances for all elements. We repeated the analysis using for each element, whichever is worse, fission or natural. Figure A2-5 shows the result in the same format as Figure A2-4. The relative importance of the lanthanides and $\mathrm{Nb}$ to Te transition metals increases, which are all produced as fission products. Recall that the total mass of these elements has not increased; each element is kept to the same limit. However, the isotopic mixes of the elements have changed. The neutron capture has increased by factors of 1.75 (FR-metal), 199 (FR-oxide), and $1.50(\mathrm{MOX}-\mathrm{Pu})$ relative to assuming natural isotopic abundances. The differential reactivity has increased factors of 1.62 (FR-metal), 1.50 (FR-oxide), and $1.56(\mathrm{MOX}-\mathrm{Pu})$. The transition from natural to worse, to 
fission to worse, occurs with the elements $\mathrm{Sr}, \mathrm{Y}$, and $\mathrm{Zr}$; that is, below $\mathrm{Sr}$ natural abundance is worse; above $\mathrm{Zr}$ fission abundance is worse. For those three elements, it depends on the reactor/fuel cases and the metric (neutron capture or differential reactivity). At the other end of the fission product regime, the transition from fission to worse, to natural to worse occurs with the elements Sm, Eu, Gd, Tb, and Dy. An extreme case of natural abundance having higher neutron capture is Gd. For MOX-Pu, natural Gd has about 100 times higher neutron capture than fission product Gd. Gd 155, Gd157, and Gd161 each have thermal neutron capture cross sections over 1000 barns; their natural isotopic abundances are $14.8 \%$, $15.65 \%$, and $21.88 \%$, respectively. The fraction of these isotopes to total $\mathrm{Gd}$ in discharged MOX-Pu is $0.13 \%, 0.10 \%$, and $<0.01 \%$, two orders of magnitude lower than natural Gd. Their capture cross sections are so high they "burn out" during irradiation.

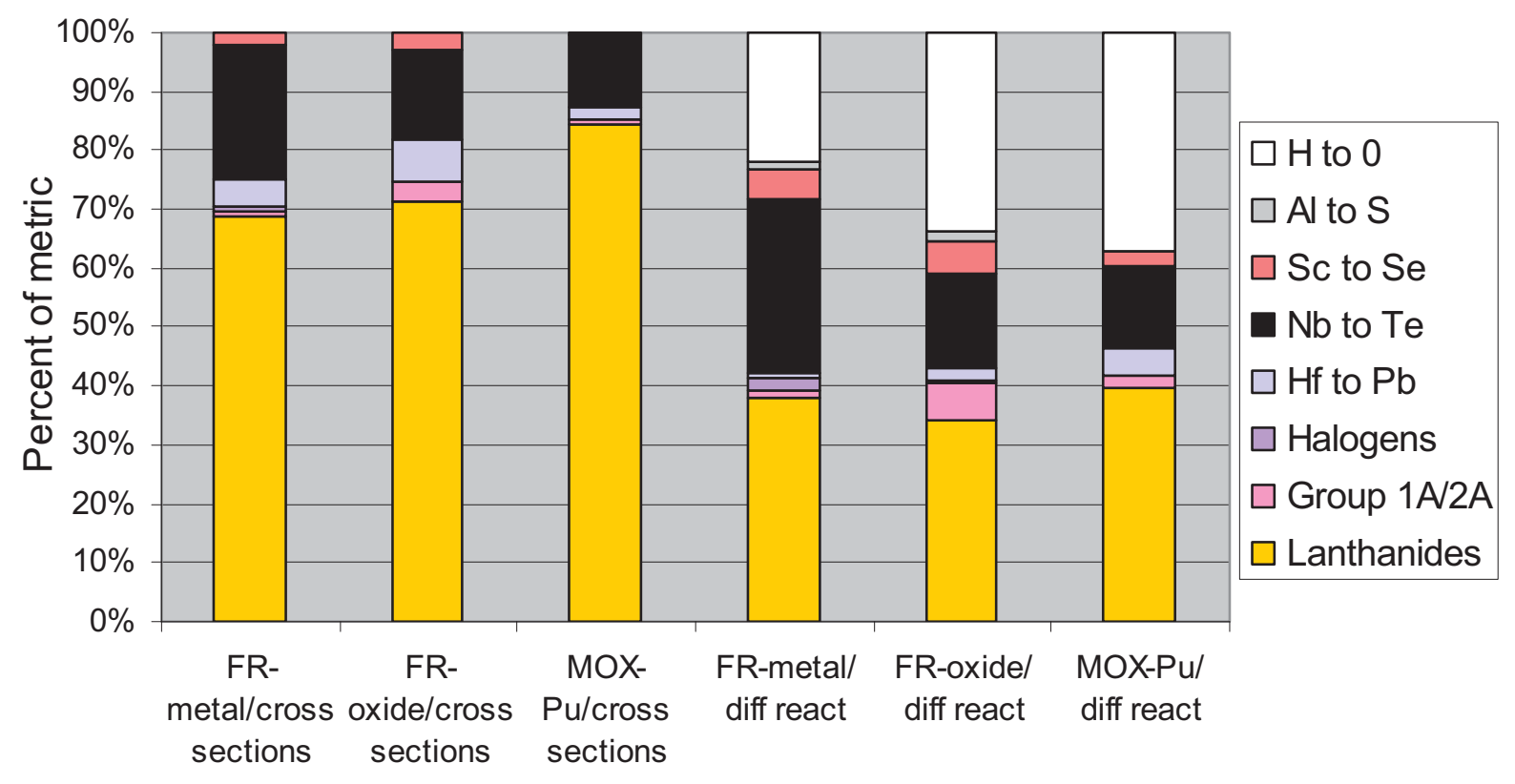

Figure A2-5. Percent weighted cross sections or percent of differential reactivity, assuming the worse of natural or fission product isotopic abundances.

\section{A-2.2.1 Fast reactors}

For the metal-fuel fast reactor case, Hoffman considered several ways to bound the impact of hypothetical impurities as estimated using differential reactivity. He found the most relevant approach would be to account for impurities by increasing the heavy metal fuel mass $(\mathrm{kg} /$ cycle) by $0.87 \%$.

Alternative methods would have higher impact. These fast reactor cases have a low change in reactivity with burnup and higher end of cycle burnup than LWRs. So, the same impurity level would have more impact on cycle length if that were the chosen method of compensating for impurities. Hoffman estimated the bounding value at about $14 \%$ reduction in cycle length, hence the average discharge burnup.

\section{A-2.2.2 LWRs}

The same differential reactivity assessment for MOX-Pu was performed by Hoffman. As noted in previous Table A2-4, the reactivity penalty in units of percent milli-rho per microgram of impurity per gram of fuel mass is about the same as in the fast reactor cases.

To compensate for the impurities by increasing the Pu loading would require 4\% increase in $\mathrm{Pu}$, compared with $0.87 \%$ for the metal-fuel fast reactor. 
To compensate by cycle length reduction, the impact would be about $8.6 \%$ decrease in burnup, less than the corresponding impact in the $\mathrm{CR}=0.50$ fast reactor cases.

\section{A-3. References}

Bays, S., Piet S., et al, 2009, Transmutation Dynamics: Impacts of Multi-Recycling on Fuel Cycle Performances, Advanced Fuel Cycle Initiative, AFCI-SYSA-PMO-MI-DV-2009-000185, INL/EXT-09-16857, September 2009.

Hoffman, E. A., 2009, “FY-09 ANL AFCI Transmutation Studies,” ANL-AFCI-271, August 31, 2009.

Meyer, G. A. to D. Persinko of the NRC, 2000, Transmittal of MOX Fuel Qualification Plan, MOX.00.035.doc, July 14, 2000.

Piet, S. J., et al, 2008, "Description of Transmutation Library for Fuel Cycle System Analyses," GNEPSYSA-PMO-MI-DV-2009-000004, INL/EXT-08-15053, October 31, 2008.

Piet, S. J., 2009, "Selection of Isotopes and Elements for Fuel Cycle Analysis," Advances In Nuclear Fuel Management IV (ANFM IV), INL/CON-08-15050 April 12-15, 2009. 
Appendix B

\section{System Losses Data and Cost Input Tables}




\section{Appendix B System Losses Data and Cost Input Tables}

Section 0 provides a description of the simplified system losses model. An Excel model was used to store the values for performance variables and cost data that were used in the analysis. Figures B1-1 and B1-2 display the data tables that provided the basis for the trade-off analysis. These data were input to the Decision Programming Language (DPL) model that was used to perform the cost calculations and uncertainty analysis and generate the results for the Bounding System Loss charts shown in Sections 5.1 and 5.2.

\begin{tabular}{|c|c|c|c|c|c|c|}
\hline \multicolumn{7}{|c|}{ Metal - Fuel Cycle Strategy/Decision Matrix } \\
\hline & \multicolumn{4}{|c|}{ Losses to Waste (as a percent) } & \multicolumn{2}{|c|}{ Performance Factors } \\
\hline & Head-end & Separation & Process & Fuel Fab & HLW Loading & Fuel Performance \\
\hline High & $2.0 \%$ & $2.0 \%$ & $2.0 \%$ & $1.0-3.5 \%$ & $95 \%$ & $90 \%$ \\
\hline Mid-High & $1.0 \%$ & $1.0 \%$ & $1.0 \%$ & & $98 \%$ & $95 \%$ \\
\hline Nominal & $<1 \%$ & $<1 \%$ & $<1 \%$ & $0.1-0.15 \%$ & $100 \%$ & $100 \%$ \\
\hline Mid-Low & $0.3-1 \%$ & $0.3-1 \%$ & $0.3-1 \%$ & & $102 \%$ & $105 \%$ \\
\hline Low & $0.3 \%$ & $0.3 \%$ & $0.3 \%$ & $0.05-0.07 \%$ & $105 \%$ & $110 \%$ \\
\hline \multicolumn{7}{|c|}{ Variable Cost Change (as a cost multiplier) } \\
\hline High & 0.90 & 0.90 & 0.90 & 0.80 & $105 \%$ & $90 \%$ \\
\hline Mid-High & 0.95 & 0.95 & 0.95 & 0.90 & $102 \%$ & $95 \%$ \\
\hline Nominal & 1.00 & 1.00 & 1.00 & 1.00 & $100 \%$ & $100 \%$ \\
\hline Mid-Low & 1.10 & 1.10 & 1.10 & 1.10 & $98 \%$ & $105 \%$ \\
\hline Low & 1.20 & 1.20 & 1.20 & 1.20 & $95 \%$ & $110 \%$ \\
\hline Null & 0.00 & 0.00 & 0.00 & 0.00 & & \\
\hline $\begin{array}{l}\text { Nominal Cost (\$/kgHM) } \\
\text { Nominal BU (MWd/MTHM) }\end{array}$ & $\overline{1,000}$ & $\overline{11,000}$ & 2,000 & $2,2,000$ & $2,2,000$ & $\begin{array}{l}-131,860 \\
\end{array}$ \\
\hline \multicolumn{7}{|c|}{ Oxide - Fuel Cycle Strategy/Decision Matrix } \\
\hline & \multicolumn{4}{|c|}{ Losses to Waste (as a percent) } & \multicolumn{2}{|c|}{ Performance Factors } \\
\hline & Head-end & Separation & Process & Fuel Fab & HLW Loading & Fuel Performance \\
\hline High & $3.00 \%$ & $6.3 \%$ & $2.0 \%$ & $1.0-3.5 \%$ & $95 \%$ & $90 \%$ \\
\hline Mid-High & $2.25 \%$ & $3.5 \%$ & $1.0 \%$ & $0.50 \%$ & $98 \%$ & $95 \%$ \\
\hline Nominal & $1.50 \%$ & $1.1 \%$ & $<1 \%$ & $0.1-0.15 \%$ & $100 \%$ & $100 \%$ \\
\hline Mid-Low & $0.85 \%$ & $0.6 \%$ & $0.3-1 \%$ & $0.09 \%$ & $102 \%$ & $105 \%$ \\
\hline Low & $0.15 \%$ & $0.1 \%$ & $0.3 \%$ & $0.05-0.07 \%$ & $105 \%$ & $110 \%$ \\
\hline \multicolumn{7}{|c|}{ Variable Cost Change (as a cost multiplier) } \\
\hline High & 0.90 & 0.99990 & 0.90 & 0.80 & $105 \%$ & $90 \%$ \\
\hline Mid-High & 0.95 & 0.99995 & 0.95 & 0.90 & $102 \%$ & $95 \%$ \\
\hline Nominal & 1.00 & 1.00000 & 1.00 & 1.00 & $100 \%$ & $100 \%$ \\
\hline Mid-Low & 1.10 & 1.00005 & 1.10 & 1.10 & $98 \%$ & $105 \%$ \\
\hline Low & 1.20 & 1.00010 & 1.20 & 1.20 & $95 \%$ & $110 \%$ \\
\hline Null & & - & - & - & & \\
\hline $\begin{array}{l}\text { Nominal Cost (\$/kgHM) } \\
\text { Nominal BU (MWd/MTHM) }\end{array}$ & 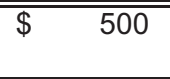 & $\overline{c 500}$ & $\bar{~} 1,000$ & "6,000 & 2,000 & $\begin{array}{l}- \\
131,860\end{array}$ \\
\hline
\end{tabular}

Figure B1-1. Performance and cost inputs used in the bounding analysis for metal and oxide fuel. 


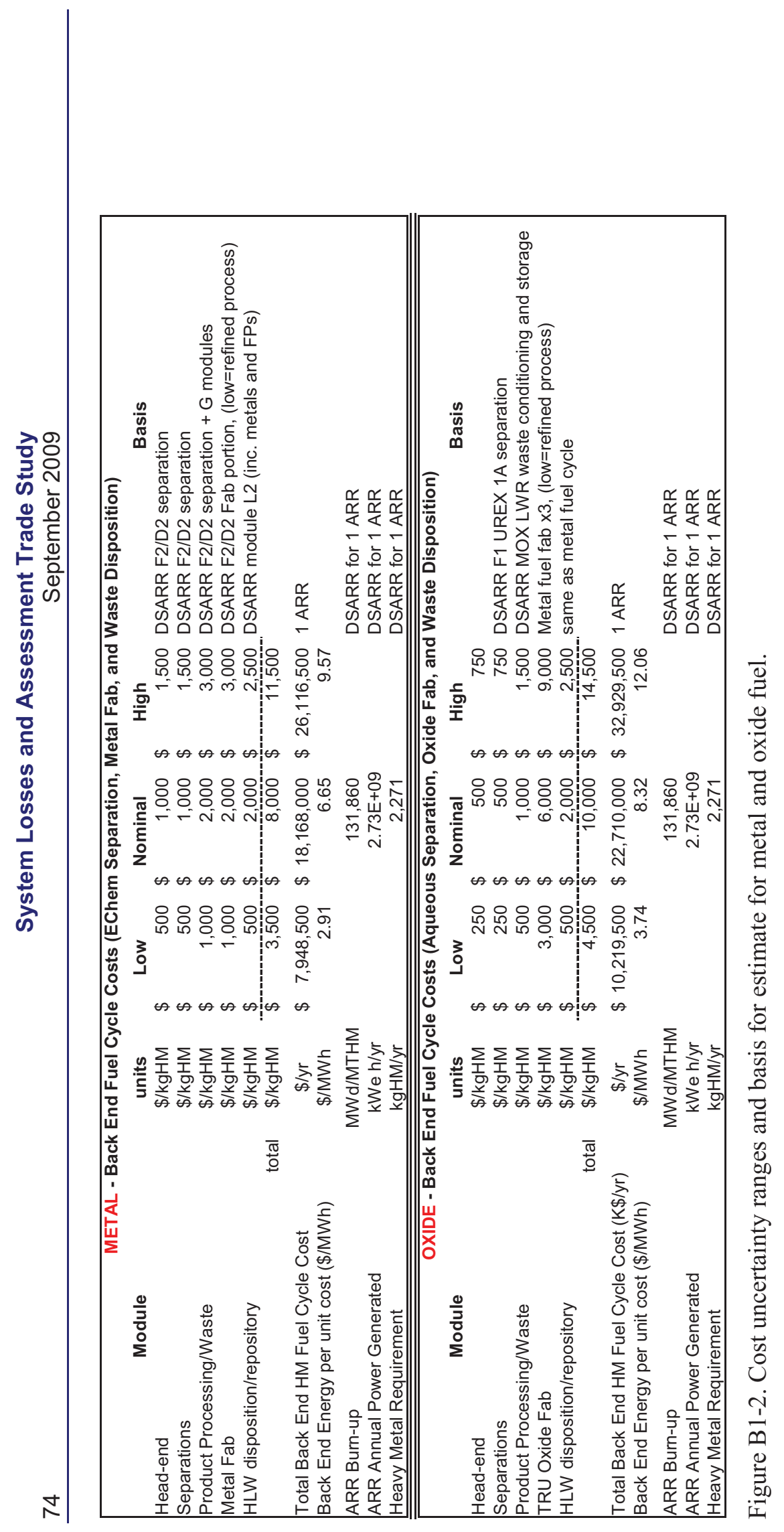

